Políticas de escalonamento de tempo-real para garantia de QoS absoluta em array de servidores web heterogêneos

Maycon Leone Maciel Peixoto 



\title{
Políticas de escalonamento de tempo-real para garantia de QoS absoluta em array de servidores web heterogêneos
}

\section{Maycon Leone Maciel Peixoto}

Orientador: Prof. Dr. Francisco José Monaco

Dissertação apresentada ao Instituto de Ciências Matemáticas e de Computação - ICMC, USPde Ciências Matemáticas e de Computação - ICMC-USP, como parte dos requisitos para obtenção do título de Mestre em Ciências - Ciências de Computação e Matemática Computacional.

\author{
USP - São Carlos \\ Fevereiro/2008
}



A minha familia, em especial aos meus pais, Jair Peixoto e Elizeth Peixoto. 



\section{Agradecimentos}

A Deus, em primeiro lugar, por me conceder saúde, força e coragem para conquistar mais este objetivo na minha vida.

Aos meus pais, e o meu irmão, por todo o apoio e amor que foram a mim dedicados através de ensinamentos, conselhos, lições de vida e colaboração em todos os sentidos.

Agradeço a toda minha família que fizeram e fazem parte da minha trajetória de vida, tios e tias que sempre me motivaram a prosseguir.

Ao professor Francisco José Monaco pela orientação e suporte ao longo de todo o trabalho, além da amizade que se firmou em diversos momentos difíceis e felizes da minha vida.

Agradeço de maneira especial a minha namorada Priscila, pois seu carinho foi imprescindivel em todos os momentos, apoiando durante as produções dos artigos e pela paciência demonstrada em todos os momentos.

A todos os colegas do Laboratório Tott, Lucas, Michelle, Felipe, Júlio, Thiago, Bruno, Jonathan pelo apoio, ajuda e companheirismo. Aos meus amigos Cássio, Leonardo e Ricardo pelo convívio, ajuda e pela companhia ao longo desses anos.

Aos professores do grupo de Sistemas Distribuídos e Programação Concorrente, que contribuíram com sugestões e críticas sempre construtivas. Ao Instituto de Ciências Matemáticas e de Computação - ICMC, formado por todos os funcionários, pela colaboração no desenvolvimento deste trabalho, que sempre se mostraram disponiveis nos momentos em que os solicitei.

A CAPES pelo suporte financeiro.

E a todos que participaram direta ou indiretamente deste trabalho. 

"Almost all computer systems of the future will utilize real-time scientific principles and technology."

John A. Stankovic 

1 Introdução 1

1.1 Contextualização . . . . . . . . . . . . . . . . . . . . . . 1

1.2 Motivação . . . . . . . . . . . . . . . . . . . 3

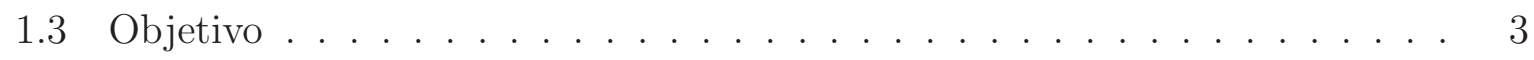

1.4 Estrutura do Texto . . . . . . . . . . . . . . . . . . 4

2 Fundamentação Teórica 5

2.1 Considerações Iniciais . . . . . . . . . . . . . . . . . . . . . 5

2.2 Qualidade de Serviço - QoS . . . . . . . . . . . . . . 6

2.2.1 QoS em nível de Aplicação . . . . . . . . . . . . . . . . 8

2.3 Tempo-Real . . . . . . . . . . . . . . . . . . . . . . . . . . . 8

2.3.1 Sistemas de Tempo-Real Hard e Soft . . . . . . . . . . . . . . . . . 10

2.3.2 Parâmetros Temporais . . . . . . . . . . . . . . . . . 11

2.3.3 Dinâmica de Carga . . . . . . . . . . . . . . . . . 12

2.4 Políticas de Escalonamento . . . . . . . . . . . . . . . . . . . . . . . 13

2.4.1 Algoritmos de Escalonamento . . . . . . . . . . . . . . . . . . . . 13

2.4 .2 On-line e Off-line . . . . . . . . . . . . . . . . . 16

2.4 .3 Estático e Dinâmico . . . . . . . . . . . . . . . 16

2.4.4 Escalonabilidade em sistemas $R T$. . . . . . . . . . . . 18

2.5 Simulação Baseada em Eventos . . . . . . . . . . . . . . . . . . . 21

2.5.1 A biblioteca SMPL . . . . . . . . . . . . . . . . 22

2.6 Teoria das Filas . . . . . . . . . . . . . . . . . . . . . . . . 23

2.6.1 Notação de Kendall . . . . . . . . . . . . . . . . . . . . 23

2.6.2 Padrão de Chegada das Requisições . . . . . . . . . . . . . . . . . 24

2.6.3 Padrão de Serviço dos Servidores . . . . . . . . . . . . . . . . . . . 24

2.6.4 Número de Canais de Serviço . . . . . . . . . . . . . . . . 25

2.6.5 Disciplina de Filas . . . . . . . . . . . . . . . . 25

2.6.6 Capacidade do Sistema . . . . . . . . . . . . . 26 
2.6.7 Desempenho de Sistema . . . . . . . . . . . . . . . 26

2.7 Considerações Finais . . . . . . . . . . . . . . . . . . . . . . . . 27

3 Trabalhos relacionados $\quad 29$

3.1 Considerações Iniciais . . . . . . . . . . . . . . . . . . . . . . . . . . . . . . 29

3.2 Revisão Bibliográfica . . . . . . . . . . . . . . . . . . . . 30

3.3 Estado da Arte . . . . . . . . . . . . . . . . . . . . . . . . . . . . . 33

3.4 Considerações Finais . . . . . . . . . . . . . . . . . . . . . 35

4 Desenvolvimento $\quad 37$

4.1 Considerações Iniciais . . . . . . . . . . . . . . . . . . . . . . . . 37

4.2 Contextualização . . . . . . . . . . . . . . . . . . . . . . . . . . 38

4.2 .1 Modelo de Recursos . . . . . . . . . . . . . . . . . . . . . . . . . . . 38

4.2 .2 Modelo de Tarefas . . . . . . . . . . . . . . . . . . . . . . . 39

4.3 Controle de Admissão . . . . . . . . . . . . . . . . . . . . . . . . . . . . 39

4.4 Satisfação do Cliente . . . . . . . . . . . . . . . . . . . . . . . . 41

4.5 Arquitetura Ortogonal . . . . . . . . . . . . . . . . . . . . 41

4.5.1 Política de Fila . . . . . . . . . . . . . . . . . . . . . . . 42

4.5.2 Política de Recurso . . . . . . . . . . . . . . . . . . . . . . 45

4.6 Considerações Finais ～. . . . . . . . . . . . . . . . . . . . . . . . . . . . . 49

5 Experimentos, Resultados e Análise $\quad 51$

5.1 Considerações Iniciais . . . . . . . . . . . . . . . . . . . . . . . . . 51

5.2 Planejamento de Experimentos . . . . . . . . . . . . . . . . . . 52

5.2.1 Caracterização do Ambiente . . . . . . . . . . . . . . . . . 53

5.2 .2 Taxa de Utilização do Sistema . . . . . . . . . . . . . . . . . . . 54

5.3 Comportamento do Escalonador . . . . . . . . . . . . . . . 54

5.4 Overhead do Escalonador . . . . . . . . . . . . . . . . . . . . . 69

5.5 Controle de Admissão . . . . . . . . . . . . . . . . . . . . 70

5.6 Avaliação da Satisfação do Cliente . . . . . . . . . . . . . . . . . . . . 72

5.7 Política Adaptativa . . . . . . . . . . . . . . . . . . 75

5.8 Considerações Finais . . . . . . . . . . . . . . . . . . . . . . . . 77

$\begin{array}{lll}6 & \text { Conclusão } & 79\end{array}$

6.1 Conclusões Gerais . . . . . . . . . . . . . . . . . . . . . . . . . 79

6.2 Contribuições . . . . . . . . . . . . . . . . . . . . . . . . 81

6.3 Trabalhos Futuros . . . . . . . . . . . . . . . . . . . . . . 82

6.3.1 Métrica Satisfação do Cliente . . . . . . . . . . . . . . . . 83

6.3.2 Controle de Admissão . . . . . . . . . . . . . . . . . . 83

6.3.3 Interface e Protótipo da Arquitetura Ortogonal . . . . . . . . . . . 84 
APÊNDICE

A Demais Gráficos

85

Referências Bibliográficas

91 

Lista de Figuras

2.1 Sinalização do $R S V P$ (Zhao et al., 2000). . . . . . . . . . . . . . . . . . . . . 8

2.2 Caracterização das tarefas. . . . . . . . . . . . . . . . . . . . . . . . . . 12

2.3 Escalonamento SJF. . . . . . . . . . . . . . . . . . . . 14

2.4 Escalonamento EDF Uniprocessado. . . . . . . . . . . . . . . . . . 15

2.5 Sistema Multiprocessado. . . . . . . . . . . . . . . . . 16

2.6 Tipos de testes de escalonabilidade. . . . . . . . . . . . . . . . . . . 19

2.7 Centro de Serviço. . . . . . . . . . . . . . . . . . . . . . 23

2.8 Sistemas Multicanais. . . . . . . . . . . . . . . . . 25

3.1 Servidor Web com Diferenciação de Serviços. (Teixeira, 2004). . . . . . . . . . . 34

4.1 Modelo Ortogonal . . . . . . . . . . . . . . . . . . . . . . . . . 42

4.2 Exemplo do Modelo Multiple Queue. . . . . . . . . . . . . . . . . . . 46

4.3 Modelo Single Queue. . . . . . . . . . . . . . . . . . . . . . . . 47

4.4 Modelo Dynamic Single Queue. . . . . . . . . . . . . . . . . . . 48

4.5 Exemplo do Modelo Dynamic Single Queue. . . . . . . . . . . . . . . . . . 49

5.1 Comparativo do Cenário 1 (MQ-(FIFO,SJF) X DSQ-(EDF,EBS)) com Variação Contratual de $10 \%$. . . . . . . . . . . . . . . . 55

5.2 Comparativo do Cenário 1 (MQ-(EDF,EBS) X DSQ-(EDF,EBS)) com Variação Contratual de $10 \% \ldots \ldots$. . . . . . . . . . . . . 56

5.3 Comparativo do Cenário 1 (SQ-(EDF,EBS) X DSQ-(EDF,EBS)) com Variação Contratual de $10 \% \ldots \ldots$. . . . . . . . . . . . . 57

5.4 Intervalo de Confiança do Cenário 1 com Variação Contratual de 10\% . . . 57

5.5 Comparativo do Cenário 1 (MQ-(FIFO,SJF) X DSQ-(EDF,EBS)) com Variação Contratual de $50 \%$. . . . . . . . . . . . . . . . . . 58

5.6 Comparativo do Cenário 1 (MQ-(EDF,EBS) X DSQ-(EDF,EBS)) com Variação Contratual de $50 \% \ldots \ldots \ldots$. . . . . . . . . . . . . . 58 
5.7 Comparativo do Cenário 1 (SQ-(EDF,EBS) X DSQ-(EDF,EBS)) com Variação Contratual de $50 \%$. . . . . . . . . . . . . . . . . . 59

5.8 Intervalo de Confiança do Cenário 1 com Variação Contratual de 50\% . . . 59

5.9 Comparativo do Cenário 2 (MQ-(FIFO,SJF) X DSQ-(EDF,EBS)) com Variação Contratual de $40 \%$. . . . . . . . . . . . . . . . . 60

5.10 Comparativo do Cenário 2 (MQ-(EDF,EBS) X DSQ-(EDF,EBS)) com Variação Contratual de $40 \%$. . . . . . . . . . . . . . . . 61

5.11 Comparativo do Cenário 2 (SQ-(EDF,EBS) X DSQ-(EDF,EBS)) com Variação Contratual de $40 \%$. . . . . . . . . . . . . . . . . . 61

5.12 Intervalo de Confiança do Cenário 2 com Variação Contratual de 40\% . . . 62

5.13 Comparativo do Cenário 3 (MQ-(FIFO,SJF) X DSQ-(EDF,EBS)) com Variação Contratual de $50 \%$. . . . . . . . . . . . . . . . 62

5.14 Comparativo do Cenário 3 (MQ-(EDF,EBS) X DSQ-(EDF,EBS)) com Variação Contratual de $50 \%$. . . . . . . . . . . . . . . 63

5.15 Comparativo do Cenário 3 (SQ-(EDF,EBS) X DSQ-(EDF,EBS)) com Variação Contratual de $50 \%$. . . . . . . . . . . . . . . . . . 64

5.16 Intervalo de Confiança do Cenário 3 com Variação Contratual de 50\% . . . 64

5.17 Comparativo do Cenário 4 (MQ-(FIFO,SJF) X DSQ-(EDF,EBS)) com Variação Contratual de $30 \%$. . . . . . . . . . . . . . . . 65

5.18 Comparativo do Cenário 4 (MQ-(EDF,EBS) X DSQ-(EDF,EBS)) com Variação Contratual de $30 \%$. . . . . . . . . . . . . . . . . . 65

5.19 Comparativo do Cenário 4 (SQ-(EDF,EBS) X DSQ-(EDF,EBS)) com Variação Contratual de $30 \%$. . . . . . . . . . . . . . . 66

5.20 Intervalo de Confiança do Cenário 4 com Variação Contratual de 30\% . . . 67

5.21 Comparativo do Cenário 5 (MQ-(FIFO,SJF) X DSQ-(EDF,EBS)) com Variação Contratual de $50 \%$. . . . . . . . . . . . . . . . . 67

5.22 Comparativo do Cenário 5 (MQ-(EDF,EBS) X DSQ-(EDF,EBS)) com Variação Contratual de $50 \%$. . . . . . . . . . . . . . . . . . 68

5.23 Comparativo do Cenário 5 (SQ-(EDF,EBS) X DSQ-(EDF,EBS)) com Variação Contratual de $50 \%$. . . . . . . . . . . . . . . . 69

5.24 Intervalo de Confiança do Cenário 5 com Variação Contratual de 50\% . . . 69

5.25 Intervalo de Confiança para a Satisfação dos Usuários do Cenário 1 . . . . 73

5.26 Intervalo de Confiança para a Satisfação dos Usuários do Cenário 2 . . . . 74

5.27 Intervalo de Confiança para a Satisfação dos Usuários do Cenário 3 . . . . 74

5.28 Intervalo de Confiança para a Satisfação dos Usuários do Cenário 4 . . . . 74

5.29 Intervalo de Confiança para a Satisfação dos Usuários do Cenário 5 . . . . 75

5.30 Abordagem Adaptativa com Referência o Tempo Médio de Resposta . . . . 76

5.31 Abordagem Adaptativa com Referência a Satisfação do Cliente . . . . . . . 76 
A.1 Comparativo do Cenário 2 (MQ-(FIFO,SJF) X DSQ-(EDF,EBS)) com Va-

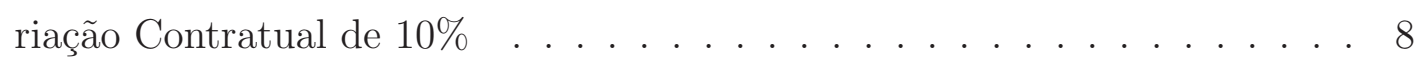

A.2 Comparativo do Cenário 2 (MQ-(EDF,EBS) X DSQ-(EDF,EBS)) com Variação Contratual de $10 \%$. . . . . . . . . . . . . . . . . . 85

A.3 Comparativo do Cenário 2 (SQ-(EDF,EBS) X DSQ-(EDF,EBS)) com Variação Contratual de $10 \%$. . . . . . . . . . . . . . . 86

A.4 Intervalo de Confiança do Cenário 2 com Variação Contratual de 10\% . . 86

A.5 Comparativo do Cenário 3 (MQ-(FIFO,SJF) X DSQ-(EDF,EBS)) com Variação Contratual de $40 \% \ldots \ldots$. . . . . . . . . . . . . 86

A.6 Comparativo do Cenário 3 (MQ-(EDF,EBS) X DSQ-(EDF,EBS)) com Variação Contratual de $40 \% \ldots$. . . . . . . . . . . . . . . . 87

A.7 Comparativo do Cenário 3 (SQ-(EDF,EBS) X DSQ-(EDF,EBS)) com Variação Contratual de $40 \%$. . . . . . . . . . . . . . . . 87

A.8 Intervalo de Confiança do Cenário 3 com Variação Contratual de 40\% . . . 87

A.9 Comparativo do Cenário 4 (MQ-(FIFO,SJF) X DSQ-(EDF,EBS)) com Variação Contratual de $40 \% \ldots$. . . . . . . . . . . . . . . . . 88

A.10 Comparativo do Cenário 4 (MQ-(EDF,EBS) X DSQ-(EDF,EBS)) com Variação Contratual de $40 \%$. . . . . . . . . . . . . . . . . . 88

A.11 Comparativo do Cenário 4 (SQ-(EDF,EBS) X DSQ-(EDF,EBS)) com Variação Contratual de $40 \%$. . . . . . . . . . . . . . . . . . . 88

A.12 Intervalo de Confiança do Cenário 4 com Variação Contratual de 40\% . . 89

A.13 Comparativo do Cenário 5 (MQ-(FIFO,SJF) X DSQ-(EDF,EBS)) com Variação Contratual de $20 \%$. . . . . . . . . . . . . . . . . . . . . . . 89

A.14 Comparativo do Cenário 5 (MQ-(EDF,EBS) X DSQ-(EDF,EBS)) com Variação Contratual de $20 \%$. . . . . . . . . . . . . . . . . 89

A.15 Comparativo do Cenário 5 (SQ-(EDF,EBS) X DSQ-(EDF,EBS)) com Variação Contratual de $20 \%$. . . . . . . . . . . . . . . . . . . 90

A.16 Intervalo de Confiança do Cenário 5 com Variação Contratual de 20\% . . 90 



\section{Lista de Tabelas}

2.1 Exemplo de Demanda por Recursos . . . . . . . . . . . . . . . . . . . . 14

2.2 Notação de Kendall . . . . . . . . . . . . . . . . . . . . . . . . . . . . 23

2.3 Descrição das Distribuições Probabilísticas . . . . . . . . . . . . . . . . 24

2.4 Disciplinas de Filas . . . . . . . . . . . . . . . . . . . . . . . . 26

2.5 Métricas em Redes de Filas . . . . . . . . . . . . . . . . 27

5.1 Taxa de Utilização dos Servidos do Sistema (\%) . . . . . . . . . . . . . . . 54

5.2 Estatísticas do Overhead do Escalonador . . . . . . . . . . . . . . . 70

5.3 Valor Médio de Descartes do Controle de Admissão . . . . . . . . . . . . . 71

5.4 Valor Médio de $\Omega$ e Satisfação dos Clientes . . . . . . . . . . . . . . . . . 72 



\section{Lista de Símbolos}

$\begin{array}{ll}\text { DM } & \text { Deadline Monotonic } \\ D M A & \text { Direct Memory Access } \\ D S Q & \text { Dynamic Single Queue } \\ E B S & \text { Exigency Based Scheduling } \\ \text { EDF } & \text { Earliest Deadline First } \\ \text { FIFO } & \text { First in First Out } \\ G D & \text { Generic Distribution } \\ H T T P & \text { HyperText Transfer Protocol } \\ I P & \text { Internet Protocol } \\ \text { LIFO } & \text { Last in First Out } \\ M Q & \text { Multiple Queue } \\ \text { QOS } & \text { Quality of Service } \\ R M & \text { Rate Monotonic } \\ R R & \text { Round Robin } \\ R S V P & \text { Resource Reservation Protocol } \\ R T & \text { Real-Time } \\ R T P & \text { Real-Time Transport Protocol } \\ S I R O & \text { Serve In Random Order } \\ S J F & \text { Shortest Job First } \\ S Q & \text { Single Queue } \\ S W D S & \text { Servidor Web com Diferenciação de Serviço } \\ V I P & \text { Voice over IP } \\ W W W & \text { World Wide Web } \\ & \end{array}$





\section{Resumo}

Em relação aos significativos resultados em Qualidade de Serviço (QoS) para servidores $W e b$, existem ainda muitos problemas não resolvidos. Enquanto as abordagens atuais se limitam a prover $Q o S$ relativa através de diferenciação de serviço, este projeto apresenta e compara três modelos que tem por objetivo prover QoS absoluta para um array de servidores Web heterogêneos por meio de uma arquitetura de escalonamento ortogonal: A Multiple Queue (MQ), a Single Queue (SQ) e a Dynamic Single Queue (DSQ). A MQ consiste em receber a requisição HTTP e enviá-la para o servidor escolhido do array de servidores através do balanceamento de carga. A $S Q$ e a $D S Q$ possuem uma única fila gerenciada de forma centralizada. Enquanto a $S Q$ envia a requisição somente quando o servidor esta livre, a $D S Q$ seleciona o servidor com mais curto tempo de término mediante o uso de filas virtuais. Os modelos foram simulados considerando diferentes parâmetros e configurações para o ambiente. A avaliação de desempenho da arquitetura ortogonal demonstra que a mesma provê um bom desempenho na provisão de QoS absoluta com relação as mudanças instantâneas das cargas de trabalho no ambiente $W e b$. Esta pesquisa estende os resultados da politica de escalonamento chamada EBS, concebida para provisão de garantias de tempo de resposta estocásticas em ambientes interativos online, especificamente para os servidores Web. Os resultados demonstram que a combinação da EBS na política de fila com a disciplina de recurso proposta neste trabalho é superior às outras combinações examinadas. Um modelo de política adaptativa é também introduzido. 



\begin{abstract}
Despite the significant body of results in Quality of Service $(Q o S)$ for Web-Servers, many real-world problems are not easily supported. While the current approaches limit to provide relative QoS through service differentiation, this work presents and compares three models aiming at providing absolute QoS to Web Server on heterogeneous cluster by means of an Orthogonal Scheduling Architecture: The Multiple Queue $(M Q)$, the Single Queue $(S Q)$ and the Dynamic Single Queue $(D S Q)$. The $M Q$ consists in receiving the HTTP requests and delivering them for the selected processor in the server array to balance the load. $S Q$ and $D S Q$ have only one queue being managed by a central server. While $S Q$ sends requests to the first free processors, the DSQ selects the processor with the minimun completion time with the aid of a virtual queue. The models were simulated considering different parameters and configurations for the environment. Performance evaluation of the Orthogonal Architecture demonstrates that it performs well in providing absolute $Q_{0} S$ in face of instantaneous changes in the workloads. This work extends the results of a scheduling policy named EBS, tailored for providing stochastic response-time guarantees in online interactive systems, specifically for Web servers. Results show that the combination of EBS as the queue discipline with the resource discipline proposed in this work outperforms the other studied. An adaptive policy model is also introduced.
\end{abstract}





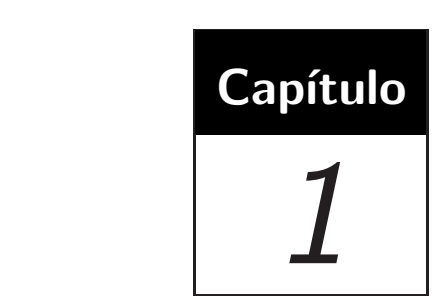

Introdução

\subsection{Contextualização}

Ao longo dos últimos anos a Web tem agregado funcionalidades em atendimento às necessidades de um crescente número de utilizações inovadoras e tornado-se uma das mais populares e importantes aplicações da Internet. Por outro lado, tem sido submetida a mudanças substanciais na infra-estrutura de comunicação e de negócios para atender a todos esses requisitos de serviços. O incremento de pesquisas para prover qualidade nessas áreas de concentração se dá com maior rigor nas aplicações que possuem uma relação temporal para atendimento de um serviço, por exemplo, aplicações de e-commerce, e-banking, VoIP, tele medicina, TV digital, entre outras aplicações de Internet. Nessas situações torna-se difícil para um servidor Web prover um serviço em um tempo específico dadas as condições de seu ambiente temporalmente não-determinístico (Rashid et al., 2005)(Abdelzaher \& Bhatti, 1999)(Traldi et al., 2006)(Ye et al., 2005).

Tipicamente um servidor Web recebe numerosos pedidos de serviços, não sendo capaz de gerenciar todos ao mesmo tempo. Por isso, normalmente é usado um buffer ou uma fila para armazenar os pedidos que chegam e ficam esperando por um serviço. Essas requisições são mantidas exatamente na ordem em que chegam ao sistema. O servidor Web recebe a primeira requisição da fila e a atende. Este é o modelo comumente utilizado, denominado escalonamento FIFO (primeiro a chegar primeiro a ser servido) (Ye et al., 2005). Com essa abordagem não é possível atender a nenhuma restrição temporal para os clientes. Por exemplo, a ocorrência de tráfego de rajada tende a causar atrasos em 
aplicações sensíveis ao tempo, além de oferecerem um pobre desempenho em situações de sobrecarga. Por isso, a política FIFO não é especialmente adequada para aplicações que requerem $Q_{o} S^{1}$ também em nível de aplicação (Abdelzaher \& Bhatti, 1999)(Traldi et al., 2006).

No escopo das estratégias para prover QoS em servidores Web encontra-se a predição estimada de demanda e correspondente alocação de recursos. Porém, além de ser difícil prever com precisão a demanda, superestimar recursos para tratar curtos períodos de sobrecarga pode ser economicamente ineficiente. Uma medida alternativa para contornar esse problema é incluir mecanismos e algoritmos que gerenciam os recursos do servidor para implementar prioridades no serviço prestado.

Para buscar confiabilidade nesse tipo de ambiente imprevisível, diversos algoritmos de escalonamento adaptativos têm sido desenvolvidos nos últimos anos por (Vasiliou \& Lutfiyya, 2000)(Zhang et al., 2002)(Abdelzaher et al., 2003)(Teixeira et al., 2005)(Traldi et al., 2006)(Barbato et al., 2006). O modelo de melhor esforço baseado em diferenciação de serviço (Almeida et al., 1998)(Kang et al., 2003)(Lee et al., 2003)(Stankovic et al., 1998) em servidores Web prioriza os clientes dependendo de sua classe, mas não provê qualquer garantia em relação ao tempo em que a requisição será atendida.

A QoS pode ser definida em termos relativos ou absolutos. Diferenciação de serviço geralmente está relacionada à $Q o S$ relativa, e é a abordagem mais utilizada em servidores Web (Eggert \& Heidemann, 1999)(Franklin, 1993)(Henriksson et al., 2004)(Kang et al., 2003)(Lu et al., 2001), uma vez que garante apenas que a classe mais alta² receberá um serviço melhor (ou no mínimo não pior) que qualquer classe mais baixa, baseando-se em algum critério para distinção dos serviços oferecidos. Por outro lado, a confiabilidade é tipicamente especificada em termos de valores absolutos, por exemplo: na média o cliente será atendido em $10 \mathrm{~ms}$ ou nenhuma requisição do cliente atrasará mais do que $15 \mathrm{~ms}$ (Vasiliou \& Lutfiyya, 2000).

Qos Absoluta acresce substancialmente o nível de complexidade dos mecanismos destinados a prover garantias temporais em ambientes não-determinísticos. Nesse modelo uma classe não possui maior prioridade do que outra, mas, ambas devem cumprir o contrato estipulado previamente. Implementar QoS absoluta dessa forma implica em considerar o servidor Web um sistema de tempo-real. Para isso, existem diversos algoritmos de escalonamento projetados para atender restrições temporais.

\footnotetext{
${ }^{1}$ Quality of Service.

${ }^{2}$ Classe mais alta: de maior prioridade; classe mais baixa: de menor prioridade.
} 
Dentre os algoritmos clássicos, têm-se o EDF (Earliest Deadline First) (Liu \& Layland, 1973), que trata primeiro as requisições que estão mais próximas de perder o seu prazo de conclusão, e possui bons resultados para determinados cenários em ambientes uniprocesados. Entretanto, utilizado de maneira isolada em um ambiente multiprocessado, degrada rapidamente o desempenho em condições de sobrecarga do sistema (Stankovic et al., 1998). Portanto, outros algoritmos de escalonamento têm sido propostos (Bampis \& Kononov, 2001)(Manimaran et al., 1998)(Ramamritham et al., 1990) para resolver esse problema de escalonamento em ambiente multiprocessado, o qual é caracterizado como NP-difícil (Stankovic et al., 1998)(Liebeherr et al., 1995)(Ramamritham et al., 1990). Há assim, um vasto campo de investigação sobre abordagens de escalonamento de tempo-real para ambientes distribuídos, principalmente sobre conjunto de recursos heterogêneos.

\subsection{Motivação}

Fundada na crescente relevância dada à $W e b$, no domínio dos sistemas de informação, a motivação deste trabalho está concentrada na importância de aprimoramento de técnicas de gerência e manipulação de recursos com o intuito de oferecer garantias de QoS e atender as exigências de novas aplicações.

O interesse pela QoS absoluta na Web trás a necessidade do desenvolvimento de mecanismos de decisão, que busquem atender às expectativas de qualidade dos clientes, tanto quanto aumentar a eficiência da utilização de recursos por parte do provedor de serviços.

\subsection{Objetivo}

No contexto do predomínio de trabalhos que abordam a garantia de $Q o S$ para os sistemas uniprocessados, o objetivo deste trabalho é desenvolver e avaliar uma abordagem para oferecimento de suporte à QoS absoluta também para o modelo de sistemas multiprocessados, contribuindo, assim, para o fornecimento de suporte de qualidade de serviço em escala maior.

É reconhecido vasto o terreno para pesquisas de escalonamento de tempo-real em ambiente multiprocessados, principalmente naqueles que possuem características heterogêneas. Com o objetivo de proporcionar aos clientes de um ambiente Web qualidade de serviço absoluta, definida em termos estocásticos, é especificada na forma de valores médios de tempo de respostas dentro de uma faixa de tolerância determinada pelo contrato de serviço firmado entre o usuário e o provedor Web. Este trabalho propõe um modelo 
de arquitetura ortogonal que utiliza uma disciplina de recursos original aliada à disciplina de fila EBS. Foram realizadas simulações e comparações com os algoritmos clássicos mais amplamentes empregados com o alvo de avaliar as propriedades dessa arquitetura.

\subsection{Estrutura do Texto}

O restante deste documento está organizado como segue:

- No capítulo capítulo 2 é apresentada a fundamentação teórica que embasa o trabalho, reunindo de forma sucinta os principais conceitos utilizados no seu desenvolvimento e que são importantes para seu entendimento, tais como Qualidade de Serviço (seção 2.2), Tempo Real (seção 2.3), Políticas de Escalonamento (seção 2.4), Simulação de Sistemas (seção 2.5) e Teoria de Filas (seção 2.6).

- No capítulo 3 relacionam-se alguns trabalhos mais relevantes da área estudada, revelando quais linhas de pesquisa têm recebido mais esforços, as que carecem de desenvolvimento, e os fundamentos e contribuições que podem ser aproveitados na busca por aprimoramento na área.

- No capítulo 4 descreve-se o projeto propriamente dito, apresentando a metodologia utilizada para avaliação dos resultados, os algoritmos propostos (seção 4.2), o controle de admissão empregado (seção 4.3), o estabelecimento da métrica de satisfação (seção 4.4) e as fases de desenvolvimento da arquitetura ortogonal (seção 4.5).

- No capítulo 5 apresentam-se os resultados obtidos por meio da avaliação das políticas de acordo com as caracterização de ambiente em que esta envolvido o trabalho (seção 5.2.1), fazendo-se uma análise baseada nas métricas propostas pela modelagem analítica.

- No capítulo 6 resumem-se os principais resultados obtidos, as contribuições do projeto e sugerem-se trabalhos futuros.

- Finalmente são apresentadas as Referências e o Apêndice com demais gráficos, por clareza não incluídos na seção de análise dos resultados. 


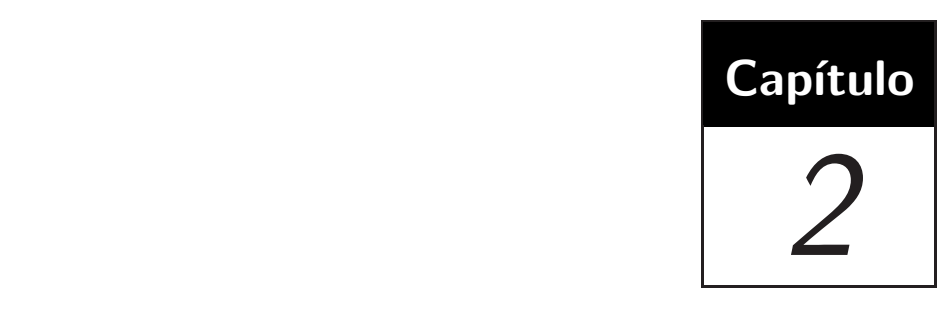

Fundamentação Teórica

\subsection{Considerações Iniciais}

Neste capítulo é apresentado um embasamento teórico que servirá de apoio para o entedimento dos principais conceitos abordados nesta dissertação. Esforços em outras áreas, como Tempo Real, também têm sido feitos com o intuito de propor novas abordagens para o problema, sendo importante uma breve revisão de seus principais conceitos.

O capítulo começa com uma discussão sobre conceitos básicos relacionados à Qualidade de Serviço (Seção 2.2), apresentando seus componentes e destacando a relevância de seu uso em todos os elementos da rede, inclusive no nível de aplicação. Em seguida, aborda-se de forma sucinta alguns fundamentos da área de Tempo Real (Seção 2.3), pois, ao relacionar parâmetros de serviço em termos temporais são utilizados conceitos desse campo. São apresentados também na Seção 2.4 os princípios e técnicas empregados em escalonamento de sistemas de Tempo-Real como principal componente de garantia de controle de QoS.

Por fim, apresentam-se os aspectos relacionados com a simulação de sistemas (seção 2.5), bem como os principais simuladores de eventos discretos. Além de definições básicas de simulação, apresenta-se também na Seção 2.6 a teoria a partir da qual ela é fundamentada, para modelagem de sistemas com ocorrência de filas, foco deste trabalho. 


\subsection{Qualidade de Serviço - QoS}

A garantia de requisitos mínimos relacionados à qualidade dos serviços oferecidos por sistemas computacionais tem sido um tema de crescente relevância no âmbito acadêmico e industrial nos últimos anos. No contexto das tecnologias de rede, têm-se aplicação em todos os níveis da arquitetura de protocolos, com destaque para os avanços realizados nas camadas inferiores. Na camada de aplicação, por outro lado, os esforços são mais recentes.

As redes $I P^{1}$ constituem a infra-estrutura de milhares de redes de computadores em todo o mundo com uma expectativa constante de crescimento. A disseminação desse padrão deve-se, em parte, à velocidade de expansão da Internet e ao estabelecimento do $T C P / I P^{2}$ como protocolo de suporte às aplicações em redes. O predomínio dos computadores usando TCP/IP nas suas comunicações tornam o IP o padrão universal de suporte para aplicações na Internet, e o faz presente em milhões de máquinas espalhadas por todo o mundo.

As redes IP foram desenvolvidas sob requisitos pouco exigentes de confiabilidade $^{3}$ e tendo como objetivo poderem ser utilizada sobre qualquer tipo de meio físico. Como o IP é um protocolo simples, ele tem algumas restrições como, por exemplo, a falta de garantia no trânsito de pacotes, atrasos, etc. Com o crescimento das aplicações (voz, multimídia, vídeo-conferência, etc) sobre IP, evidenciaram-se as limitações do IP, motivando a buscar por alternativas para adequá-lo à nova realidade, dado que a banda ${ }^{4}$ de comunicação está compartilhada com um número cada vez maior de usuários, podendo ocorrer congestionamento e possíveis perdas de pacotes.

Para obter qualquer tipo de garantia de que o serviço será realizado é preciso aplicar métodos que permitam atingir um nível de qualidade satisfatório e confiável para os dados e aplicações. A implementação de um esquema de reserva de recursos, como o protocolo de tempo real $R T P^{5}$, depende da utilização do serviço de entrega do IP subjacente, e portanto, da custosa intervenção na infra-estrutura da rede. Isso evidencia a importância de avanços em métodos alternativos para o campo das aplicações que necessitem realizar operações em tempo-real (Brun et al., 2002).

\footnotetext{
${ }^{1}$ Internet Protocol - RFC 791.

${ }^{2}$ Transmission Control Protocol / Internet Protocol.

${ }^{3}$ No sentido de garantia de desempenho.

${ }^{4}$ Banda é um expressão pouco rigorosa mas bastante difundida de referir-se à capacidade de transmissão (throughput) da rede.

${ }^{5}$ Real-time Transport Protocol- RFC 1889.
} 
Qualidade de Serviço (QoS) ${ }^{6}$ apresenta-se nesse contexto, e pode ser explicada como a percepção do usuário quanto à eficiência de um serviço. No caso da comunicação, pode relacionar-se às características de tempo de resposta e à perfeição na transferência do conteúdo. QoS pode ser definida, no contexto da camada de rede, como a capacidade de um elemento em prover certo grau de garantia do cumprimento dos requisitos de seu tráfego e serviços oferecidos, tais como níveis mínimos de perdas e atrasos de dados requisitados pelo usuário.

QoS pode ser definida em termos absolutos ou relativos. Por exemplo, no primeiro caso é tipicamente especificada como: "a perda de pacotes não excederá 3\%" ou "nenhum pacote atrasará mais que 100 ms". Já no segundo caso garante-se apenas que a classe mais alta receberá um serviço melhor (ou no mínimo não pior) que qualquer classe mais baixa (Vasiliou \& Lutfiyya, 2000).

Substancial desenvolvimento nesse campo tem se dado no estudo e na elaboração de técnicas aplicáveis às camadas inferiores das arquiteturas de redes de comunicação (tendo como base o modelo de referência ISO $\left./ \mathrm{OSI}^{7}\right)$. Da mesma forma, contratos dinâmicos podem utilizar algum protocolo de sinalização (como o RSVP), que possibilitam solicitar serviço sob demanda, indicando a necessidade do usuário em um dado momento (Zhao et al., 2000).

Um exemplo de funcionamento básico do RSVP está ilustrado pela Figura 2.1. Nele, um sistema emissor (sender) manda uma mensagem PATH ao receptor especificando as características do tráfego (1). Cada roteador intermediário (router) repassa esta mensagem para o próximo roteador (2), até a mensagem chegar ao receptor (receiver) final (3). Quando isso ocorre, o receptor responde com uma mensagem RESV (4), que percorre o caminho contrário no sentido do emissor (5), tentando solicitar a reserva de recursos para o fluxo de dados. Caso algum roteador intermediário rejeite a solicitação, uma mensagem de erro é enviada de volta ao receptor (2), sinalizando o fim do processo. Se a mensagem for aceita, certa capacidade de banda e espaço em buffer são reservados, com o roteador passando a manter informações de estado do fluxo de dados (2) (Zhao et al., 2000).

A QoS pode ser analisada sob o ponto de vista de várias camadas da pilha de protocolos, mas é sob o ponto de vista da aplicação que se desenvolve este trabalho. Atualmente, tem havido crescente interesse na provisão de QoS em nível de aplicação. Entretanto, é neste âmbito que mais se evidenciam as discrepâncias entre as características e necessidades de cada uma delas.

\footnotetext{
${ }^{6}$ Quality of Service.

${ }^{7}$ International Organization for Standardization / Open System Interconnection.
} 


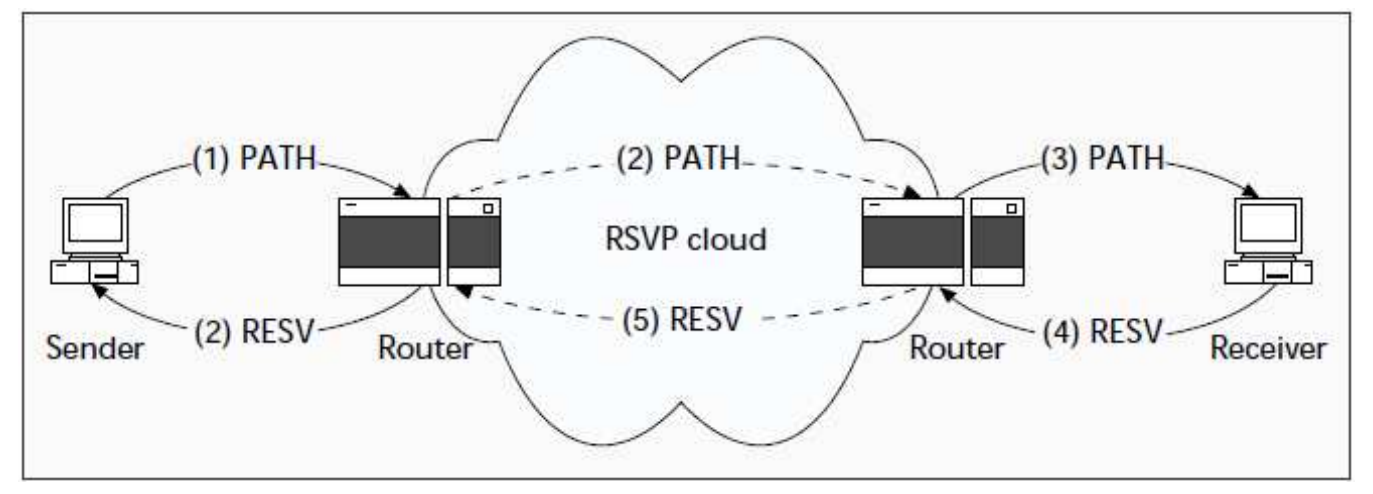

Figura 2.1: Sinalização do RSVP (Zhao et al., 2000).

\subsubsection{QoS em nível de Aplicação}

A utilização do modelo de serviço de melhor esforço na Internet(Leiner et al., 1997) significa que todos os usuários e aplicações têm o mesmo tratamento nos roteadores no caminho entre origem e destino dos pacotes. Em situações de congestionamento, roteadores guardam pacotes em filas na ordem estrita de chegada (FIFO). Quando a capacidade da fila transborda, os pacotes são simplesmente descartados.

Esse modelo apresenta uma grande simplicidade e robustez, que foi o motivo do sucesso da Internet. No entanto, não permite o desenvolvimento de aplicações avançadas e a diferenciação de serviços entre usuários. Uma das formas de prover garantias de QoS em nível de aplicação é através do uso de algoritmos de escalonamento específicos que forneçam uma solução integrada para QoS fim-a-fim na Web.

Os algoritmos de prioridade fazem parte de outros mecanismos utilizados para garantida de qualidade de serviço. Um outro aspecto que deve ser considerado, diz respeito sobre os mecanismos de descarte de requisições. A política do controle de admissão é necessária na ocorrência de um congestionamento e visa igualmente a garantia de eqüidade quanto à distribuição dos recursos para processamento. O Capítulo 3 irá permitir ao leitor uma análise de trabalhos relacionados a esse tópico.

\section{$2.3 \quad$ Tempo-Real}

Em aplicações de sistemas e dispositivos com abordagem de tempo-real, a correta computação não depende somente dos efeitos ou resultados que são produzidos, mas também o tempo no qual foram gerados; sistemas de tempo-real são aqueles cuja correção depende tanto do resultado lógico produzido, quanto do tempo no qual tal resultado foi gerado, ou seja, a sincronização dos eventos de entrada e saída (Cheng, 2002). 
Um exemplo de sistema de tempo-real aplicado é o controle de freio de automóveis modernos. Quando o motorista de um veículo aciona o freio, o mecanismo de controle irá, possivelmente, recolher informações do ambiente envolvido, por exemplo, velocidade do carro, direção em que está se movendo, e realizar a ativação do dispositivo de frenagem com a freqüência apropriada, em fração de segundos. Ambos os resultados (ativação do freio) e o tempo no qual os resultados foram produzidos são importantes para garantir a segurança do carro, motorista e passageiros (Cheng, 2002). Exemplos de sistemas de tempo-real podem ser encontrados em domínios de aplicações que envolvem monitoramento e controle de plantas industriais, usinas nucleares, processos químicos, controle automotivo, navegação aviônica, tráfego aéreo, marítimo, ferroviário e rodoviário, sistemas de telecomunicação, robótica, defesa militar, missões espaciais, dentre outros.

A especificação de requisitos de sistemas de tempo-real em aplicações de automação industrial é, em geral, formulada em termos de limites superiores para os atrasos nos tempos de resposta, caracterizando, assim, sistemas de tempo-real rígido. O projeto de sistemas de tempo real com requisitos temporais determinísticos requer conhecimento de parâmetros também determinísticos acerca da dinâmica do ambiente e do sistema, incluindo o comportamento da carga quanto à taxa de chegada de requisições de serviço e tempo de execução - predominam aí as técnicas dedicadas ao monitoramento e controle de processos síncronos temporizados.

Por outro lado, a recente difusão de aplicações e serviços on-line de acesso remoto, destacando-se a Internet, demanda o desenvolvimento de novas técnicas que estendam a abordagem de tempo-real para aplicações computacionais interativas - que incluem comércio eletrônico, telemedicina, ensino a distância etc. - visando garantia de QoS associada ao cumprimento de requisitos temporais, os quais têm impacto direto no desempenho, na usabilidade e na confiabilidade de tais sistemas e serviços.

Sistemas computacionais interativos são em geral orientados a eventos (event driven), i.e, permanecem inativos, reagindo passivamente apenas à ocorrência de eventos prédeterminados e apresentam, muitas vezes, tempo de execução não-determinístico. Em servidores Web, por exemplo, essa característica é implícita no modelo cliente-servidor e no comportamento estocástico do tempo de recuperação de documentos em servidores multi-tarefa de carga variável (Nissanke, 1997).

Em ambientes computacionais onde as noções de tempo são tratadas sob a forma de qualidade de serviço e são especificados explicitamente, conceitos e técnicas de escalonamento formam o ponto central do comportamento de sistemas de tempo real (Sha et al., 2004). 


\subsubsection{Sistemas de Tempo-Real Hard e Soft}

O ambiente pode apresentar uma dinâmica determinística ou estocástica, sendo este segundo caso consideravelmente mais difícil de tratar, especialmente na condição de um ambiente de recursos insuficientes. A abordagem utilizada em boa parte dos trabalhos na área de escalonamento de tarefas de periodicidade e tempo de execução variável, é tratar tarefas aperiódicas como processamento em background no intervalo de inatividade entre o atendimento de tarefas periódicas. Soluções para aproveitamento da capacidade ociosa foram pesquisadas em Sprunt et al. (1989) e Strosnider et al. (1989).

Requisitos temporais dados na forma determinística, especificando um limite superior de variação (atraso, por exemplo), caracterizam restrições denominadas de tempo real hard. Quando são dados de forma não determinística, ou estocástica, caracterizam restrições denominadas de tempo real soft. Formalmente: se $a(t)$ representa a fração das requisições atrasadas por mais de um tempo $t$ em relação à sua data de expiração (deadline), sistemas de tempo-real hard satisfazem à condição da equação (2.1).

$$
a(t)=0
$$

Um sistema de tempo-real soft, por outro lado, pode ser dado em uma expressão continua como demonstra a equação $(2.2)$, onde $\beta(t)$ indica qual a fração de requisições que pode ser atrasada por mais que um determinado tempo $t$. Alternativamente, o requisito pode ser formulado, por exemplo, de modo discreto como $a(t=1)=b 1, a(t=2)=b 2 \ldots$ $a(t>n)=0$.

$$
a(t) \leq \beta(t)
$$

A distinção entre soft e hard pode ser medida através de termos determinísticos ou probabilísticos de forma quantitativa. Se uma tarefa não permite a perda de deadline de suas requisições, então ela é classificada como Hard. Por outro lado, se for aceitável a perda eventual de deadline, desde que signifique apenas degradação no desempenho do sistema, ela é nomeada soft. Um exemplo seria o de um sistema multimídia que provesse ao usuário qualidade de serviço garantida. Nele, um filme exibido não consegue obter uma taxa constante de transmissão pois a rede pela qual este é transportado pode incorrer em algumas faltas de pequenos trechos. Essas falhas podem ser toleradas se ocorrerem pouco freqüentemente, já que o usuário, na maioria das vezes, não desejaria pagar o custo da completa eliminação desse problema. Por essa razão os requisitos de tempo de sistemas 
multimídia são garantidos por bases estatísticas, como uma média de atrasos/perdas de quadros por minuto menor que 2. Em sistemas soft a qualidade de serviço garantida é flexível, assim como a validação exigida e as restrições de tempo que especificam a qualidade (Liu, 2000).

\subsubsection{Parâmetros Temporais}

Além do deadline, outros parâmetros temporais são relevantes tanto para caracterizar o sistema em questão quanto para impor o comportamento temporal que deve ser obedecido durante a execução das tarefas. Dentre os parâmetros importantes, têm-se:

- Tempo de Início: Corresponde ao instante de início do processamento da requisição em uma ativação.

- Tempo de Término: Define o instante de conclusão da execução de uma requisição.

- Tempo de Resposta: Equivale ao tempo entre o recebimento de um estímulo externo pelo sistema (um conjunto de entradas) e a realização do comportamento esperado do sistema (resposta), incluindo a disponibilização de todas as saídas associadas.

- Tempo de Execução: Especifica a quantidade de tempo gasto para completar a execução de uma dada requisição, quando ela executa sozinha e de posse de todos os recursos necessários. Este é um parâmetro que depende diretamente da complexidade da requisição e da velocidade do processador utilizado para sua execução.

- Tempo de Chegada: Define o instante em que o escalonador toma conhecimento da ativação de uma requisição. Nas tarefas periódicas, o tempo de chegada coincide sempre com o início do período de ativação. Já as requisições aperiódicas, apresentam o tempo de chegada coincidindo com o tempo de requisição do processamento aperiódico.

- Tempo de Liberação: Coincide com o instante em que uma requisição é incluída na fila de pronto ${ }^{8}$. Em geral, é assumido que tão logo uma tarefa chegue, será liberada para a esta fila. A partir disto ela poderá ser escalonada e executada a qualquer momento, dependendo apenas da disponibilidade de seus dados e do cumprimento

\footnotetext{
${ }^{8}$ Lista com todos os jobs no estado de pronto; a organização depende da política adotada.
} 
das dependências de controle existentes. Tempo de liberação e deadlines são dois parâmetros muito utilizados para a distinção de tarefas de sistemas de tempo-real e tempo-virtual.

- Jitter: É uma variação estatística do retardo na entrega de dados, ou seja, pode ser definida como a medida de variação do atraso entre as sucessivas requisições do usuário.

\subsubsection{Dinâmica de Carga}

Existem três tipos principais de tarefas: periódica, aperiódica e esporádica.

É dito que uma tarefa é periódica quando suas instâncias são lançadas em intervalos de tempo regulares (Figura 2.2(a)), apresentando várias iterações e um período fixo entre liberações consecutivas, com as requisições de processamento do mesmo tamanho (Lin \& Tarng, 1991). Uma tarefa é chamada de esporádica (Figura 2.2(b)) quando se conhece apenas o intervalo mínimo de tempo entre lançamentos de instâncias consecutivas, por exemplo, uma tarefa esporádica pode executar uma manobra de emergência de uma aeronave quando o botão de emergência é pressionado, com um tempo mínimo de 20 segundos entre duas requisições de emergência. Tarefas ainda podem ser aperiódicas. Neste caso, (Figura 2.2(c)) não se conhece nada sobre a freqüência de ativação de suas instâncias. O atributo período é geralmente empregado para especificar tarefas periódicas ou esporádicas (Cruz \& Lima, 2005).

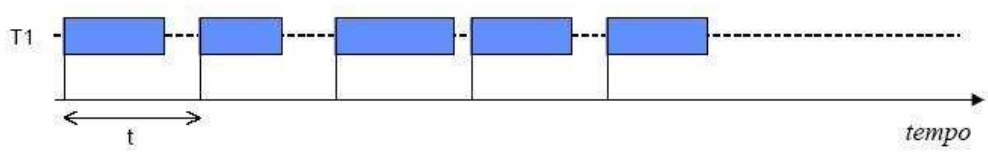

(a) Periódica

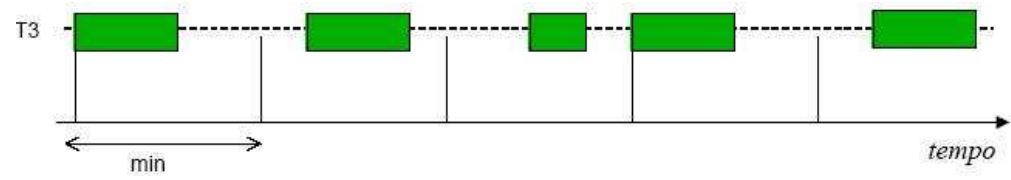

(b) Esporádica

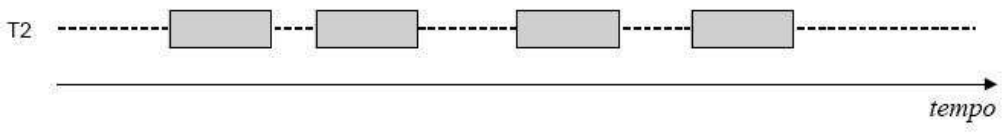

(c) Aperiódica

Figura 2.2: Caracterização das tarefas. 


\section{$2.4 \quad$ Políticas de Escalonamento}

Um escalonador produz soluções através de escalas de alocações dos recursos para uma dada demanda, sob as restrições especificadas. O escalonamento se refere a como os processos são distribuídos para execução nos processadores em um sistema de computação, respeitando as restrições de tempo de cada um, bem como condições de precedência, disponibilidade de recursos e demais características relevantes. Na terminologia da área, a unidade de trabalho agendada e executada por um sistema é denominada requisição, ou job, enquanto o grupo de requisições relacionadas, que conjuntamente desempenham alguma função no sistema, recebe o nome de tarefa, ou task. A transmissão de pacotes de dados, recuperação de um arquivo, cálculo para um sistema de controle, são exemplos de uma tarefa e cada pacote processado, ou trecho de dado manipulado, corresponde a um job da tarefa (Liu, 2000).

A forma com que ocorre o escalonamento é, em grande parte, responsável pela produtividade e eficiência atingidas por um sistema de computação. Mais do que um simples mecanismo, o escalonamento deve representar uma política de tratamento dos processos que permita obter os melhores resultados possíveis em um sistema de acordo com o seu propósito. As regras de tomada de decisão compõem a Política de Escalonamento, distinta do mecanismo que a implementa. Quanto à política, esta pode ser derivada de diferentes métodos, desde analíticos até empíricos, conforme a abordagem praticável em cada caso de uso.

\subsubsection{Algoritmos de Escalonamento}

Em cenários específicos, diversos algoritmos têm sido desenvolvidos. Alguns são muito importantes em função de sua larga aplicação e relevância científica. Em sistemas de tempo-virtual, a meta típica do escalonamento é maximizar a média do throughput ${ }^{9} \mathrm{e} / \mathrm{ou}$ minimizar a média do tempo de espera das requisições. O algoritmo de escalonamento mais utilizado em servidores Web é o FIFO.

O servidor Web que possui o algoritmo de escalonamento FIFO - First In First Out recebe as requisições que são armazenadas exatamente na ordem em que chegam ao sistema. A primeira requisição da fila e recebida e logo é atendida (Ye et al., 2005). Para ilustrar essa situação, a Tabela 2.1 mostra um exemplo com quatro requisições de mesmo deadline em uma fila.

\footnotetext{
${ }^{9}$ Número de requisições completadas por unidade de tempo.
} 
Tabela 2.1: Exemplo de Demanda por Recursos

\begin{tabular}{|l|l|}
\hline Requisição & Demanda \\
\hline$R_{1}$ & $9 u t$ \\
\hline$R_{2}$ & $7 u t$ \\
\hline$R_{3}$ & $5 u t$ \\
\hline$R_{4}$ & $3 u t$ \\
\hline ut.: Unidade de Tempo \\
\hline
\end{tabular}

Se essas requisições fossem processadas na ordem de chegada (FIFO) os tempos de espera em fila das requisições seriam dados da seguinte forma: o da primeira seria 0ut, 9ut para a segunda requisição, 16ut para a terceira requisição, e 21ut para a quarta. Com isso, a média do tempo de resposta proporcionado por este escalonamento seria $(0+9+16+21) / 4=11.5$ ut .

Uma forma de proporcionar tempos médios de espera menores do que aqueles obtidos com o FIFO é com o uso da política de escalonamento SJF- Shortest Job First. Nela as requisições em espera por atendimento são organizadas em uma fila segundo o tempo de processamento $\left(T_{p}\right)$, sendo colocados à frente os menores jobs, isto é, os que serão processados em intervalos de tempo menores. Observar-se na Figura 2.3 o resultado das operações caso fosse aplicado o conceito da política SJF ao servidor Web.

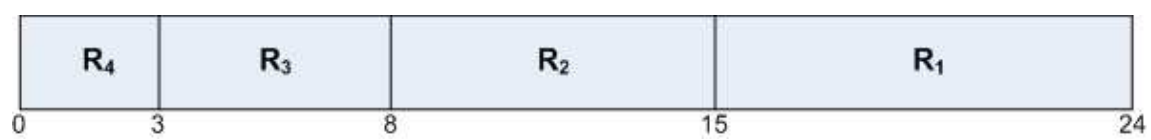

Figura 2.3: Escalonamento SJF.

Desta forma o tempo de espera da primeira requisição seria 15ut, o da segunda seria $3 u t$, o da terceira seria 8ut, e o da quarta requisição seria 0ut, com um tempo médio de espera $(15+3+8+0) / 4=6.5$ ut. O SJF provê um tempo de resposta ótimo ${ }^{10}$ pelo fato de oferecer mínimos tempos de espera ao conjunto de requisições escalonadas. Realocar as requisições mais curtas na frente das que exigem maior tempo de processamento permite que o tempo de espera das mais curtas diminua mais do que aumenta o das requisições mais longas, possibilitando uma diminuição na média de tempo de resposta oferecida pelo sistema.

Entretanto, no caso de escalonamento de sistemas $R T^{11}$, a meta corresponde a satisfazer o deadline de todas as requisições, garantindo para isso que cada uma possa completar sua execução dentro de seu deadline pré-estabelecido (Cheng, 2002). Escalonamento em

\footnotetext{
${ }^{10}$ Considerado ótimo quando o conjunto de requisições a ser escalonado é conhecido previamente.

${ }^{11}$ Real-Time
} 
sistemas $R T$ refere-se à especificação da ordem temporal de alocação de requisições para um processador (ou um conjunto de processadores), respeitando as restrições de tempo de cada uma, bem como condições de precedência e a disponibilidade dos recursos. Em sistemas onde a noção de tempo e de concorrência são tratadas explicitamente, conceitos e técnicas de escalonamento formam o ponto central na previsibilidade do comportamento do sistema (Nissanke, 1997). O algoritmo de escalonamento mais utilizado em ambientes de RT é o EDF - Erliest Deadline First.

O tipo de escalonamento baseado no Earliest Deadline First utiliza uma fila de prioridades. Toda vez que ocorre um evento (tarefa finaliza, novas tarefas são liberadas, etc.) é procurado na fila um processo mais próximo de descumprir seu deadline. Esse processo irá, então, ser escalonado para a próxima execução.

Ocorre nesse tipo de escalonamento a atribuição dinâmica de prioridades que define a ordenação das tarefas segundo os seus deadlines absolutos $\left(D_{i}\right)$. A tarefa mais prioritária é a que tem o deadline $D_{i}$ mais próximo do tempo atual. A cada chegada de tarefa, a fila de prontos é reodernada, considerando a nova distribuição de prioridades (Farines et al., 2000).

O EDF é um algoritmo de escalonamento ótimo utilizado em um único processador desde de que seja: preemptivo, e o conjunto de tarefas caracterizado por um tempo de chegada, tempo de execução e um deadline, de forma que todas as tarefas completam seus deadlines. O EDF sempre funciona para qualquer conjunto de processos escalonáveis. O custo disso é a complexidade do algoritmo. O exemplo da Figura 2.4 mostra como o conjunto de tarefas é submetido pelo escalonador, sendo as características das tarefas definidas por (Tempo de Computação, Período e Deadline). A Tarefa A つ (10,20,20) e a Tarefa B $\supset(25,50,50)$.

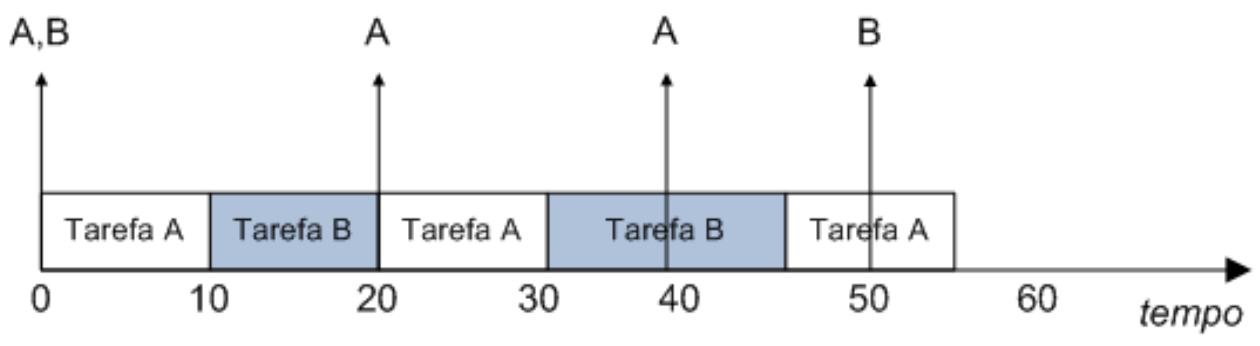

Figura 2.4: Escalonamento EDF Uniprocessado.

Esse é um algoritmo clássico que é conhecido por ter bons resultados em ambientes uniprocessados. Entretanto, aplicado de forma isolada em um ambiente multiprocessado exibe um resultado pobre. Por exemplo, suponha que existam três tarefas para executar 
em dois processadores de potência iguais $P_{1}$ e $P_{2}$, e as tarefas tem (Tempo de processamento e deadline) $T_{1} \supset(1,1), T_{2} \supset(1,2), T_{3} \supset(3,3.5)$, então o EDF envia $T_{1}$ para $P_{1}$ e $T_{2}$ para $P_{2}$ e $T_{3}$ não cumpre seu contrato. Entretanto, se $T_{3}$ fosse enviado para $P_{1}$, e depois $T_{1}$ e $T_{2}$ enviadas para $P_{2}$, todos os contratos seriam cumpridos (Stankovic et al., 1995). Ambos os casos são mostrados na Figura 2.5.

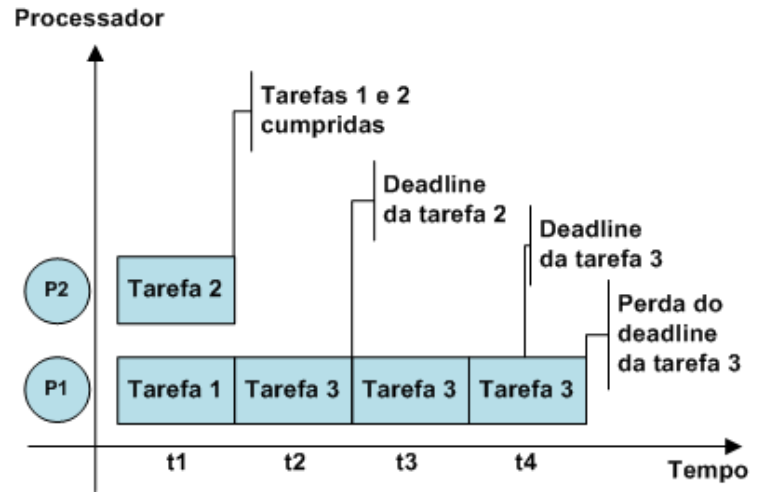

(a) EDF

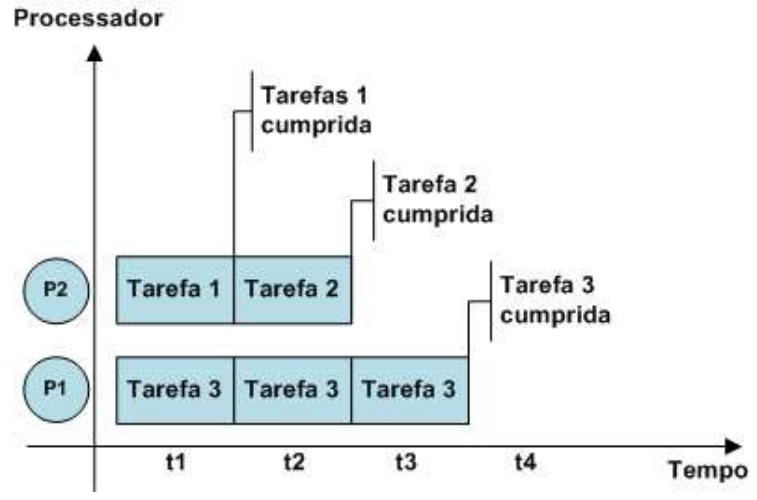

(b) Algoritmo ótimo

Figura 2.5: Sistema Multiprocessado.

\subsubsection{On-line e Off-line}

O escalonamento pode ser realizado a priori ou durante o processo de execução das requisições: têm-se respectivamente os casos de escalonamento off-line e on-line. No primeiro caso, o problema trata de escolher um conjunto determinado de jobs para posterior processamento. Por exemplo, assume-se que há tempo suficiente para encontrar a escala antes do inicio da execução da primeira requisição. No segundo caso, trata-se de processar as requisições conforme são recebidas pelo sistema, as quais possivelmente se acumulam em uma fila, portanto um sistema aberto. Cabe destacar neste último cenário o escalonador em si, também é um sistema de tempo-real, e portanto tem-se escalonamento de tempo-real em tempo-real.

\subsubsection{Estático e Dinâmico}

Considerando à natureza do problema, o escalonamento pode ser classificado em estático ou dinâmico.

O escalonamento estático possui o conhecimento prévio das características relevantes de todas as requisições, as quais podem ser levadas em conta na hora do escalonamento. É aplicável a problemas com requisitos de escalonamento bem conhecidos, por exemplo 
freqüência de processamento de requisições e tempos de computação. As prioridades estabelecidas em tais escalonamentos são fixas enquanto durar a aplicação. Entretanto, qualquer mudança nas informações providas ao escalonador, especialmente quando se trata de novas requisições, requer o completo reescalonamento delas. Desse modo algoritmos de escalonamento estáticos não são indicados para ambientes pouco previsíveis. Apesar dessa inflexibilidade, o escalonamento estático apresenta algumas vantagens como baixo custo (já que o escalonamento não é feito em tempo de execução), e facilidade de verificação (característica relevante em aplicações críticas).

Por outro lado, algoritmos de escalonamento dinâmicos são projetados para trabalhar com requisições em ambientes imprevisíveis com relação ao tempo de chegada, e possivelmente com tempo de serviço desconhecido. Espera-se de tais escalonamentos uma resposta pronta às necessidades do ambiente, adaptando-se a elas. Apesar da flexibilidade, o escalonamento dinâmico demanda alto custo de processamento para garantir o reescalonamento durante o tempo de execução (Nissanke, 1997).

O escalonamento off-line é freqüentemente equiparado ao escalonamento estático, porém isso é um equivoco. Na construção de um sistema $R T$, a análise do escalonamento off-line deve sempre ser feita, independentemente de possuir conhecimento se a execução final do algoritmo será estática ou dinâmica. Em muitos sistemas $R T$, os projetitas podem identificar um conjunto máximo de tarefas com seus piores casos de execução, assumindo e aplicando um algoritmo de escalonamento estático para produzir um escalonador estático. Esse escalonador é fixado e utilizado on-line e dado que todos os pressupostos permanecem verdade, todas as tarefas irão atender seus deadlines. Em outros casos, a análise off-line poderia produzir um conjunto estático de prioridades para ser usado em tempo de execução. O próprio escalonador não é fixo, porém as prioridades que o orientam são fixas.

Se o sistema $R T$ está operando em um ambiente dinâmico, utilizar a abordagem de escalonamento estático (tudo é conhecido a priori) não é viável. Nesses casos, projetistas escolhem um algoritmo e o analisam off-line para as esperadas condições do ambiente dinâmico. Normalmente, podem causar degradação do desempenho global do sistema. Geralmente, um algoritmo de escalonamento (possivelmente com algumas modificações) pode ser aplicado ao escalonamento estático ou dinâmico e utilizando a análise on-line ou off-line. Uma diferença importante é conhecimento sobre o desempenho do algoritmo em cada caso. Por exemplo, considere o algoritmo de escalonamento EDF. Quando aplicado ao escalonamento estático, EDF é ótimo em muitas situações já ditas anteriormente, mas 
quando aplicado ao escalonamento dinâmico em um sistema multiprocessado, ele não é ótimo (Stankovic et al., 1995).

Mediante a imprecisão dos resultados obtidos nesse tipo de ambiente, são desenvolvidos testes de escalonabilidade para serem executados off-line, os quais são capazes de atestar que, dadas as premissas assumidas, nenhum deadline será perdido. Tais testes de escalonabilidade são construídos a partir de cenários de pior caso, ou seja, cenários onde acontece a pior combinação de eventos possíveis, resultanto no maior tempo de resposta possível ou na maior demanda por processamento possível.

\subsubsection{Escalonabilidade em sistemas $R T$}

Realizar o teste de escalonabilidade significa verificar se todas as suas tarefas irão cumprir seus deadlines. Independentemente de qualquer tipo de interferência ou bloqueio, o tempo de computação de uma tarefa é variável, em função das características do hardware (cache, DMA, pipeline, etc) e do software (laços com número de iterações variável, fluxos de execução alternativos, etc). Entretanto, no sentido de construir um cenário de pior caso, os testes de escalonabilidade consideram sempre o tempo de execução no pior caso de cada tarefa. Uma vez que o teste pretende mostrar que todos os deadlines serão cumpridos, a probabilidade de uma tarefa realmente apresentar o seu tempo de execução no pior caso é irrelevante.

A análise de escalonamento é dita suficiente caso forneça um limite superior de escalonabilidade do sistema. Após esse limite, nada pode ser dito com relação à escalonabilidade do conjunto de tarefas analisado. Assim, nem todos os conjuntos de tarefas escalonáveis são considerados como tal por análises apenas suficientes.

Se a análise de escalonamento é apenas necessária, ela fornece limites de nãoescalonabilidade do sistema. Em outras palavras, se o conjunto de tarefas não é escalonável, a análise assim o acusa. Caso contrário, nada pode ser afirmado. O ideal é usar uma análise exata que é ao mesmo tempo necessária e suficiente. Dessa forma, tanto os limites de escalonabilidade, quanto os de não-escalonabilidade, podem ser conhecidos. Em alguns casos, quando a complexidade do modelo matemático não é excessivo, é praticável uma abordagem analítica para a verificação de escalabilidade.

Esses testes, descritos por Kopetz (1997), variam de acordo com o modelo de tarefas e políticas definidas em um problema de escalonamento. A Figura 2.6 ilustra esses três tipos de testes descritos. 


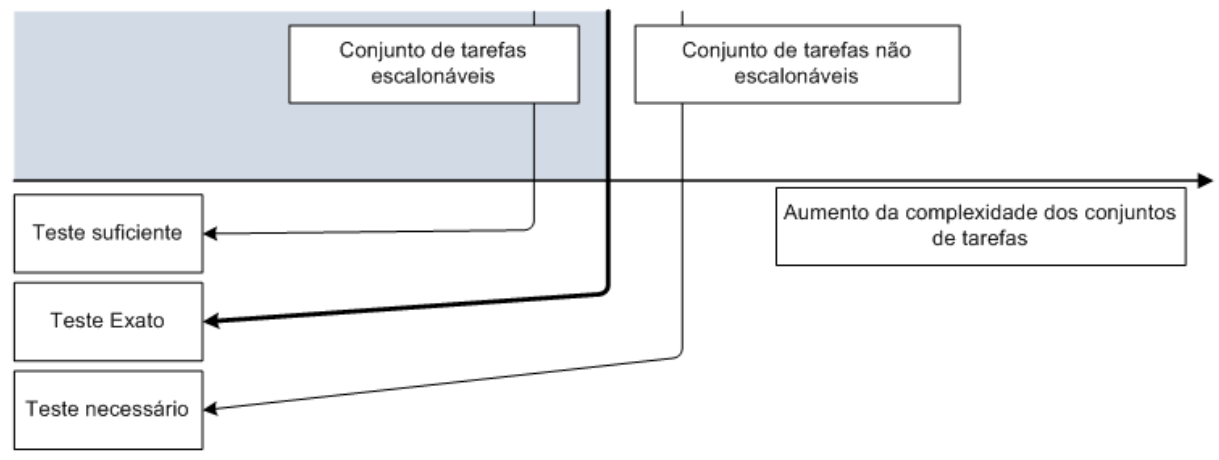

Figura 2.6: Tipos de testes de escalonabilidade.

Existem duas abordagens analíticas bastante utilizadas para se analisar a escalonabilidade de sistemas de tempo-real. São aquelas que realizam cálculo da utilização máxima do processador ou verificam se os tempos de resposta das tarefas no pior caso ultrapassam seus deadlines.

\section{Teste Baseado na Taxa de Utilização do Processador}

Seja um conjunto de $n$ tarefas periódicas e preemptíveis $\Gamma=\left(t_{1}, t_{2}, \ldots, t_{n}\right)$, que não compartilham recursos e são escalonadas num sistema com um único processador. Cada tarefa $T_{i}$ é ativada no sistema a uma taxa de $\frac{1}{T_{i}}$ e executada no máximo $C_{i}$ na unidade de tempo, ou seja, cada tarefa utiliza no máximo $u_{i}=\frac{C_{i}}{T_{i}}$ do potencial do processador. Assim, o fator de utilização máximo desse conjunto de tarefas é dado pela equação 2.3.

$$
U=\sum_{\forall t_{i} \in \Gamma} \frac{C_{i}}{T_{i}}
$$

A equação (2.3) é a forma geral da análise de escalonamento baseado na utilização do processador. Essa função matemática, devido à sua simplicidade, pode ser calculada em tempo de execução. Por essa razão, muitas vezes, esse tipo de teste de escalonabilidade é usado na abordagem on-line (Liu, 2000) (Buttazo, 1997).

A utilização da equação (2.3) é comum em sistemas que adotam o tipo de escalonamento de prioridades fixas, tanto quanto o de prioridades variáveis. Por exemplo, o EDF, quando suas condições de otimalidade são verificadas e quando os deadlines das tarefas são iguais aos seus respectivos períodos, basta verificar se $U \leq 1$ para determinar se o sistema é escalonável (Liu \& Layland, 1973). 


\section{Teste Baseado no tempo de resposta}

Esse tipo de abordagem calcula, para cada tarefa $t_{i} \in \Gamma$, seu pior tempo de resposta, $T s_{\max }$. Se $T s_{\max } \leq D_{i}$, onde $D_{i}$ é o deadline, a tarefa é escalonável. A implementação do procedimento para o cálculo de $T s_{\max }$ é simples (Burns \& Wellings, 2001).

Assume-se um conjunto $\Gamma$ de tarefas que são escalonadas por algum critério baseado em prioridades fixas (RM e DM). O critério utilizado sobre como as prioridades são atribuídas é irrelevante para a validade da análise (apesar de ter importância para a escalonabilidade do sistema). Além disso, o modelo de tarefas é periódico, sem recurso compartilhado, preemptivos e $D_{i} \leq P_{i}$.

Verifica-se que o pior tempo de resposta de cada tarefa $t_{i} \in \Gamma$ ocorre quando é necessário $C_{i}$ unidades de tempo para executar $t_{i}$ e que $t_{i}$ sofre interferência máxima ${ }^{12}$ das tarefas que possuem prioridades mais elevadas que $t_{i}$. Convenciona-se $A_{i}$ a essa interferência. Então, o tempo máximo de resposta de $t_{i}$ é dado pela equação 2.4 .

$$
T s_{\text {max }}=C_{i}+A_{i}
$$

No momento em que todas as tarefas $t_{j} \in \Gamma$, que têm prioridades maiores que $t_{i}$, são ativadas no mesmo instante $t_{i}$, ocorre a interferência de $A_{i}$. Cada $t_{j}$ pode ocorrer $\left\lceil\frac{T s_{\max }}{T j}\right\rceil$ vezes ${ }^{13}$ durante o tempo de resposta de $T_{i}$. No pior caso, para cada uma dessas vezes, a execução de $t_{j}$ interfere $C_{j}$ na execução de $t_{i}$. Assim, o termo $A_{i}$ é dado por:

$$
A_{i}=\sum_{j \in h p(i)}\left\lceil\frac{T s_{\max }}{T_{j}}\right\rceil C_{j}
$$

onde $\mathrm{hp}(i)$ é o conjunto de tarefas mais prioritárias que $t_{i}$.

\section{Testes Adaptativos}

Outras abordagens são baseadas na carga imposta à CPU. O adequado é aplicar um teste de acordo com o cenário de caso de uso ou a junção de duas ou mais abordagens. Existem muitas aplicações com requisitos de tempo real que, na verdade, toleram perdas eventuais de deadlines. Por exemplo, sistemas de controle de variáveis físicas contínuas são normalmente implementados como tarefas periódicas com deadline igual ao período, o qual é especificado em função da dinâmica do sistema físico controlado. Embora a abordagem clássica seja garantir que todos os deadlines dessa tarefa serão cumpridos, tais sistemas

\footnotetext{
${ }^{12}$ Isso ocorre devido a preempção existente neste processo.

${ }^{13} \mathrm{~A}$ operação $\lceil x\rceil$ retorna o menor inteiro que é maior ou igual a $x$.
} 
toleram a perda eventual de um deadline, desde que isto não ocorra repetidamente de forma indiscriminada. Vários trabalhos anteriores reconhecem este fato e apresentam testes de escalonabilidade que incluem a possibilidade de perdas eventuais de deadlines.

Algumas vezes é tolerável que as tarefas sofram perdas eventuais de deadline. A existência de uma tolerância para a perda de deadlines permite a construção de um sistema a partir de simulações baseadas em eventos que opere sobre o ambiente de servidores Web considerando a natureza probabilística do tempo de execução de cada tarefa.

\subsection{Simulação Baseada em Eventos}

Simulação é a técnica de estudar o comportamento e reações de um determinado sistema, que imitam na totalidade ou em parte as propriedades e comportamentos deste sistema, permitindo sua manipulação e estudo detalhado. Isso é útil quando deseja-se analisar o desempenho de sistemas computacionais em casos onde o sistema não está disponível, tendo como objetivo o de prever os diversos comportamentos decorrentes da facilidade de realizar comparações para uma maior variedade de cargas e ambientes computacionais (MacDougall, 1989)(Banks et al., 2000).

A solução por simulação pode ser classificada em discreta ou contínua. Nos casos discretos, o sistema depende de variáveis que assumem valores discretos, isto é, em um domínio de valores finitos ou enumeráveis tais como o conjunto de números inteiros, por outro lado, nos casos contínuos, depende de variáveis que assumem valores contínuos, isto é, em um domínio de valores contínuos tais como o conjunto de números reais (Freitas, 2001).

A solução por simulação orientado a eventos discretos as variáveis de estado sofrem alterações apenas nos pontos discretos do tempo, ou seja, no momento em que ocorrem os eventos, a mudança de estado é determinada pela ocorrência de um evento em um tempo determinístico ou estocástico. Os eventos são instâncias acionadas no tempo relacional, escalonadas ou não, tais como chegadas de processos ao sistema, liberação de processos após a execução, etc.

O objetivo da simulação de eventos discretos é reproduzir as atividades das entidades que compõe o sistema e conhecer o comportamento e desempenho do sistema. Portanto, é necessário definir o estado do sistema e as atividades que conduzem o sistema de um estado a outro. Na simulação orientada a eventos existe um procedimento associado com cada tipo de evento no sistema. O simulador ciclicamente gerencia os eventos, atualiza 
o relógio para o próximo evento a ocorrer e executa o procedimento associado ao evento (Thesen \& Travis, 1988).

Esses componentes descritos são utilizados para estruturar o modelo de simulação a ser construído. As linguagens de simulação mais comumentes conhecidas são classificadas em: orientadas a atividade, a evento, ou a processo. Dessas, as orientadas a processo e a evento são as mais utilizadas. Linguagens orientadas a processo, como ASPOL(MacDougall \& McAlpine, 1973), CSIM(Schwetman, 1986), e SIMULA(Birtwhistle et al., 1973), são mais recomendadas para implementar modelos de simulação de grande-escala, devido a grande similaridade entre modelo e sistema. Enquanto que linguagens orientadas a evento, como NS2(Heidemann et al., 2007), SIMPACK(Fishwick, 1992) e SMPL (MacDougall, 1987), são indicadas para modelos de pequena e média-escala, cuja representação em um único nível e a visão geral do sistema não significam problemas (MacDougall, 1989)(Lazowska et al., 1984)(Jain, 1991).

\subsubsection{A biblioteca SMPL}

SMPL baseia-se em uma extensão funcional escrita na linguagem de programação C. Essa extensão apresenta uma biblioteca (subsistema smpl) orientada a eventos. A visão do SMPL sob a perspectiva do sistema de simulação caracteriza as entidades em: recursos, tokens e eventos. Os recursos podem ser uma CPU, um barramento, memória, etc. A função dos recursos é prestar um serviço. Os tokens representam as entidades ativas do sistema. O comportamento dinâmico do sistema é modelado pelo movimento dos tokens entre um conjunto de recursos. O token pode representar diversas funções a critério do modelador; para o SMPL é apenas um inteiro, conhecido apenas por sua prioridade. Por fim, os eventos são considerados as mudanças de estados de qualquer entidade do sistema. Do ponto de vista do subsistema de simulação, um evento é identificado pelo seu número, o instante de tempo em que deve ocorrer e possivelmente a identidade do token envolvido com o evento.

Em geral, através do SMPL torna-se possível a construção de modelos mais próximos da realidade. Utilizam-se para isso, conceitos e técnicas de redes de filas. A teoria de filas (seção 2.6) da qual é derivada, é um ramo da probabilidade que estuda sistemas geradores de filas. 


\subsection{Teoria das Filas}

A teoria das filas é uma ferramenta matemática que trata de eventos aleatórios. Foi desenvolvida para prover modelos que retratem previamente o comportamento de um sistema que forneça serviços que possuam demandas que aumentem aleatoriamente, tornando possível realizar adaptações de forma a satisfazer os clientes e ser viável economicamente para o provedor do serviço.

A fila irá ocorrer à medida que a procura por um determinado serviço é maior que a capacidade do sistema de prover este serviço. Utilizam-se técnicas de rede de filas para modelagem desses tipos de sistemas. Redes de filas são representadas por conjunto de entidades interligadas que oferecem serviços através dos centros de serviço aos clientes do sistema.

Um centro de serviço (Figura 2.7) pode ser representado através dos recursos do sistema, compreendendo $n$ servidores homogêneos ou heterogêneos e um conjunto de clientes que aguardam pelo atendimento do serviço.

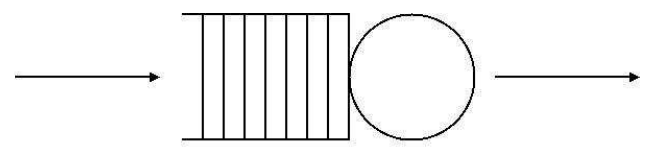

Figura 2.7: Centro de Serviço.

\subsubsection{Notação de Kendall}

O sistema de filas é classificado por suas características e utiliza-se a notação Kendall, representada pela tuple ${ }^{14} \mathrm{~A} / \mathrm{S} / \mathrm{c} / \mathrm{k} / \mathrm{m} / D$, descritas na Tabela 2.2.

Tabela 2.2: Notação de Kendall

\begin{tabular}{|l|l|}
\hline Símbolo & Descrição \\
\hline $\mathbf{A}$ & Distribuição de tempo interchegada \\
\hline $\mathbf{S}$ & Distribuição de tempo de serviço \\
\hline $\mathbf{c}$ & Número de canais de serviço simultâneo (servidores) \\
\hline $\mathbf{k}$ & Quantidade de Buffers ou capacidade do sistema \\
\hline $\mathbf{m}$ & Tamanho da população \\
\hline $\mathbf{D}$ & Disciplina de serviço \\
\hline
\end{tabular}

\footnotetext{
${ }^{14}$ Conjunto de variáveis.
} 
Geralmente omitem-se os parâmetros $k$ ou $m$ quando assumem valores infinitos. O parâmetro $D$ também é omitido quando representa a disciplina de fila FIFO. As distribuições utilizadas para o tempo entre chegadas e o tempo de serviço são simbolizadas por uma letra, conforme a Tabela 2.3:

Tabela 2.3: Descrição das Distribuições Probabilísticas

\begin{tabular}{|l|l|}
\hline Símbolo & Descrição \\
\hline$D$ & Distribuição determinística \\
\hline$M$ & Distribuição exponencial \\
\hline$E_{k}$ & Distribuição Erlang de estágio $k$ \\
\hline$H_{k}$ & Distribuição hiper-exponencial de estágio $k$ \\
\hline$G$ & Distribuição arbitrária \\
\hline
\end{tabular}

Algumas dessas características básicas dos processos de filas fornecem uma descrição adequada de um sistema de filas, tais como: padrão de chegada dos clientes (seção 2.6.2), padrão de serviço dos servidores (seção 2.6.3), número de canais de serviço (seção 2.6.4), disciplina de filas (seção 2.6.5), capacidade do sistema (seção 2.6.6).

\subsubsection{Padrão de Chegada das Requisições}

Os processos de chegadas de filas em ambientes comuns são estocásticos, ou seja, são conduzidos no tempo e no espaço conforme leis de probabilidade.

Suponha que os clientes chegam em instantes $t_{1}, t_{2}, \ldots, t_{n}$ a variável randômica $\chi_{n}=$ $t_{n}-t_{n-1}$ é nomeada de tempo interchegadas. Assume-se que os $\chi_{n}$ formam uma seqüência de variáveis aleatórias independentes identicamente distribuídas. Os mais comuns modelos de filas estocásticos assumem que os tempos de interchegada e serviço obedecem a uma distribuição exponencial ou, equivalentemente, que a taxa de chegada e a taxa de serviço seguem uma distribuição de Poisson.

\subsubsection{Padrão de Serviço dos Servidores}

Pode-se assumir que os conceitos mencionados nos padrões de chegadas são válidos para os padrões de serviço. O tempo gasto por cada cliente são variáveis aleatórias independentes identicamente distribuídas chamadas de tempo de serviço. A distribuição mais utilizada é a distribuição exponencial. 


\subsubsection{Número de Canais de Serviço}

Tipicamente os números de canais de serviços são previamente definidos, e assim, determina-se o número de estações de serviços paralelos que podem servir os clientes simultaneamente. A figura 2.8(a) ilustra um sistema com canal simples, enquanto a figura 2.8(b) mostra duas variações dos sistemas multicanais. Os dois sistemas multicanais diferem pelo fato que o primeiro possui uma única fila, enquanto o segundo possui uma fila para cada canal. O banco é um exemplo do primeiro tipo de multicanal. Por outro lado, um supermercado representa a segunda opção de multicanal. É geralmente assumido que os mecanismos de canais paralelos operam independentemente um do outro.

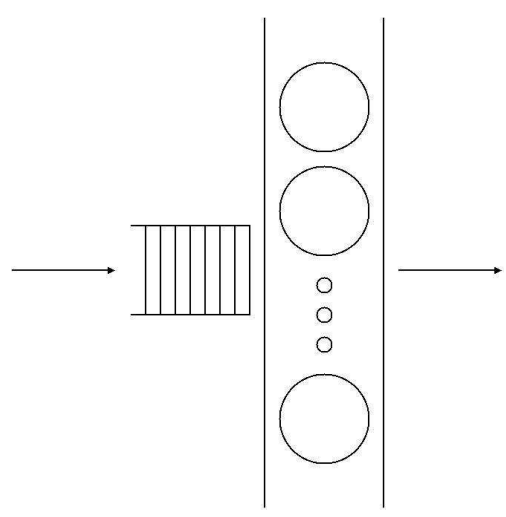

(a) Multiservidor

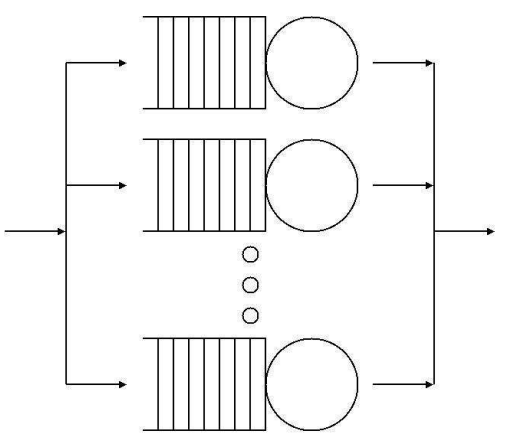

(b) Servidores em Paralelo

Figura 2.8: Sistemas Multicanais.

\subsubsection{Disciplina de Filas}

A disciplina de filas determina como os clientes são escolhidos para entrar em serviço após uma fila ser formada. A disciplina mais utilizada é a FCFS (First-Come-FirstServed), ou seja, o primeiro a chegar é o primeiro a ser servido. Entretanto, existem outras disciplinas, tais como, LCFS(Last-Come-First-Served), aplicável em sistemas de controle de estoque onde o item mais recente é mais fácil de ser apanhado, e diversas outras disciplinas, Tabela 2.4 , podendo ser baseadas em esquemas de prioridade.

Existem duas situações gerais em disciplinas de prioridade, preemptivo ou nãopreemptivo. No primeiro caso, o cliente com a mais alta prioridade é permitido entrar em serviço independentemente de outro cliente com menor prioridade estar sendo servido, de forma que, o cliente com menor prioridade é interrompido e tem seu trabalho reiniciado mais tarde. Quando reiniciado, ele pode iniciar do ponto onde parou ou reiniciar todo o processo. Na segunda situação de prioridade, os clientes com mais alta prioridade vão 
Tabela 2.4: Disciplinas de Filas

\begin{tabular}{|l|l|}
\hline Disciplina de Serviço & Descrição \\
\hline FCFS/FIFO & Primeiro a chegar, primeiro a ser servido \\
\hline LIFS/LIFO & Último a chegar, primeiro a ser servido \\
\hline RSS/SIRO & Seleção randômica \\
\hline RR & Atendimento por meio de uma lista circular \\
\hline GD & Distribuição genérica \\
\hline
\end{tabular}

para o início da fila, mas só entram em serviço quando o cliente sendo atendido deixa o sistema, mesmo que ele tenha uma prioridade baixa.

Essas prioridades podem se basear em questões como: tempo esperado de atendimento, tamanho do trabalho gerado pelo cliente, sensibilidade de atrasos e qualidade de serviço (QoS).

\subsubsection{Capacidade do Sistema}

Em alguns processos de filas a capacidade máxima de clientes no sistema poderá ser limitada por questões de espaço, de modo que, se as filas alcançarem certo comprimento, nenhum novo cliente poderá entrar no sistema até que espaço disponível seja obtido com o atendimento de um cliente e a conseqüente diminuição do tamanho da fila. Estas situações são referidas como sistemas de filas finitos, ou seja, existe um limite finito do tamanho máximo do sistema.

Sistemas com capacidade infinita são mais fáceis de analisar sendo todos os clientes atendidos. A capacidade do sistema inclui os clientes esperando ser servidos e os que estão sendo atendidos.

\subsubsection{Desempenho de Sistema}

Durante a simulação são atualizadas variáveis de contagem que permitem o cálculo de métricas de desempenho. Desde que as maiorias dos sistemas de filas possuem elementos estocásticos, estas medidas são freqüentemente variáveis aleatórias e possuem distribuições de probabilidade, ou pelo menos valores esperados.

Uma variável que merece destaque é o tempo de resposta que inclui tanto o tempo de espera como o tempo em atendimento.

Algumas definições de variáveis, vistas na Tabela 2.5, são utilizadas para caraterização dos componentes de rede de filas. 
Tabela 2.5: Métricas em Redes de Filas

\begin{tabular}{|l|l|}
\hline Símbolo & Descrição \\
\hline$\tau$ & tempo entre chegadas \\
\hline$\lambda$ & taxa média de chegada \\
\hline$\mu$ & taxa média de serviço por servidor \\
\hline$s$ & tempo de serviço por usuário \\
\hline$n$ & número de usuários no sistema \\
\hline$n_{q}$ & número de usuários esperando para receber serviço \\
\hline$n_{s}$ & número de usuários recebendo serviço \\
\hline$r$ & tempo de resposta ou tempo no sistema \\
\hline$w$ & tempo de espera ou tempo de fila \\
\hline$T$ & período de tempo observado \\
\hline$C$ & número de serviços completados no tempo $T$ \\
\hline$B$ & tempo ocupado do servidor durante $T$ \\
\hline
\end{tabular}

\subsection{Considerações Finais}

O objetivo deste capítulo foi de apresentar os conceitos e técnicas mais comuns que formaram a base dessa pesquisa de mestrado.

Esses conceitos são responsáveis por estabelecer parâmetros de serviço em termos temporais utilizando-se de abordagens oriundas da área de Tempo-Real. Assim definiu-se alguns conceitos preliminares para o entendimento dessa área, outros importantes para definição e classificação de sistemas do gênero, além de apresentar alguns algoritmos mais utilizados por pesquisas e desenvolvimento em Tempo Real.

Foi apresentada uma visão geral da área de qualidade de serviço, abordando seus conceitos básicos. Deu-se especial atenção na possibilidade de utilização de QoS na Web, com o objetivo de que a mesma possa dar suporte a novos tipos de aplicações, oferecendo níveis de serviços superiores aos do modelo atual de melhor esforço. Foram destacadas as arquiteturas de serviços integrados e diferenciados, com ênfase nesta última.

Por fim, para o estudo científico de um sistema $W e b$ utilizou-se a técnica de modelagem para representá-lo. Conceitos gerais de Redes de fila foram apresentados, como nomenclaturas, relações algébricas e classificação de modelos. E como ferramentas oferecidas pela probabilidade e estatísticas são de importância para uma análise adequada de sistemas, seus principais conceitos também foram abordados. 
Este capítulo de fundamentação teórica apresentado proporciona entender melhor a área e as técnicas necessárias para a realização do trabalho proposto, como os conceitos de Qualidade de Serviço, que embasa o projeto; teoria de Tempo-Real, importante devido o enfoque temporal dos parâmetros de serviço; e conceitos de Simulação de Sistema, utilizada para análise da política proposta.

O próximo capítulo detalha os principais trabalhos relacionados a essa área de pesquisa, tornando mais claro a existência de abordagens que surgem nos dias de hoje para criar soluções que apresentem garantias de QoS para o ambiente Web. 


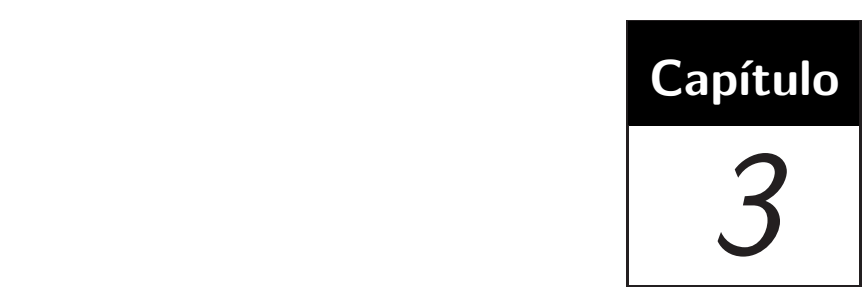

Trabalhos relacionados

\subsection{Considerações Iniciais}

Atualmente, o tráfego na rede é muito diversificado e cada tipo possui um requisito único em termos de largura de banda, atraso, perda e disponibilidade. Com o crescimento da Internet, a maioria das redes do momento são baseadas no protocolo IP. O fato de possuir um único protocolo de transporte é benéfico, visto que a manutenção dos esquipamentos de rede se torna menos complexa, resultando em custos operacionais mais baixos. Entretanto, isso é contrastado pelo fato de que o IP é um protocolo sem conexões, isto é, os pacotes IP não possuem um caminho específico à medida que trafegam pela rede. Isso resulta numa qualidade de serviço inadequada em uma rede best effort. Por isso, neste capítulo, serão introduzidas as várias pesquisas desta área, objetivando a garantia de QoS sobre os serviços em redes IP e principalmente os esforços realizados para melhorar a QoS no nível de aplicação, principalmente nos servidores Web, os principais responsáveis pelo atendimento das requisições que trafegam pela rede mundial de computadores.

Como discutido na seção 2.2, a provisão de qualidade de serviço será dada de forma mais eficaz e propiciará melhores resultados se houver a cooperação de todos os componentes do sistema, inclusive do nível de aplicação, como os servidores $W e b$, foco desta pesquisa. Sendo assim, alguns trabalhos relacionados a essa linha de pesquisa merecem destaque, seja pelo apoio ao desenvolvimento de alternativas que venham a complementar as soluções já propostas, como também para orientar sobre as lacunas de pesquisas existentes. 


\subsection{Revisão Bibliográfica}

Com relação ao tema $Q o S$ na $W e b$, as pesquisas sobre controle de admissão e diferenciação de serviços têm sido preponderantes. A primeira para evitar a sobrecarga no sistema e a segunda garantir diferenciação na prestação de serviço para cada classe do sistema.

Chen \& Heidemann (2003) propuseram um algoritmo nomeado SFD (Short Flow Differentiating) que apesar de ser um trabalho que enfoca QoS no nível de rede, pode-se perceber a importância e o impacto da priorização de serviços com tráfegos mais curtos, pois esse tipo de fluxo de operação corresponde a mais de $80 \%$ das respostas Web.

Por outro lado, no nível de aplicação, em (Kanodia \& Knightly, 2003), é proposta uma pesquisa para prestação de serviço na $W e b$ para determinar os tempos de resposta contratados. Além de tentar manter valores individuais das classes, a técnica também realiza um controle adaptativo dos tempos de resposta entre as classes. A proposta dessa pesquisa é demonstrada por meio de simulação orientada a traces.

Com o intuito de conseguir garantias de confiabilidade em relação à qualidade de serviço prestado sob o ambiente da Web, vários algoritmos de escalonamento adaptativos, no nível de aplicação, têm sido desenvolvidos nos últimos anos por (Abdelzaher et al., 2003)(Traldi et al., 2006)(Vasiliou \& Lutfiyya, 2000)(Zhang et al., 2002). O modelo de melhor esforço baseado em diferenciação de serviço (Almeida et al., 1998)(Kang et al., 2003)(Lee et al., 2003)(Stankovic et al., 1998) em servidores Web realiza o melhor serviço para os clientes dependendo de sua classe mas não prover qualquer garantia em relação ao tempo que a requisição será atendida.

Vários algoritmos com diversas abordagens têm sido propostos na literatura, tais como: (Bampis \& Kononov, 2001)(Lee et al., 2003)(Liebeherr et al., 1995)(Manimaran et al., 1998)(Ramamritham et al., 1990)(Wang et al., 1990)(Stankovic et al., 1995). Para um sistema com único processador, foi mostrado que os algoritmos EDF e o LLF (Least Laxity First )(Liu \& Layland, 1973)(Stankovic et al., 1995) possuem bons resultados em condições normais de uso dos recursos existentes. Entretanto, em sistemas multiprocessados, o escalonamento em tempo-real é NP-difícil (Liebeherr et al., 1995)(Liu \& Layland, 1973)(Ramamritham et al., 1990)(Stankovic et al., 1998)(Ghosal et al., 1991)(Babbar \& Krueger, 1994).

No passado, os algoritmos de escalonamento de tempo-real em ambientes multiprocessados assumiam que as tarefas eram executadas em somente um processador, isso se 
deve ao fato do nível de complexidade envolvido. Recentemente, pesquisas vêm sendo desenvolvidas para que tarefas de tempo-real possam ser executadas usando múltiplos processadores em paralelo para reduzir o tempo computacional de execução, aumentando a confiabilidade e podendo atender mais tarefas dentro do prazo estipulado (Lee et al., 2003).

De formal geral, para dois ou mais processadores, não existe um algoritmo de escalonamento de tempo-real que pode ser ótimo sem o completo conhecimento dos deadlines, do tempo de computação e do tempo de início das tarefas (Mok, 1983). Isso implica que qualquer teoria dos algoritmos clássicos, que requeira conhecimento do tempo de início da tarefa não pode garantir ser ótimo se usado em um ambiente on-line. Isso mostra que desenvolver um algoritmo de forma geral ótimo é uma tarefa difícil, o que não significa, contudo, que algoritmos ótimos não possam existir para um dado conjunto de condições especiais (Stankovic et al., 1995).

O desafio do escalonamento de tempo-real em ambientes de processadores paralelos encontra-se no cerne desta proposta de investigação. De fato, em um array ${ }^{1}$ de servidores, o escalonamento em tempo-real é comumente reconhecido como um problema computacional NP-difícil ${ }^{2}$ e algoritmos citados anteriormente não são ditos ótimos (Lee et al., 2003).

No caso particular de Servidor Web, agrava-se a situação em função do comportamento estocástico do servidor. Para um tratamento analítico, ainda que estatístico, é necessária uma descrição bem detalhada da dinâmica do ambiente para que se possam prever com precisão as necessidades do sistema.

Um artifício diante dessa dificuldade é assumir que todas as situações de pior caso existem simultaneamente. Se esse cenário é escalonável, então também será escalonável em tempo de execução (ainda que os tempos de chegada sejam diferentes). Onde tais abordagens sobre os piores casos não são possíveis para um dado sistema, usualmente porque condições suficientes não podem ser desenvolvidas ou porque medir estas condições possui um alto custo, melhores abordagens probabilísticas são necessárias (Stankovic et al., 1995).

As técnicas existentes, mesmo as assíncronas, baseadas em eventos, que tratam com garantias probabilísticas, não são abrangentes o suficiente para que possam ser eficientes

\footnotetext{
${ }^{1}$ É caracterizado por um vetor ou lista (para arrays uni-dimensionais) ou matriz (para arrays bidimensionais).

${ }^{2} \mathrm{Na}$ teoria de complexidade computacional NP-difícil é uma classe de problemas não-determinísticos, informalmente definidos como os mais difícies de serem resolvidos da classe NP.
} 
diante deste novo contexto de aplicações emergentes em sistemas computacionais interativos, incluindo os sistemas Web, foco deste trabalho.

Um perfeito e detalhado tratamento analítico das condições de escalonabilidade, a priori em cenários realísticos, costuma ser impraticável em termos de engenharia; do ponto de vista da teoria computacional envolvida, a otimização de escalonamento de tempo-real resulta, em geral, em um problema intratável (Lee et al., 2003; Stankovic et al., 1995).

São úteis, como visto em (Stankovic et al., 1995) e (Zhang et al., 2001), abordagens alternativas baseadas em simulação e heurísticas para definição de políticas de escalonamento dinâmico, por exemplo, onde a tomada de decisão do processo de escalonamento seja realizada com base na condição instantânea da fila de requisições pendentes e no estado do conjunto de processadores, levando em conta os deadlines e tipos de carga ${ }^{3}$ associados às requisições pendentes, em função da heterogeneidade e da carga presente no conjunto de processadores.

Tentativas para resolver essa situação incluem buscar heurísticas off-line que baseiamse em abordagens da teoria clássica. Essas técnicas off-line buscam somente um escalonador viável, não necessariamente o ótimo. Muitas heurísticas apresentam um bom desempenho no caso médio e somente deterioram para complexidade exponencial no pior caso (Stankovic et al., 1995).

A aplicação de heurísticas na busca por uma solução tenta reduzir o espaço do problema a ser analisado. As regras heurísticas classificam as opções em promissora e nãopromissora, associando medidas de benefício ou custo relativo, permitindo selecionar um opção que apresente um maior benefício ou um menor custo.

A pequisa na área de escalonamento heurístico está associada à identificação de heurísticas que reduzam o tempo de busca e aumentem a qualidade do escalonamento produzido. À medida que se aumenta o número de fatores a considerar no processo de determinar essas heurísticas, aumenta também a sua complexidade (Zhang et al., 2001).

Um bom número de heurísticas existem para escalonamento dinâmico em um ambiente multiprocessado. Mas ainda é necessária uma análise estocástica destas condições. É especialmente importante criar algoritmos que operem com níveis de garantia de entrega de serviço. Ainda que o sistema opere estocasticamente e não seja ótimo, ele poderá prover um nível mínimo de garantia de desempenho (Stankovic et al., 1995), em que, a perda de deadline pode diminuir a qualidade do serviço (QoS), mas não causa uma falta crítica no sistema (Buttazo et al., 1998).

\footnotetext{
${ }^{3}$ Impacto que representa para cada um dos processadores.
} 
Como dito anteriormente, do conjunto dos algoritmos clássicos, têm-se o EDF (Earliest Deadline First) (Liu \& Layland, 1973), que trata primeiro as requisições que estão mais próximas de perder o seu prazo de conclusão, e possui bons resultados para determinados cenários em ambientes uniprocesados. Entretanto, utilizado de maneira isolada em um ambiente multiprocessado, causa rapidamente a degradação do desempenho em condições de sobrecarga do sistema (Stankovic et al., 1998). Criando assim, uma abertura de investigação no campo de abordagens de escalonamento de tempo-real para ambientes multiprocessados, principalmente sobre conjunto de recursos heterogêneos.

\subsection{Estado da Arte}

O grupo de pesquisa $\mathrm{SDPC}^{4}$ do $\mathrm{SSC}-\mathrm{ICMC} / \mathrm{USP}$ tem desenvolvido trabalhos na área de serviços diferenciados, no qual fornece um modelo de QoS, em nível de aplicação, com base na definição de tipos de serviços, baseado no modelo de Diferenciação de Serviços $\left(\right.$ DiffSer $\left.^{5}\right)$. Nesse tipo de estrutura abordado, classes de serviço normalmente são especificadas de acordo com contratos de nível de serviço, firmados entre o usuário e o provedor de serviço de Internet, ou entre domínios adjacentes. O contrato pode ser estático ou dinâmico. Contratos estáticos são negociados de maneira regular (semanalmente ou mensalmente, por exemplo).

Estendendo esses trabalhos de pesquisa, Teixeira (2004) elaborou o modelo SWDS ${ }^{6}$, o qual visa o fornecimento de serviços diferenciados na Web, em nível de aplicação. Ele propõe uma arquitetura composta basicamente por três módulos: (1) Classificador; (2) Controle de Admissão; e (3) Cluster de servidores. O Classificador é o responsável por atribuir as requisições à classe de serviço correspondente. O Controle de Admissão gerencia a aceitação das requisições já classificadas pelo servidor. Após esta fase a requisição é atribuída a um dos elementos do Cluster. Finalmente, os resultados da requisição são retornados ao usuário. A ilustração deste modelo é visto na Figura 3.1.

Estrella et al. (2006) estendem o trabalho de (Teixeira, 2004) ao incluir um mecanismo de negociação de serviço no módulo de controle de admissão, proporcionando com isso melhores médias de tempo de resposta e menores taxas de descarte de requisições, melhorando a qualidade de serviço oferecida.

\footnotetext{
${ }^{4}$ Sistemas Distribuídos e Programação Concorrente.

${ }^{5}$ Differentiated Services.

${ }^{6}$ Servidor Web com Diferenciação de Serviços.
} 


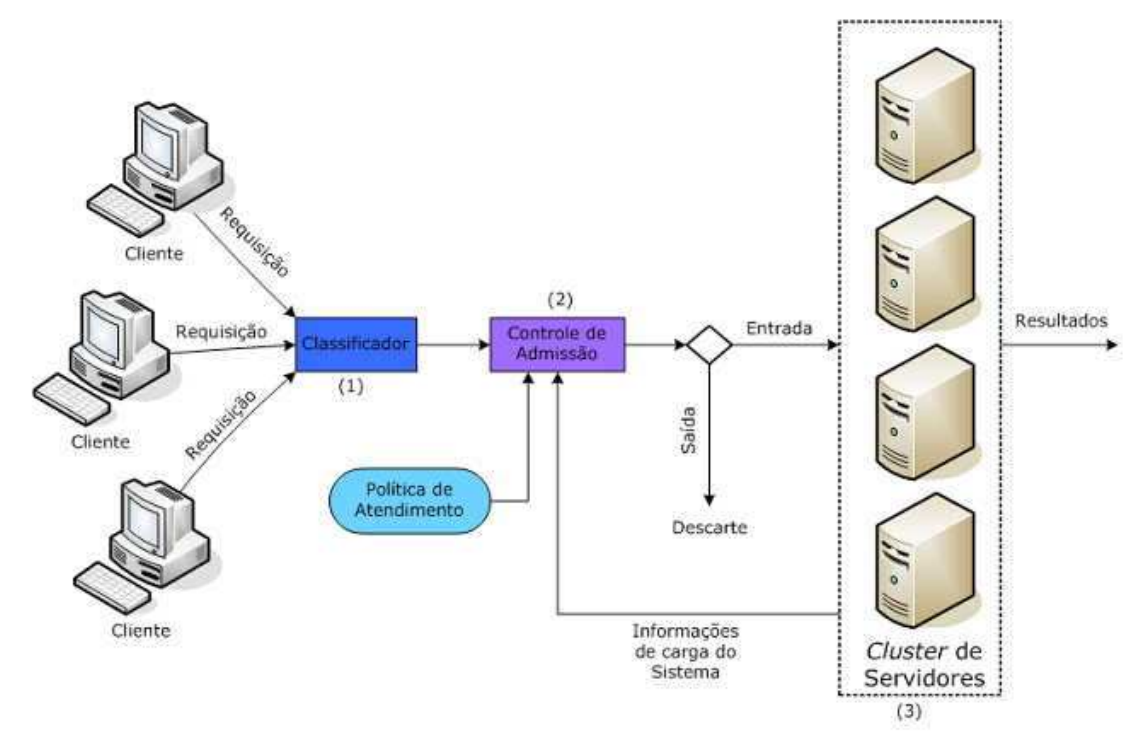

Figura 3.1: Servidor Web com Diferenciação de Serviços. (Teixeira, 2004).

Uma extensão deste modelo sob a perspectiva do atendimento de critérios temporais como medida de QoS, tal como o estudo elaborado por Casagrande (2007), no qual desenvolveu a política EBS - Exigency Based Scheduling de escalonamento em sistemas de tempo-real, tendo como domínio de aplicação a provisão de serviços diferenciados em nível de aplicação na Web. O objetivo do referido trabalho é permitir a especificação quantitativa da QoS, no que se refere ao cumprimento de requisitos temporais, permitindo ao provedor de serviço oferecer ao usuário um contrato, no qual é baseado em parâmetros de qualidade formulado em termos de limites superiores de tempo de atendimento de requisições.

Torna-se necessário a realização do gerenciamento ativo de recursos também no nível de aplicação para lidar com a QoS de modo fim-a-fim em grande escala, proporcionados por meio de um array de servidore Web. Portanto, a provisão de QoS apenas no nível de rede não é suficiente para garantir mecanismo completo de qualidade, uma vez que somente o gerenciamento de banda e controle de congestionamento não podem resolver problemas de congestionamento e gargalos de atendimento no servidor. O escalonamento FIFO desempenhado por muitos servidores pode comprometer as garantias de QoS oferecidas ao longo da rede, uma vez que um servidor ocupado pode descartar indiscriminadamente pacotes de rede de alta prioridade. Assim, uma solução integrada para QoS fim-a-fim na Web deve ter como componente um servidor Web com mecanismos de QoS para proteção contra sobrecarga e capacidade de gerenciamento de recursos sob o emprego de técnicas de escalonamento eficiente para ambientes multiprocessados. 


\subsection{Considerações Finais}

Neste capítulo foram apresentadas as principais pesquisas sobre a qualidade de serviço tanto no nível de rede quanto no nível de aplicação, além da estrutura da Web. Foi discutido também os diversos tipos de abordagens propostos para obter QoS, destacandose as aplicações interativas, aplicações orientadas à resposta, etc. Uma visão geral sobre as idéias e os fundamentos da arquitetura de serviços diferenciados também foi objeto de estudo do presente capítulo. Além da diferenciação de serviços no nível de rede, foi reiterado a importância do fornecimento de QoS no nível de aplicação, mostrando os esforços realizados por diversos pesquisadores para melhorar o desempenho dos servidores Web, estes os principais responsáveis pelo atendimento às requisições http.

Esses trabalhos que estão relacionados a pesquisa dessa dissertação apresentam contribuições importantes para aumentar o nível de fidelidade ${ }^{7}$ dos serviços oferecidos na Web. Como se pode perceber, o enfoque maior das pesquisas tem sido a especificação de QoS em termos relativos, expondo um cenário de menor desenvolvimento de trabalhos com garantias absolutas de Qos, oferecendo assim um amplo campo de pesquisa a ser explorado.

O próximo capítulo objetiva a descrição detalhada da abordagem da arquitetura Ortogonal, formado pelas políticas de recursos e pelas políticas de fila de servidor Web e que é a base para o desenvolvimento do trabalho discutido nesta dissertação de mestrado.

\footnotetext{
${ }^{7}$ Quanto ao cumprimento de requisitos temporais abordados.
} 



\section{Capítulo 4}

\section{Desenvolvimento}

\subsection{Considerações Iniciais}

Este trabalho visa a estudar o fornecimento de QoS absoluta na Web, em nível de aplicação, particularmente no contexto de servidores Web. A motivação para este tema nasce da constatação de que o modelo atual de serviços na Web, em particular, trata todas as requisições de forma equivalente, FIFO, sem nenhum tipo de diferenciação ou priorização. Contudo, verifica-se que nem todos os tipos de tráfegos e transações são equivalentes ou têm a mesma prioridade para os usuários (Dovrolis \& Ramanathan, 1999).

Este capítulo propõe uma arquitetura ortogonal para um Servidor Web, por meio de uma combinação de uma política de fila e uma política de recurso, descrevendo em detalhes seus principais componentes, parametrização e as condições de contorno necessárias do ambiente, feita através de simulação. Todos os algoritmos são bem descritos neste capítulo.

De forma mais detalhada, são apresentadas as abordagens e procedimentos utilizados para o desenvolvimento do projeto, a fundamentação analítica definida, para melhor estruturação e avaliação da política desenvolvida, e a descrição das políticas de escalonamento em si. Para isso, apresenta-se na seção 4.2 a metodologia adotada para a realização do trabalho, em seguida, na seção 4.3 discutem-se os conceitos e métricas adotados pelo controle de admissão, na Seção 4.4 é apresentada a criação de uma nova métrica adotada para efeito de comparação das disciplinas. Finalmente na seção 4.5 trata-se das várias fases de desenvolvimento da política de escalonamento com suporte a QoS proposta. 


\subsection{Contextualização}

Para avaliar o desempenho dos algoritmos desenvolvidos foi utilizado o modelo de rede de filas do servidor Web distribuído, sistema de fila M/M/4 (Seção 2.6), limitando-se às suas principais características. Para solucionar o problema envolvido foi utilizada a extensão funcional SMPL escrita na linguagem de programação C. SMPL (seção 2.5.1) é uma extensão funcional baseada em simulação orientada a eventos.

A tomada de decisão do processo de escalonamento tem como base a condição instantânea da fila de requisições e do conjunto de processadores, levando em conta os deadlines, os tipos de cargas representadas pelas requisições pendentes e as características da carga presente nos processadores a partir da heterogeneidade composta.

Assim, dois tipos de escalonamento são executados: escalonamento na fila (job), e escalonamento de recursos (processador); constituindo este segundo problema, uma contribuição deste trabalho em relação ao estudo desenvolvido por Casagrande et al. (2007) e demais abordagens clássicas.

\subsubsection{Modelo de Recursos}

Neste trabalho considera-se um array de servidores modelado como um pool $^{1}$ de processadores paralelos ou nós, $K=(K 1, K 2, \ldots, K n)$, formado por uma arquitetura heterogênea. Foi utilizado $n$ igual a quatro.

As aplicações reagem diferentemente aos diversos ambientes, principalmente por fatores associados à heterogeneidade. Assume-se previamente que o tempo de processamento de cada tarefa é conhecido, $T_{i}^{p}$, e é dependente de diversos fatores (Cheng, 2002). A idéia é modelar a distribuição do tempo de processamento e usar para obter o nível de confiança para qualquer tempo dado (Cheng, 2002). Será optado neste trabalho por este nível de granularidade na simulação.

O modelo considera que o tempo de escalonamento (tomada de decisão e despacho) é nulo, por ser este não significante comparado à ordem de grandeza dos outros tempos que definem a dinâmica do processo, tais como de processamento das requisições e tempo de espera em fila.

\footnotetext{
${ }^{1}$ É o mesmo que uma coleção.
} 


\subsubsection{Modelo de Tarefas}

O modelo inicial de tarefas assume que todas as tarefas são independentes, a execução ocorre sem restrição de precedência, sem preempção e sem recirculação. O modelo adotado é caracterizado por tarefas aperiódicas com o deadline calculado dinamicamente, ou seja, a cada ciclo de execução, os jobs são atualizados segundo os seus deadlines em função de outros fatores relevantes, tais como a carga imposta a cada processador do cluster. Para cada tarefa $i$, existe um nível de QoS $N$ correspondente, que é cumprido de acordo com o contrato previamente estipulado.

Os atributos de cada tarefa que ocorrem no texto são descritos da seguinte forma:

- $\tau_{i}^{p}$ é o tempo de término (estimado) do job $i$ no nó $p$;

- $C_{i}^{p}$ é o custo (carga de trabalho) do job $i$ no nó $p$;

- $T_{r}^{p}$ é o tempo restante necessário para que o nó $p$ seja liberado;

- $T_{i}^{p}(f)$ é o tempo de processamento em relação aos atributos $\left(D_{i}, F_{i}\right)$ do job $i$ no nó $p$

- $\sum C_{n}^{p}$ representa os jobs que aguardam na estrutura da fila virtual;

- $C_{j}^{p}(t)$ é o tempo restante de processamento do job j atualmente em execução no nó $p$

\subsection{Controle de Admissão}

O controle de sobrecarga é fundamental para garantir a qualidade dos serviços da Internet. À medida que as cargas de trabalho que chegam ao sistema tornam-se superiores à capacidade dos servidores se faz necessário o uso de um mecanismo de gestão de admissão. Por vezes, tenta-se controlar a carga do sistema estabelecendo-se limiares fixos, especificados pelo administrador, tais como número de conexões abertas ou de threads ativas (Welsh \& Culler, 2003). Entretanto, é difícil determinar os limites ideais, de forma estática (R. Iyer \& Kant, 2000), em um ambiente de características imprevisíveis como é a Web. Por esta razão, foi proposto um mecanismo de controle de admissão tal como em (Teixeira et al., 2005). Esse mecanismo é sensível a mudanças na carga de trabalho oferecida ao sistema, o qual foi implementado em todas as políticas elaboradas. 
O mecanismo de controle de admissão tem como métrica a utilização média do cluster de servidores Web. O cálculo é realizado através de uma média exponencialmente ponderada. A escolha da utilização como parâmetro de controle é bastante conveniente, pois indica, sob a visão global do sistema, se o mesmo está de fato sobrecarregado. O uso de uma média, em vez do valor real da utilização, tem o objetivo de minimizar o efeito de um congestionamento momentâneo no servidor e o peso escolhido determina a sensibilidade da média a mudanças na utilização do cluster.

O algoritmo funciona da seguinte forma: a utilização atual do cluster é medida a cada nova requisição que chega ao servidor e este valor é combinado com dados históricos a fim de obter a média exponencialmente ponderada, $M E_{c o r}$. Caso a mesma esteja acima de um limiar pré-estabelecido (THRESHOLD) adotado nesse projeto igual a 0.77 , então o controle irá recusar quaisquer novas requisições, independentemente de sua classe, até que $M E_{c o r}$ caia para níveis aceitáveis, isto é, abaixo do limiar determinado. O cálculo da média exponencialmente ponderada é definido pela equação (4.1).

$$
M E_{\text {cor }}=\left((1-p) \cdot M E_{\text {ant }}\right)+\left(p \cdot M E_{\text {atual }}\right)
$$

$M E_{\text {ant }}$ é o valor anterior da média, é o histórico. Enquanto $M E_{\text {atual }}$ é o valor atual observado para a utilização do cálculo. O peso $p$ tem a função de um coeficiente de sensibilidade das mudanças de carga de trabalho que chegam ao sistema, à medida que:

- $p \longrightarrow$ 1: Com esse tipo de configuração o servidor apresenta uma política de admissão mais rígida, o mecanismo de controle torna-se bastante sensível às mudanças na utilização do sistema. Indicado para situações em que o servidor esteja continuamente exposto a uma carga elevada. Neste caso, o tempo de resposta e as filas tendem a ser menores, pois as recusas de serviço evitam a sobrecarga do sistema.

- $p \longrightarrow 0$ : Com esse tipo de configuração empregada, a política de admissão leva em conta o histórico da carga do sistemao. O mecanismo de controle reage mais lentamente às mudanças na utilização do sistema, apresentando um comportamento mais estável. Indicado para situações em que a carga é geralmente baixa, apresentando algumas rajadas ocasionais. Nesse projeto, adotou-se essa configuração, sendo $p$ igual a 0.001 . 


\subsection{Satisfação do Cliente}

Considera-se que um usuário estará satisfeito com o serviço a ele oferecido quando obtiver uma alta porcentagem de requisições atendidas em média abaixo do limiar de qualidade contratado. Logo, analiticamente, o escalonador pode tomar como índice de satisfação do usuário a equação (4.2), em que são relacionadas a quantidade total de requisições submetidas pelo $i$-ésimo usuário $\left(R_{i}\right)$ e o número de vezes em que a média do tempo de resposta de sistema dessas requisições ficou abaixo do limiar contratado $\left(N_{i}\right)$.

Uma requisição é bem atendida quando seu tempo médio de resposta de sistema observada (real) for menor ou igual ao tempo médio de resposta somado a um desvio padrão aceitável contratados. Quanto mais próximo de $R_{i}$ for o valor de $N_{i}$, maior será a satisfação proporcionada ao usuário $i$. Esta é uma métrica suficiente para avaliar o desempenho de um escalonador no cumprimento dos níveis de $Q_{o S}$ por ele oferecidos.

$$
S_{i}=\frac{N_{i}}{R_{i}}
$$

O mecanismo de controle de admissão pode influenciar na satisfação de um dado usuário. Se alguma requisição é descartada pelo algoritmo do controle de admissão é criada uma penalização. A cada requisição descartada é decrementado o número de vezes em que a média do tempo de reposta do sistema dessas requisições ficou abaixo do limiar contratado $\left(N_{i}\right)$.

Adotou-se uma faixa de tolerância de $3 \%$ em relação aos parâmetros contratuais assumidos. Por meio destes conceitos e métricas bem definidos pode-se estruturar melhor a política de escalonamento proposta, além de possibilitar ao algoritmo algumas ferramentas de controle para monitorar e tomar decisões sobre a qualidade de serviço oferecida. A formalização apresentada nesta seção auxiliará ainda em uma melhor análise dos resultados, permitindo validar os dados coletados pela simulação do modelo implementado.

\subsection{Arquitetura Ortogonal}

No modelo de estudo, a fila de requisições é composta por jobs que contêm um par de atributos $\left(D_{i}, C_{i}\right)$, representando o deadline e o fator de carga ${ }^{2}$ do job, respectivamente.

\footnotetext{
${ }^{2}$ É uma propriedade inerente ao job associado ao seu custo computacional relativo. O custo (tempo de processamento) do job no processador $p$ é então dado por uma função $T_{p}\left(F_{i}\right)$.
} 
A abordagem proposta consiste em combinar ao escalonador de jobs um segundo escalonador, de recursos. As duas políticas de escalonamento, assim, atuam ortogonalmente (Figura 4.1), a primeira ordenando a fila de jobs e a segunda, atribuindo o job ao recurso para atendimento.

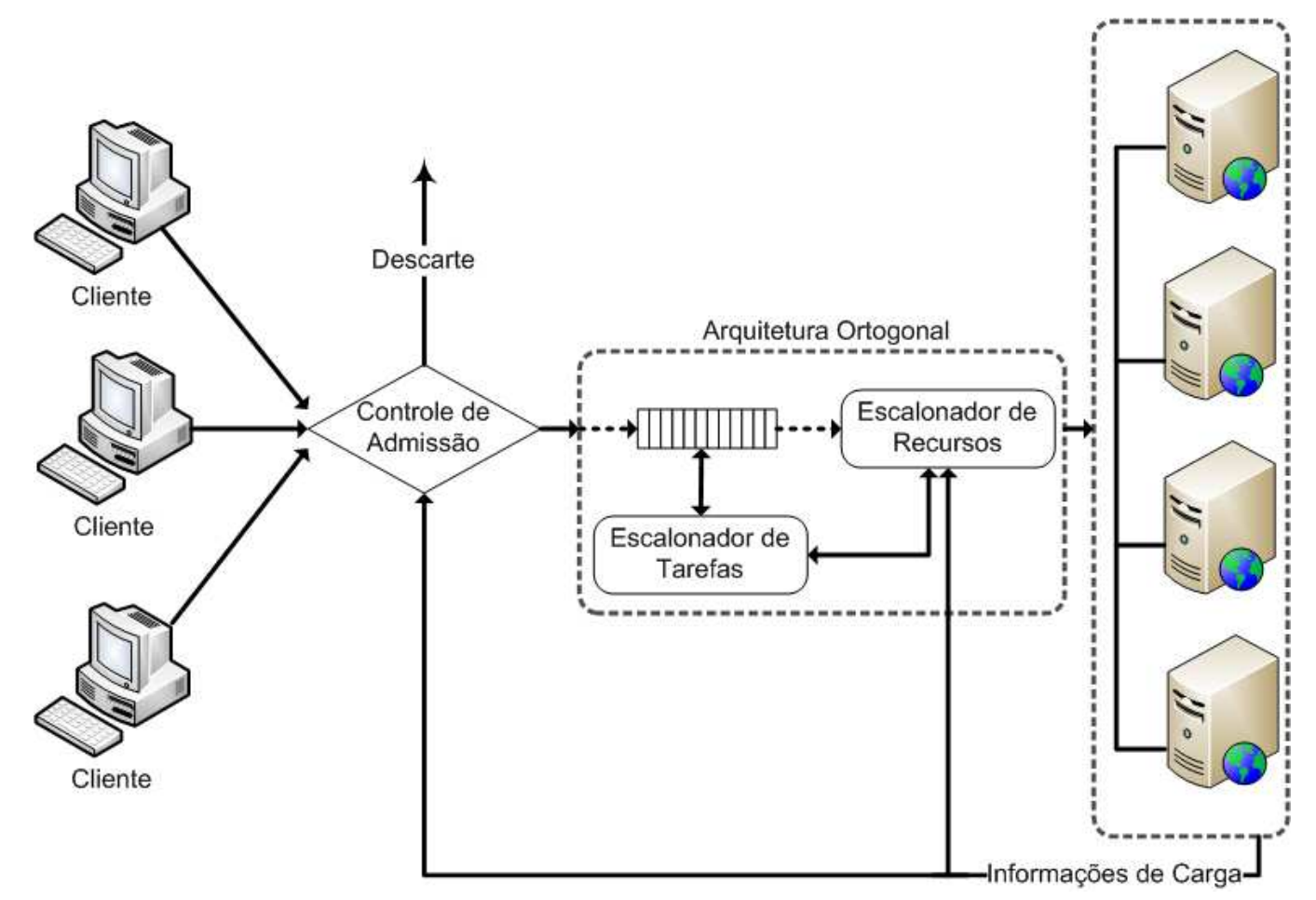

Figura 4.1: Modelo Ortogonal

A arquitetura de escalonamento ortogonal é descrita por meio de um escalonador que seleciona a ordem de execução de um job e um recurso, ou seja, para qual processador será enviado para ser executado. Esse projeto compara um conjunto de combinações de políticas de fila (EDF e EBS) e políticas de recursos (MQ, SQ e DSQ). É possível assim, traçar algumas conclusões das vantagens e limitações de cada abordagem.

\subsubsection{Política de Fila}

O escalonador de requisições possui a estratégia inicial de manipular os tempos de fila das requisições de acordo com o parâmetro contratual de cada classe. As requisições que estão mais próximas ou foram descumpridas receberão maior prioridade do escalonador, ao contrário daquelas que toleram maiores tempos de fila.

Dentre os vários algoritmos clássicos, utilizou-se o FIFO que é um algoritmo que possui larga utilização e overhead de escalonamento nulo, porém possuindo nesse ambiente pobres resultados como já vistos na Seção 2.4.1. Também foi utilizado o SJF o qual realiza a 
priorização dos jobs mais curtos. Utilizou-se também o EDF, o qual simplesmente lida primeiro com as requisições que estão mais próximas de perder seus deadlines (Liu \& Layland, 1973). Apesar de possuir os melhores resultados dos algoritmos clássicos, o algoritmo EDF, caso seja aplicado de forma isolada, irá exibir ainda um resultado pobre, apresentado na Seção 2.4.1.

\section{EBS - Exigency-Based Scheduling}

Em um trabalho recente, (Casagrande et al., 2007), foi demonstrado que a política EBS Exigency-Based Scheduling, tem capacidade superior às outras heurísticas convencionais baseadas exclusivamente na priorização dos jobs mais curtos, ou na urgência do deadline. A EBS, baseada em uma estratégia híbrida que leva em conta o custo de execução de uma requisição e o tempo de espera em fila, distingue-se por buscar impor ao sistema a menor demanda de recursos possível, garantindo um compromisso entre desempenho e estabilidade no atendimento de contratos individuais. Em sistemas interativos online, como servidores Web, a EBS proporciona resultados superiores às políticas convencionais.

A política atua com base na teoria de feedback scheduling, construindo a atualização instantânea do deadline, ou seja, sempre que o servidor terminar de atender uma dada requisição $j$ do usuário $u$ o valor de $\Omega_{u}$ (Tempo Médio de Resposta) será recalculado. Como mostra a equação 4.3, este cálculo é a média entre o antigo tempo de resposta real de $u\left(\Omega_{u}^{\prime}\right)$ e o tempo de residência da requisição $j$ recém atendida. O valor de time() representa o tempo atual, timeStamp $p_{j}$ o tempo de chegada da requisição $j$ e $R_{u}$ o número de requisições anteriormente submetidas por $u$.

$$
\Omega_{u}=\frac{\left(\Omega_{u}^{\prime} \cdot R_{u}\right)+\left(\text { time }()-\text { timeStamp }_{j}\right)}{R_{u}+1}
$$

À medida que as requisições chegam ao sistema e não encontram servidor disponível são transferidas para uma fila única de espera. Ao término da execução de uma requisição, o escalonador recalcula o tempo médio de resposta real daquele usuário, e em seguida busca na fila a requisição mais urgente, ou seja, aquela que tolera o menor tempo de espera dentre todas as existentes no sistema. Essa terá acesso ao servidor, e o ciclo se repete.

O deadline representa o quanto uma requisição ainda pode esperar na fila antes de começar a descumprir seu contrato. Para obtê-lo, isola-se na inequação 4.4 a variável $D_{j}$, que representa o deadline da requisição $j$. Como o interesse é obter o máximo tempo de espera aceitável pelo usuário $u$ antes que o valor do seu tempo médio de resposta real $\left(\Omega_{u}\right)$ ultrapasse o seu tempo médio de resposta contratado, igualam-se os termos. Os valores 
$R_{u}$ e $T_{w_{j}}$ expressam respectivamente o número de requisições feitas pelo usuário $u$ e o tempo de espera em fila da requisição $j$, até o momento.

$$
\frac{\left(\Omega_{u} \cdot R_{u}\right)+T_{w_{j}}+D_{j}}{R_{u}+1} \leq \Omega_{c_{i}}
$$

O valor de $D_{j}$ representa maior prioridade à medida que seu valor diminui, pois tem maior urgência. Basicamente este é o mesmo princípio utilizado pela política de escalonamento $E D F$, porém tratada de forma mais flexível, pois visa manter valores médios de tempo de resposta de sistema, e não-preemptiva.

Em alguns casos podem existir algumas requisições urgentes com os mesmos valores de deadline. Apesar de apresentar a mesma urgência, as requisições desse conjunto podem impor pesos distintos ao sistema, uma vez que, além do parâmetro de serviço (requisição operacional), o custo de processamento é outro fator de impacto sobre a exigência imposta ao sistema. Minimizar esse impacto é importante, pois um sistema sob menor carga terá melhores condições para lidar com os requisitos de serviço de suas requisições.

Proporcionam-se tempos médios de espera menores do que aqueles obtidos com a FIFO através do uso da política de escalonamento SJF (Shortest Job First). Nela as requisições em espera por atendimento são organizadas em uma fila segundo o tempo de processamento $\left(T_{p}\right)$. Realocar as requisições mais curtas primeiras possibilita uma diminuição na média de tempo de resposta oferecida pelo sistema.

$\mathrm{Na}$ abordagem de escalonamento desenvolvida atribuem-se prioridades baseando-se no deadline e no valor esperado do tempo de processamento da requisição. Como ilustra a equação (4.5), a prioridade de uma dada requisição $j$ em fila, do usuário $u$, é dada por $P_{j}$. Quanto menor for o valor de $P_{j}$ maior será a prioridade de escalonamento da requisição $j$, conseqüentemente as requisições que apresentarem maior urgência (menores valores de $\left.D_{j}\right)$ e menor custo esperado de processamento $\left(T_{p_{j}}\right)$ serão classificadas como mais prioritárias.

$$
\begin{aligned}
P_{j} & =D_{j} \cdot T_{p_{j}} \\
P_{j} & =\left(\left(\Omega_{c_{u}} \cdot\left(R_{u}+1\right)\right)-\left(\Omega_{u} \cdot R_{u}\right)-T_{w_{j}}\right) \cdot T_{p_{j}}
\end{aligned}
$$

Não ocorre com a EBS o problema de starvation que é apresentado pela política SJF, pois utiliza o deadline como critério de priorização. Assim, mesmo requisições mais longas 
não serão indefinidamente preteridas com a chegada de outras mais curtas, pois quanto mais tempo elas ficarem no sistema, menor se tornarão seus deadlines, o que permite serem eventualmente atendidas. Existe uma contribuição para o aumento da priorização, que são o aumento do tempo em fila $\left(T_{w_{j}}\right)$ das requisições.

Em alguns casos podem existir valores negativos ${ }^{3}$ de deadline, como nos cenários onde o sistema está saturado por requisições mais exigentes, o resultado do escalonamento é completamente o oposto quando aplicado às requisições que estão em descumprimento de contrato. Nesses casos é realizada uma correção da abordagem para a disciplina para manter o objetivo proposto. A correção resulta na equação (4.6), para as requisições mais urgentes que ainda não tiveram seus deadlines descumpridos, a prioridade é diretamente proporcional ao seu deadline e ao custo esperado de processamento. Para aquelas com descumprimento de deadline a prioridade é inversamente proporcional a seu custo esperado de processamento, já que quanto menor for esse custo menor será o valor de $P_{j}$ resultante, e assim maior será sua prioridade de escalonamento.

$$
P_{j}=\left\{\begin{array}{cc}
D_{j} \cdot T_{p_{j}} & \text { se } D_{j} \geq 0 \\
D_{j} \cdot \frac{1}{T_{p_{j}}} & \text { se } D_{j}<0
\end{array}\right.
$$

Dessa forma garante-se que as requisições mais urgentes, independente de terem descumprido ou não seus deadlines, e com menores custos esperados de processamento sejam escalonadas primeiro.

\subsubsection{Política de Recurso}

A política EBS é capaz de atender a contratos de QoS absoluto baseado em limite superior para média de tempo de resposta, o que configura um caso de tempo-real estocástico. A partir dessa premissa foi investigado a aplicabilidade da EBS demonstrado por Casagrande et al. (2007) para o caso de um array de servidores. Foram aplicadas também as estratégias FIFO, SJF e EDF os quais não são garantidas adequadas para sistemas multiprocessados (Mok, 1983)(Stankovic et al., 1995).

O escalonador de recursos assume conceitos e métodos encontrados nessas políticas e verifica-se a possibilidade de aplicação ao caso de um array de servidores Web no modelo SQ (Single Queue) e ao modelo DSQ (Dynamic Single Queue). As políticas também foram aplicadas ao modelo comumente utilizado, o MQ (Multiple Queue) ou Web Switch.

\footnotetext{
${ }^{3}$ Um valor negativo de deadline significa que o contrato foi violado, i.e. o tempo que uma requisição pode aguardar na fila é menor que zero.
} 


\section{Modelo Multiple Queue}

O primeiro modelo construído, o modelo Multiple Queue ou Web Switch, (Figura 4.2), é formado por um componente central da arquitetura que atua como um despachante, mapeando o endereço virtual para um endereço de servidor real. As requisições são encaminhadas para o módulo switch que, por sua vez, os envia para um servidor qualquer do array, de acordo com algumas regras de escalonamento (por exemplo, políticas que levam em conta as características de carga do servidor).

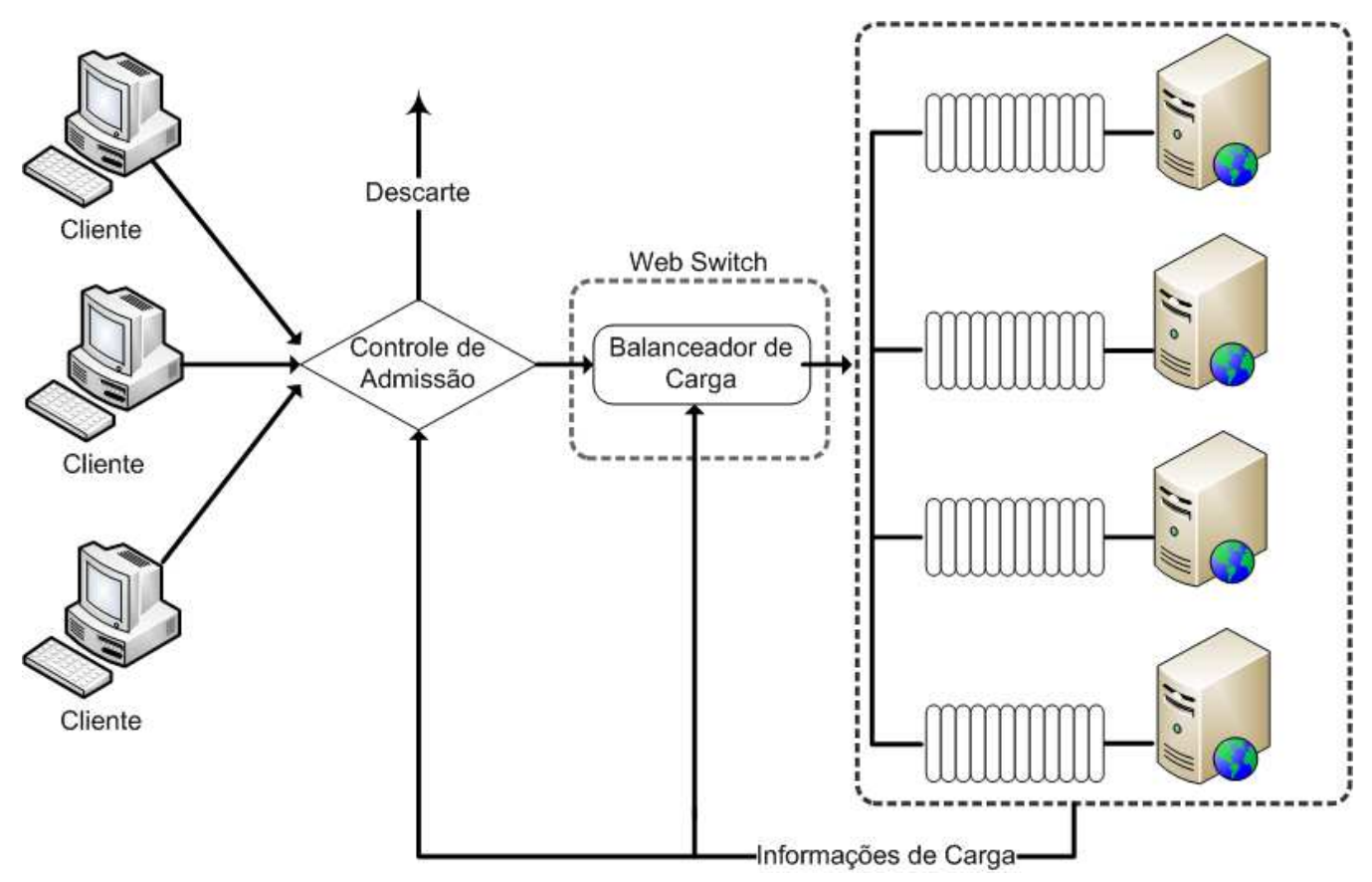

Figura 4.2: Exemplo do Modelo Multiple Queue.

\section{Modelo Single Queue}

Um modo trivial de transpor o referido método para o caso multiprocessado consiste em organizar a fila de requisições baseando-se nos resultados obtidos com sua heurística e enviar, então, o primeiro job da fila para ser executado no primeiro servidor livre do array (Figura 4.3).

Nota-se, contudo, que este simples critério de enviar o job para o primeiro servidor livre pode não ser a melhor solução, comparado ao caso em que aguardar por um processador mais eficaz resulte em ganho sob uma perspectiva do sistema como um todo. 

1. Aguarda-se até que um nó fique livre.
2. Organiza-se a fila segundo alguma política \{FIFO, SJF, EDF ou EBS .
3. Retira-se o primeiro job da fila e o envia para o primeiro nó livre do cluster.

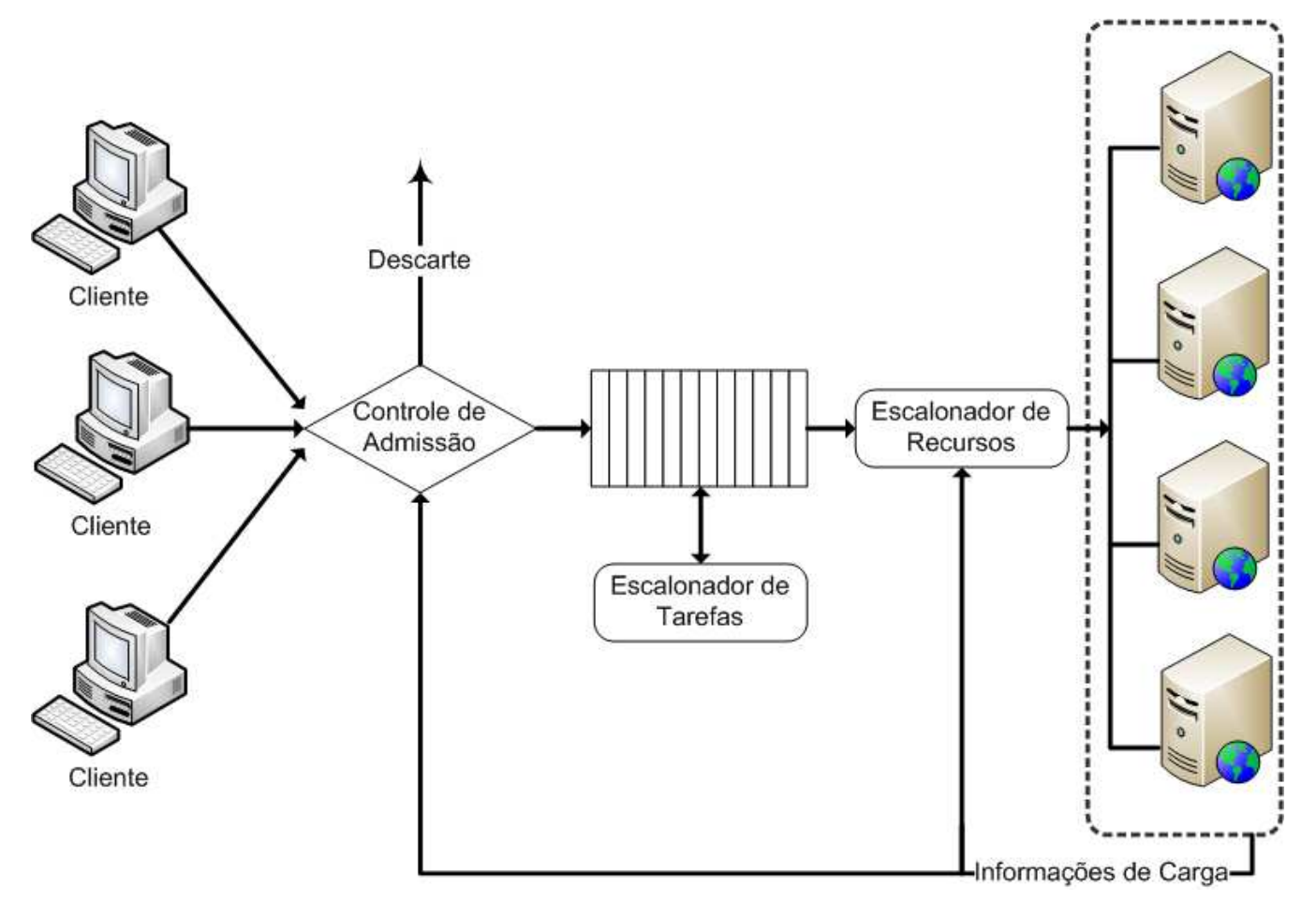

Figura 4.3: Modelo Single Queue.

\section{Modelo Dynamic Single Queue}

Uma primeira tentativa de melhorar esse esquema utiliza o critério tempo de término $(\tau)$ em cada nó do cluster e seleciona o processador que possibilita a conclusão do processamento do job primeiro (Figura 4.4). Outras políticas criteriosas podem ser utilizadas para gerenciamento da fila.

Determina-se o tempo de término do job $i$ no processador $p, \tau_{i}^{p}$, como a soma do tempo de processamento do job $i$ no processador $p, C_{i}^{p}$, adicionado ao tempo de espera pela liberação do processador $p, T_{r}^{p}$, mostrado a partir da equação 4.7:

$$
\begin{aligned}
\tau_{i}^{p} & =C_{i}^{p}+T_{r}^{p} \\
C_{i}^{p} & =T_{i}^{p}(f) \\
T_{r}^{p} & =\sum C_{n}^{p}+C_{j}^{p}(t)
\end{aligned}
$$




\footnotetext{
1. Aguarda-se até que um nó fique livre.

2. Organiza-se a fila segundo alguma política $\{F I F O, S J F, E D F$ ou $E B S\}$.

3. Determina-se o $\tau$ em cada nó para o primeiro job da fila.

4. Retira-se o job para ser executado no nó do cluster onde $\tau$ seja o menor.

5. Se o estado do nó for ocupado: insere-se o job em uma lista virtual associada ao nó e retorna-se ao passo 3. Se ele esta livre o job é executado, as filas esvaziadas e retorna-se ao passo 1.
}

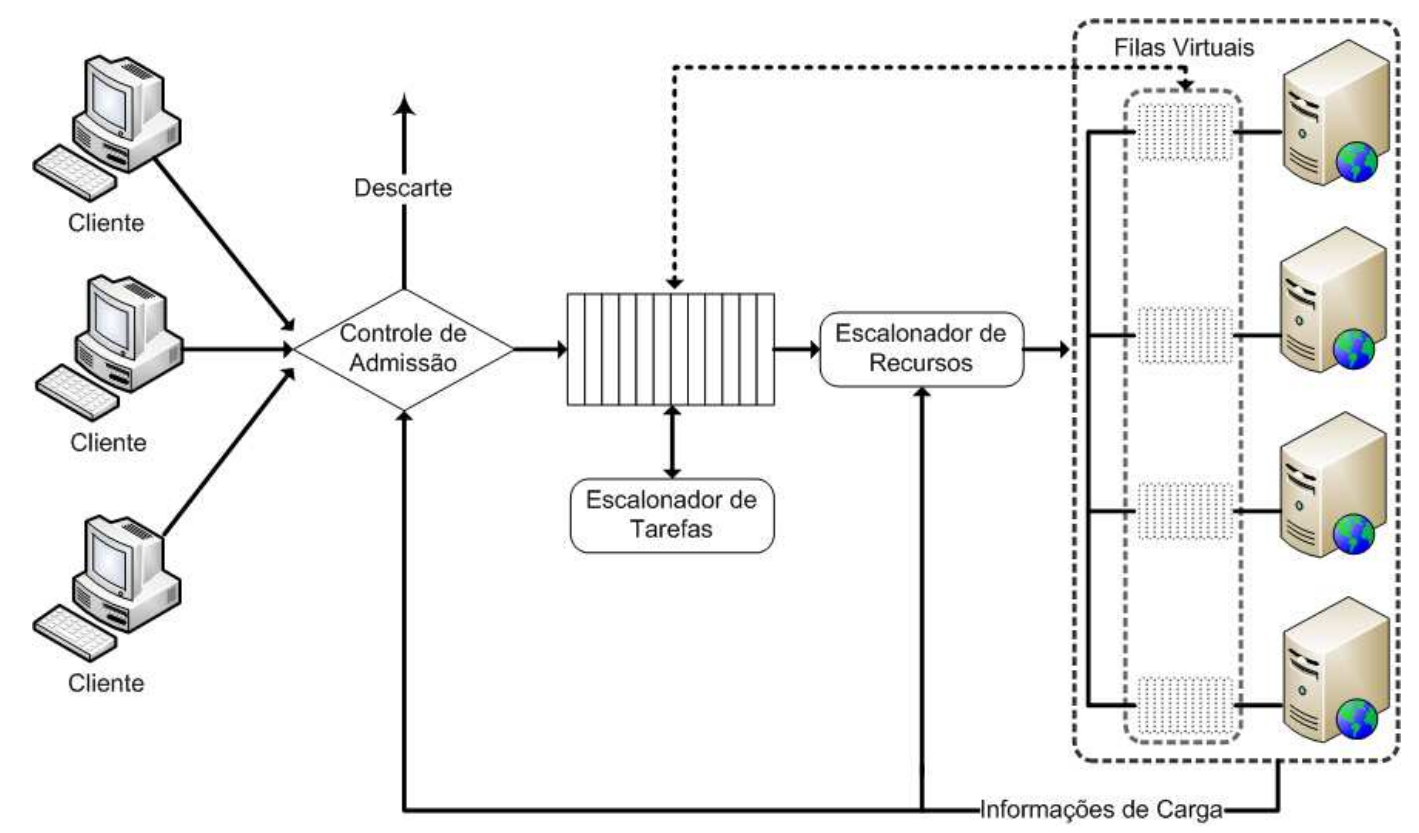

Figura 4.4: Modelo Dynamic Single Queue.

A fila virtual é apenas uma representação abstrata que serve para prover controle de gerenciamento da ordem dos jobs que já foram selecionados para execução, porém aguardam a vez de processamento. Não existe na realidade transposição dos elementos entre a fila principal e as fila virtuais. Acontece um gerenciamento implícito, que é a atribuição de um contador para cada servidor $\left(\sum C_{i}^{p}\right)$. Esse contador armazena a carga imposta aquele servidor e a estrutura principal da fila armazena todos os índices envolvidos.

Um exemplo que constitui um caso prático desse modelo de estudo é representado na Figura 4.5. Na fila de requisições organizada segundo uma $E B S$, é mostrado o fator de carga do job $i,\left(F_{i}\right)$. O escalonador realiza a função de destinar um job a um recurso. Para isso é calculado o $\tau_{i}^{p}$. O tempo de espera por aquele recurso é representado por $T_{r}^{p}$.

Os três primeiros jobs da fila possuem, respectivamente fator de carga $F$ igual a $\{2$, $4,3\}$. Pela política, $J_{1}$ será enviado para a fila virtual do processador $P 2, J_{2}$ também será enviado para a fila virtual do processador $P 2$. $J_{3}$ será enviado para execução no processador $P 1$. Isso acontece devido ao cálculo do $\tau_{i}^{p}$. 


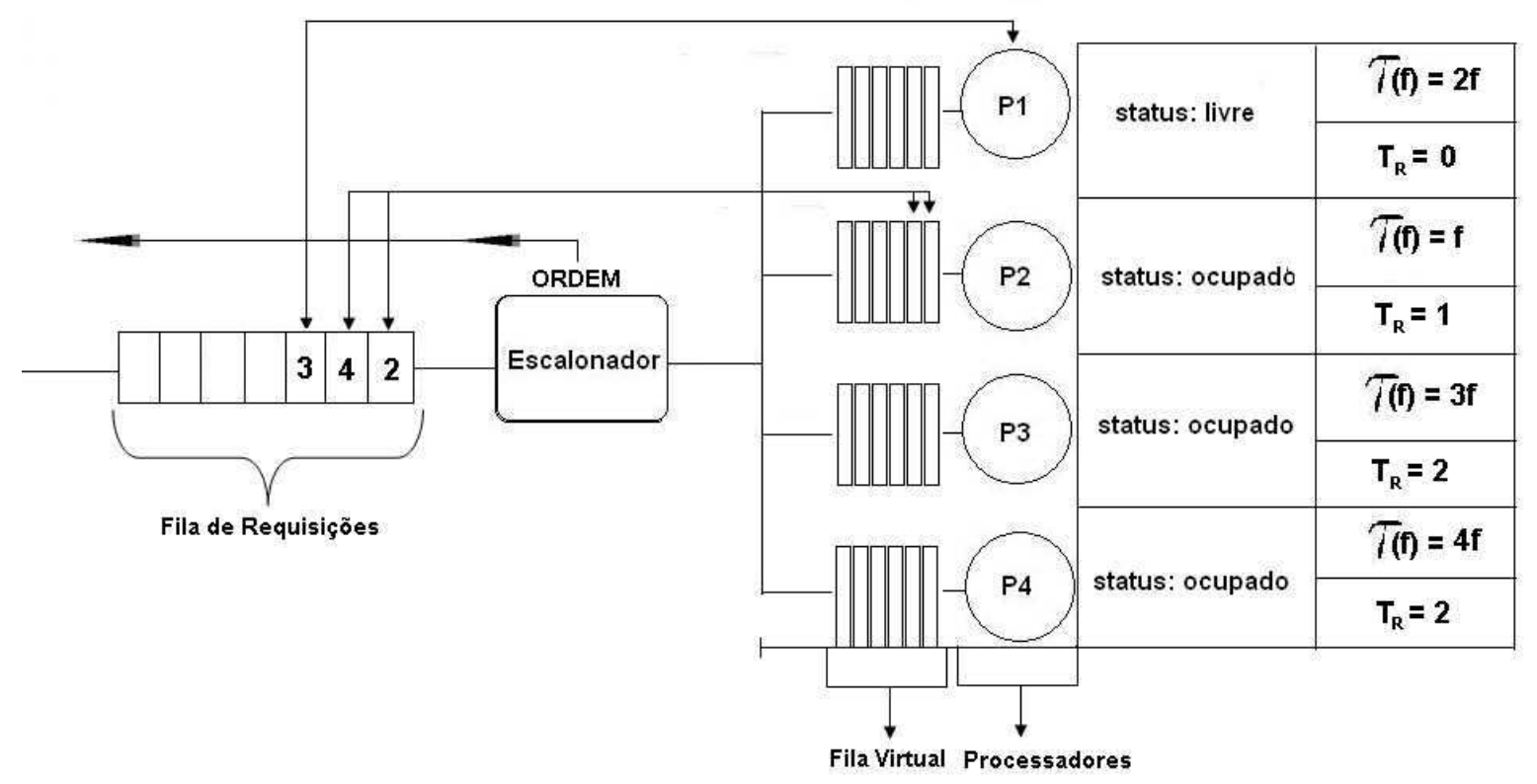

Figura 4.5: Exemplo do Modelo Dynamic Single Queue.

O job $J_{1}$ foi enviado para a fila virtual do processador $P 2$ porque no instante dado, o $\tau_{i}^{p}$ foi de: $\{4,3,6,8\}$ nos nós $P 1, P 2, P 3, P 4$, respectivamente. Em seguida, o job $J_{2}$ foi enviado para a fila virtual do processador $P 2$ porque no instante dado, o $\tau_{i}^{p}$ foi de: $\{8$, $7,12,16\}$. E por fim o job $J_{3}$ foi enviado para a execução no processador $P 1$ porque no instante dado, o $\tau_{i}^{p}$ foi de: $\{6,10,9,12\}$.

A garantia de QoS proporcionada por essa política em relação à da alocação trivial do primeiro processador livre (SQ), foram analisadas segundo os mesmos critérios utilizados em Casagrande et al. (2007).

\subsection{Considerações Finais}

Neste capítulo foi discutida a metodologia empregada para o desenvolvimento do projeto, caracterizando assim os modelos de tarefa e recursos adotados.

Descreveu-se na Seção 4.3 a especificação e implementação do módulo de Controle de Admissão nas diversas abordagens que fazem parte das combinações da arquitetura ortogonal. Foram discutidos sua arquitetura, componentes e métricas utilizadas, bem como os mecanismos de controle implementados.

Abordou-se também na Seção 4.4 a caracterização de uma nova métrica que está ligada a satisfação individual de cada cliente no sistema $W e b$.

Foi mostrado a composição geral das abordagens desenvolvidas, arquitetura ortogonal, como os principais eventos e políticas implementadas; discutindo o motivo de sua escolha e 
as adequações necessárias que foram realizadas; e por fim o parâmetro de serviço utilizado para controle da qualidade de serviço, bem como a métrica de avaliação proposta para estudar a eficácia da disciplina desenvolvida.

O capítulo a seguir trata de apresentar os resultados dos experimentos, bem como a análise dos dados encontrados. 


\section{Capítulo \\ 5 \\ Experimentos, Resultados e Análise}

\subsection{Considerações Iniciais}

Neste capítulo são apresentados e discutidos os resultados obtidos pela simulação dos modelos especificados no Capítulo 4. Para um melhor direcionamento deste estudo, além da escolha de métricas e técnicas de análise é importante salientar a relevância do planejamento de experimento realizado, constituindo da:

- verificação de quais fatores do sistema influenciam diretamente no comportamento do escalonador, e de que forma;

- análise das situações em que se conseguem ganhos consideráveis de desempenho com o emprego da política proposta;

- determinação do emprego de uma arquitetura ortogonal com suporte a QoS, verificando se oferece alguma vantagem sobre a utilização de uma política clássica de escalonamento, possivelmente ótima em outros cenários (como SJF e EDF);

- inferência das taxas de satisfação dos usuários das diversas classes perante o uso dessa e outras abordagens de escalonamento.

Para abranger todas essas questões, os dados coletados foram organizados em três tipos de gráficos. O primeiro tem por objetivo ilustrar o comportamento das políticas testadas, mostrando para cada cenário qual a média real do tempo de resposta de sistema oferecida para um dado usuário ao longo do tempo. Além de possibilitar a análise da eficácia de 
cada política em cumprir os contratos estabelecidos, este tipo de gráfico apresenta também um comparativo do desempenho entre elas, pois valores de tempos médios de resposta oferecidos para um mesmo usuário, sob as mesmas condições do ambiente, são plotados para os diferentes escalonadores empregados. O segundo tipo de gráfico representa uma validação estatística. É traçado o intervalo de confiança para os mesmos resultados obtidos no tipo de gráfico um, segundo a técnica de distribuição T-Student para confirmação dos resultados obtidos. Por fim, seguindo o mesmo tipo de validação estatística do gráfico dois, o terceiro tipo de gráfico tem por objetivo mostrar a variação da satisfação média dos usuários do sistema perante a aplicação das diferentes disciplinas de escalonamento, sob a variação de diversos fatores do ambiente, como proporção de requisições entre as classes e valores de exigência contratual.

Neste capítulo são apresentados os cenários simulados onde os limiares para atendimento dos servidores Web foram alterados. Os resultados obtidos com essas simulações foram aplicados as diversas métricas utilizadas e analisados.

Os resultados desse capítulo mostram que a utilização de um controle de admissão fazse necessário quando se deseja modelar e implementar servidores Web com QoS absoluta, sendo portanto, mais uma técnica que contribui para a melhoria do atendimento das requisições em servidores Web. A composição da métrica de Satisfação do Cliente e os resultados obtidos diante de sua utilização sinalizam que a diferença dos limiares para as classes de serviços são um outro modo de delimitar QoS em servidores Web.

\subsection{Planejamento de Experimentos}

Foram utilizadas cargas de trabalho sintéticas com a distribuição exponencial para descrever tanto os intervalos de chegada quanto o tempo de serviço das requisições. Essa é uma distribuição amplamente utilizada para analisar sistemas de filas (MacDougall, 1989). Os comportamentos ilustrados na Seção 2.5 podem ser também examinados mediante as estatísticas de utilização do sistema, e de satisfação dos requisitos. Considerando que o ambiente de simulação foi configurado da seguinte maneira:

- média de taxa de chegada $\lambda=2,35$.

- média de taxa de serviço $\mu=4,0$.

- cluster 4 servidores heterogêneos com potências relativas $P_{1}=1,00, P_{2}=0,50$, $P_{3}=0,33$ e $P_{4}=0,25$. 
Obtem-se uma potência resultante do cluster de $P_{R}=2,08$ e uma utilização efetiva média, segundo a equação 5.1, em torno de $82 \%$.

$$
\rho=\frac{\mu}{\lambda} \cdot \frac{100}{P_{R}}
$$

\subsubsection{Caracterização do Ambiente}

O ambiente de simulação foi configurado com três classes de usuários $\{\mathrm{A}, \mathrm{B}$ e $\mathrm{C}\}$ com diferentes variações contratuais. Os cenários utilizados neste projeto são os seguintes:

- Cenário 1: Proporção de requisição de 20\%, 35\% e $45 \%$ para as classes A, B e C, nessa ordem.

- Cenário 2: Proporção de requisição são iguais para todas as classes.

- Cenário 3: Proporção de requisição de 10\%, 80\% e 10\% para as classes A, B e C, nessa ordem.

- Cenário 4: Proporção de requisição de 45\%, 35\% e 20\% para as classes A, B e C, nessa ordem.

- Cenário 5: Proporção de requisição de 45\%, 10\% e 45\% para as classes A, B e C, nessa ordem.

Os cenários foram assim construídos de forma a abranger a maior parte das possíveis configurações de utilizações dos usuários naquele ambiente. Uma vez definida as proporções de requisições, o valor do contrato da classe A (CtA) e da classe C (CtC) são fornecidos a partir do contrato da classe B ( $\mathrm{CtB})$, empiricamente medido com valor de referência de 15 u.t. ${ }^{1}$. Durante as simulações, atribuiu-se à $P$ os seguintes valores para as variações contratuais: 10\%, 20\%, 30\%, 40\% e 50\%. Assim, segundo as equações 5.2 são definidos os contratos das classe $\mathrm{A}$ e $\mathrm{C}$ a serem cumpridos previamente.

$$
\begin{aligned}
& C t A=C t B-(C t B \cdot P) \\
& C t C=C t B+(C t B \cdot P)
\end{aligned}
$$

A classe a qual o usuário pertence é definida através do parâmetro de tempo médio de resposta de sistema a ser garantido às requisições de um dado usuário, pois nele está

\footnotetext{
${ }^{1}$ Unidade de Tempo.
} 
incluso o tempo de fila gerenciado pelo escalonador, o que permite controlar a qualidade do atendimento. Este parâmetro, neste texto denominado tempo médio de resposta contratada pela $i$-ésima classe $\left(\Omega_{c_{i}}\right)$, é especificado previamente por um acordo entre o provedor de serviços e o cliente, e é utilizado pelo escalonador como base para atribuição de prioridades. O valor que será comparado com $\Omega_{c_{i}}$ é o do tempo médio de resposta real $\left(\Omega_{u}\right)$, que é o tempo de resposta médio de sistema atualmente oferecido para o usuário $u$.

\subsubsection{Taxa de Utilização do Sistema}

A Tabela 5.2.2 relaciona a utilização individual de cada servidor. Os valores são representativos de um único cenário, porém não se alteram apreciavelmente para outros cenários de carga, resultando que podem ser considerados típicos para efeito de comparação.

Tabela 5.1: Taxa de Utilização dos Servidos do Sistema (\%)

\begin{tabular}{|r|r|r|r|}
\hline & $\mathrm{MQ}$ & $\mathrm{SQ}$ & $\mathrm{DSQ}$ \\
\hline Servidor & utilização & utilização & utilização \\
\hline 0 & 93,52 & 77,50 & 96,51 \\
\hline 1 & 77,35 & 78,24 & 82,16 \\
\hline 2 & 56,72 & 76,38 & 51,67 \\
\hline 3 & 38,57 & 74,64 & 23,67 \\
\hline
\end{tabular}

Esses valores mostram que a política $D S Q$ (em combinação com a disciplina de fila $E B S$ ) tende a maior utilização do servidor mais rápido, atribuindo-lhe, as requisições mais impactantes (conforme o conceito de exigência anteriormente definido) no sistema. Não obstante exibindo a mesma característica, entretanto, o $M Q$ perde por ter visões parciais de trechos das filas de requisições pendentes, ao passo que a $D S Q$ tem condições de executar a tomada de decisão de escalonamento mediante uma visão global de todos os jobs. O $S Q$, por outro lado, utiliza os servidores de forma igual, favorecendo o sistema como um todo em questões de desempenho, porém não é orientada para o cumprimento das garantias contratuais.

\subsection{Comportamento do Escalonador}

Para se ter uma ampla amostragem dos dados fixou-se como 100.000 o número de requisições submetidas em cada cenário a ser simulado, e com o intuito de alcançar confi- 
abilidade estatística realizou-se os experimentos 15 vezes, simulando todos os cenários em cada uma das vezes. Cada simulação utilizou-se de uma semente diferente já fornecida pelo simulador SMPL, amplamente testado e validado.

Com referência a um valor médio de atendimento $P$ de 15 unidades de tempo, empiricamente medido para um sistema sem diferenciação de serviço, o contrato da classe $A$ é tal que as requisições a ela pertencentes devem ser atendidas em um tempo médio de resposta que deve ser inferior em $P \%$ do valor de referência; ao passo que o limite de tempo médio de resposta da classe $C$ é $P \%$ superior ao valor de referência.

Nota-se, portanto, que este é um cenário de baixa exigência, em que a variação contratual entre as classes é baixa e a classe mais exigente $(A)$ tem poucos usuários. Com tal carga leve, frente à potência computacional do conjunto de 4 servidores, excluindo-se a abordagem MQ-FIFO, todas as políticas de escalonamento restantes os quais foram simuladas atenderam os contratos para todas as classes. O resultado interessante a destacar nesse gráfico é que, atendido o critério de confiabilidade (cumprimento do contrato de QoS).

Primeiramente, a abordagem DSQ foi comparada com as abordagens tradicionais, ou seja, as técnicas comumente chamadas de clássicas, que é a abordagem $M Q$ ou também conhecida como Switch Web com um balanceador de carga. A Política de recurso $M Q$ foi combinada às politicas de fila FIFO e SJF, enquanto a DSQ foi combinada a EDF e EBS.

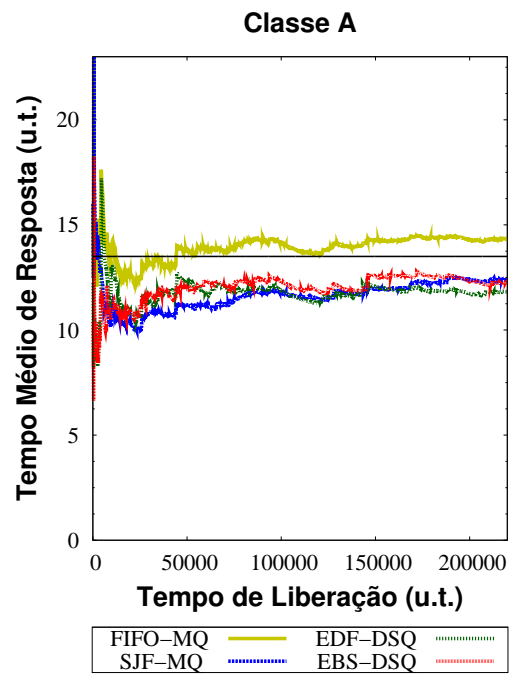

(a) CONTRATO A

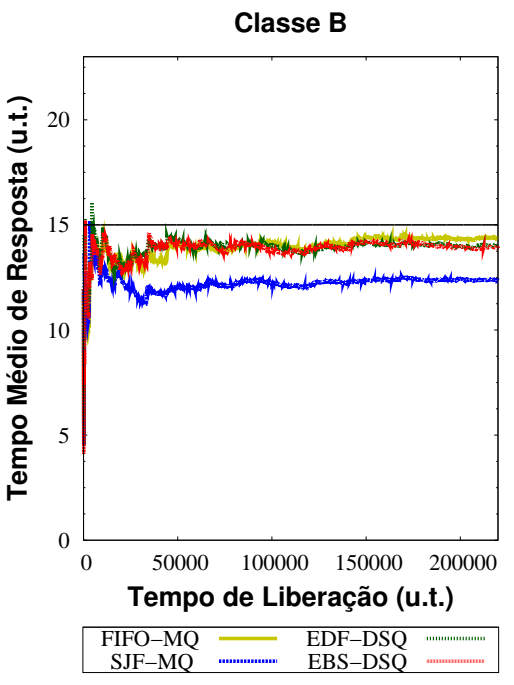

(b) CONTRATO B

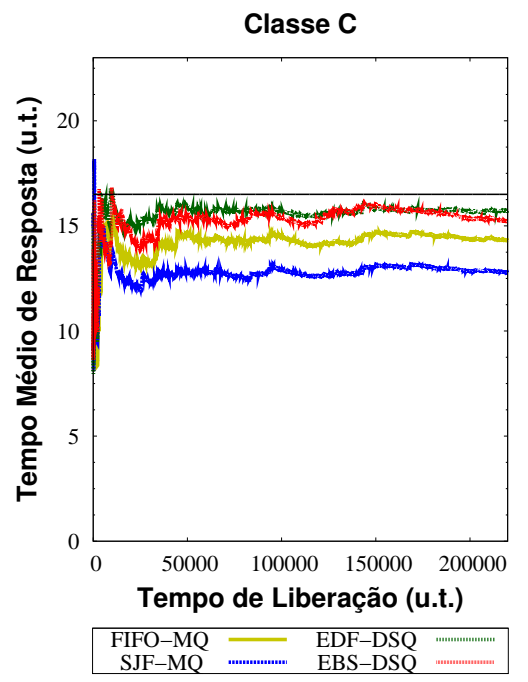

(c) CONTRATO C

Figura 5.1: Comparativo do Cenário 1 (MQ-(FIFO,SJF) X DSQ-(EDF,EBS)) com Variação Contratual de $10 \%$

Como visto na Figura 5.1, a abordagem DSQ-EDF e DSQ-EBS obtiveram menores tempos médios de respostas para a classe mais exigente, a classe A. Entretanto, foi a 
MQ-SJF que obteve os menores tempos médios para as classes B e C. Isso deve-se ao fato da pouca taxa de variação contratual, contribuindo assim para a política de fila SJF que preza pelo desempenho. Apesar da política SJF também não realizar a diferenciação de serviço, ainda assim foi possível cumprir todos os três contratos. A abordagem MQ-FIFO não foi capaz de atender o contrato da Classe A, porque a política FIFO não realiza a diferenciação de serviço e também não preza pelo desempenho.

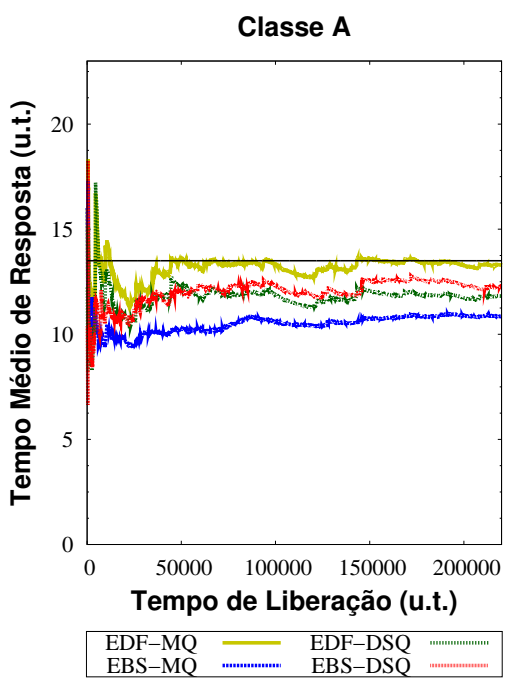

(a) CONTRATO A

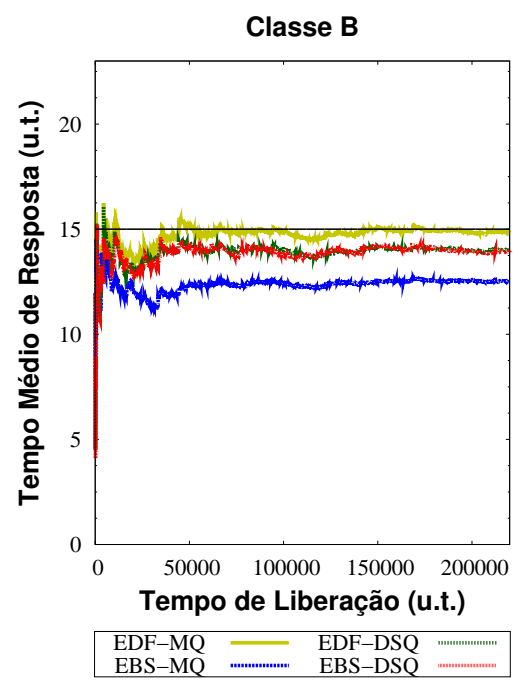

(b) CONTRATO B

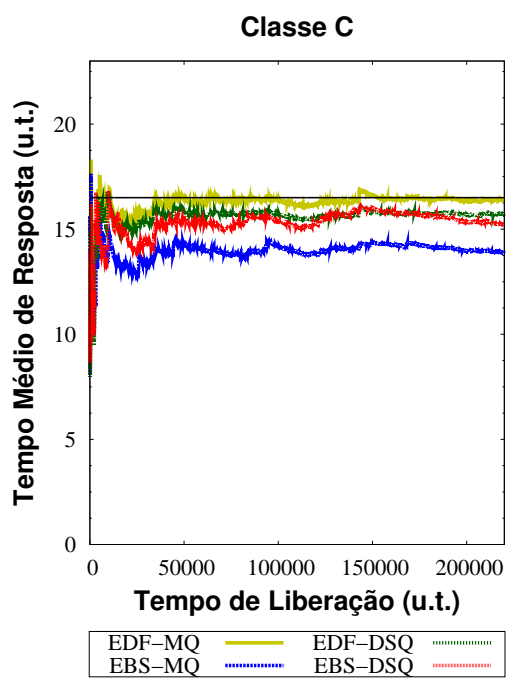

(c) CONTRATO C

Figura 5.2: Comparativo do Cenário 1 (MQ-(EDF,EBS) X DSQ-(EDF,EBS)) com Variação Contratual de $10 \%$

Analogamente, a política $M Q$ foi combinada as políticas de fila EDF e EBS e comparada com as abordagens EDF-DSQ e EBS-DSQ. Todas as abordagens cumpriram os três contratos. No entanto, segundo o gráfico da Figura 5.2 os menores tempos médios de resposta foram da abordagem EBS-MQ.

O Cenário 1 com a variação contratual de 10\% também foi comparado a abordagem $S Q$. Observa-se claramente na Figura 5.3, que a abordagem SQ-EBS foi capaz de atender os usuários com o menor tempo médio de resposta enquanto as abordagens EDF-DSQ e EBS-DSQ, embora cumprindo os contratos, obtiveram o menor desempenho, atendendo as requisições com o maior tempo médio de resposta. Esse resultado, evidentemente não aponta para a superioridade da $D S Q$ em termos de desempenho nesse tipo de cenário.

A validação estatística foi realizada para garantir a integridade dos dados do tempo médio de resposta para esse Cenário 1 com variação contratual de $10 \%$. O gráfico da Figura 5.4 mostra o intervalo de confiança dos dados da classe A que foram traçados para as principais abordagens desenvolvidas neste Cenário. 


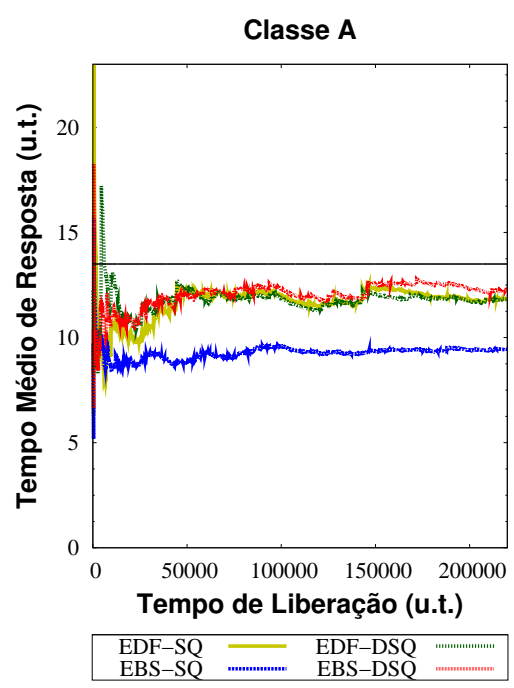

(a) CONTRATO A

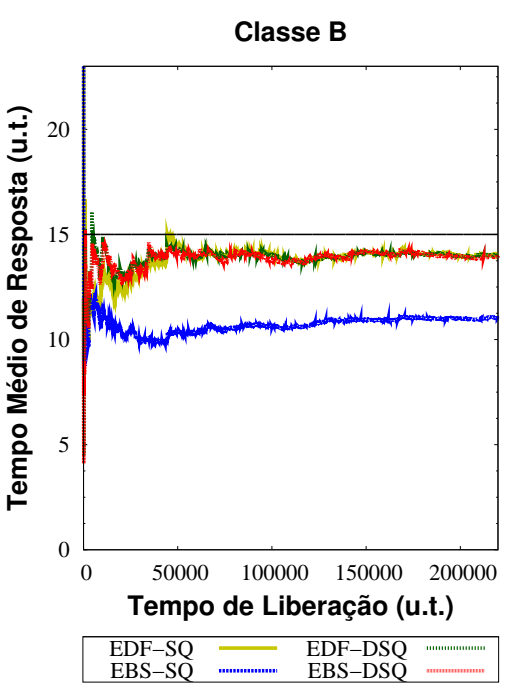

(b) CONTRATO B

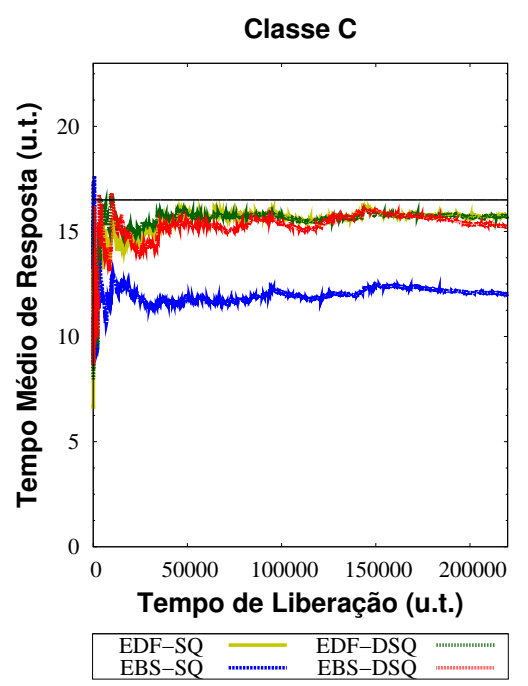

(c) CONTRATO C

Figura 5.3: Comparativo do Cenário 1 (SQ-(EDF,EBS) X DSQ-(EDF,EBS)) com Variação Contratual de $10 \%$

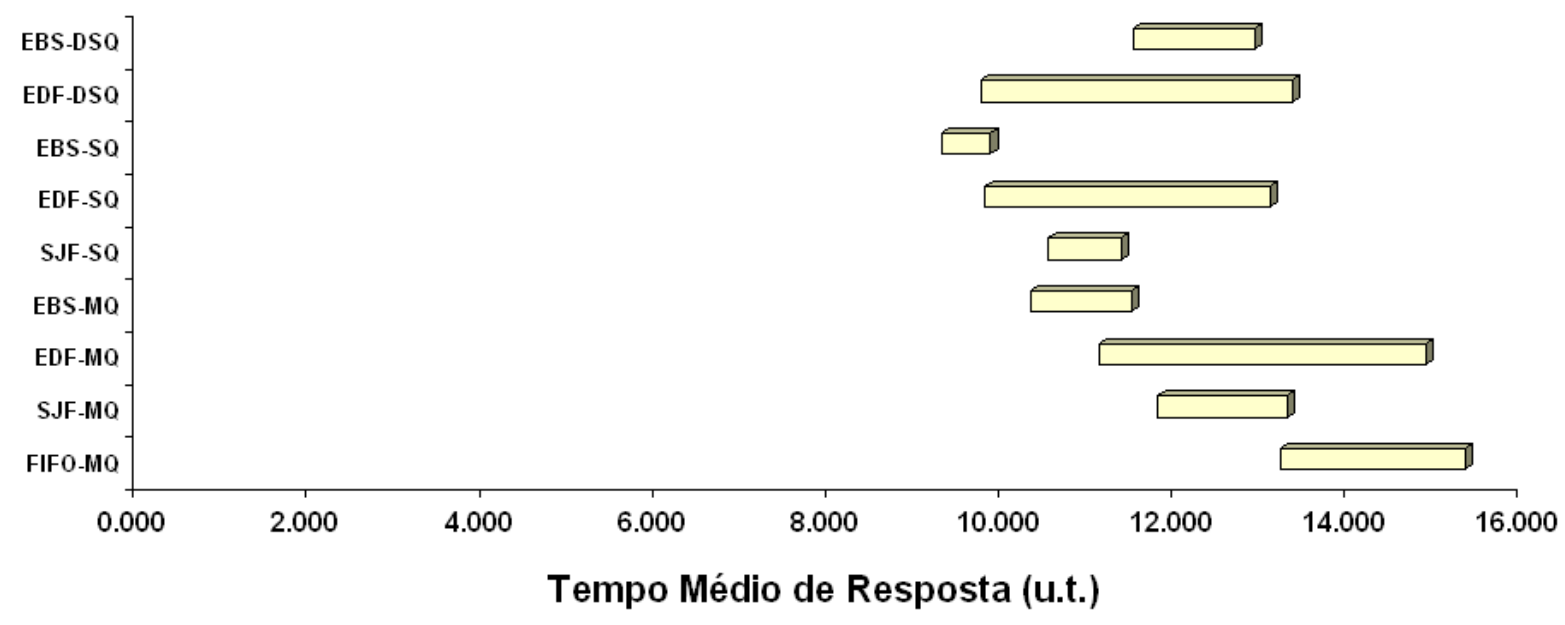

Figura 5.4: Intervalo de Confiança do Cenário 1 com Variação Contratual de 10\%

Alterando a variação contratual de $10 \%$ para 50\%, é configurado uma condição de exigência mais elevada para o Cenário 1. Em todos os gráficos da Figura 5.5, para as classes $A, B$ e $C$, nota-se que as combinações (FIFO e SJF) para a abordagem $M Q$ não foram capazes de cumprir os contratos da classe A. Entretanto, mantiveram as garantias nos cumprimentos dos contratos das classes $B$ e $C$.

Fato igual acontece com a abordagem EDF-MQ e EBS-MQ. Os gráficos da Figura 5.6 mostram que a abordagem $M Q$ é limitada quando a taxa de variação contratual torna-se alta, fazendo com que o cenário em questão apresente um carater de maior exigência para com as requisições da classe A. 


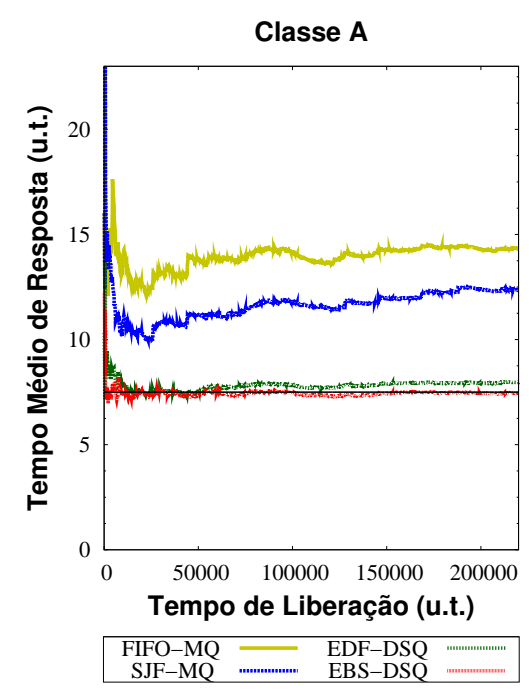

(a) CONTRATO A

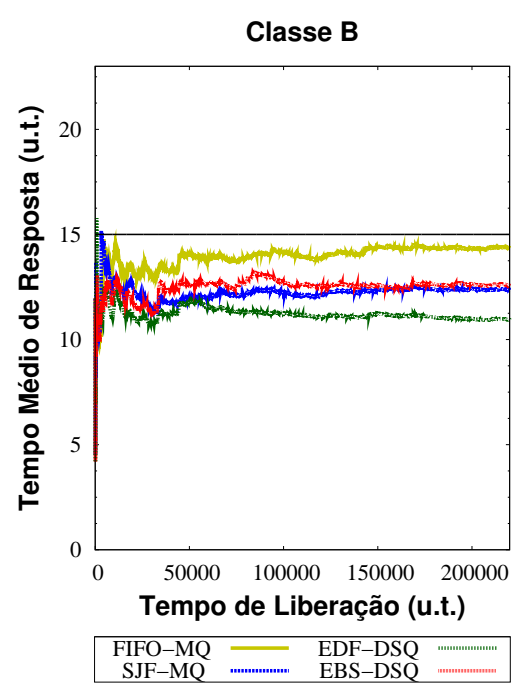

(b) CONTRATO B

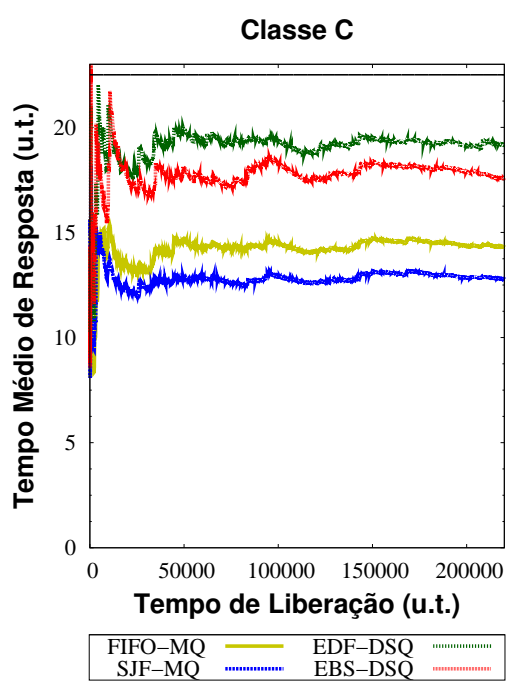

(c) CONTRATO C

Figura 5.5: Comparativo do Cenário 1 (MQ-(FIFO,SJF) X DSQ-(EDF,EBS)) com Variação Contratual de 50\%

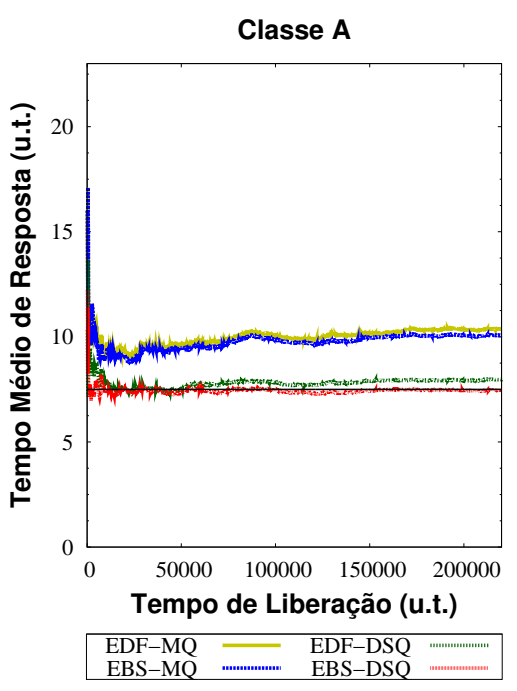

(a) CONTRATO A

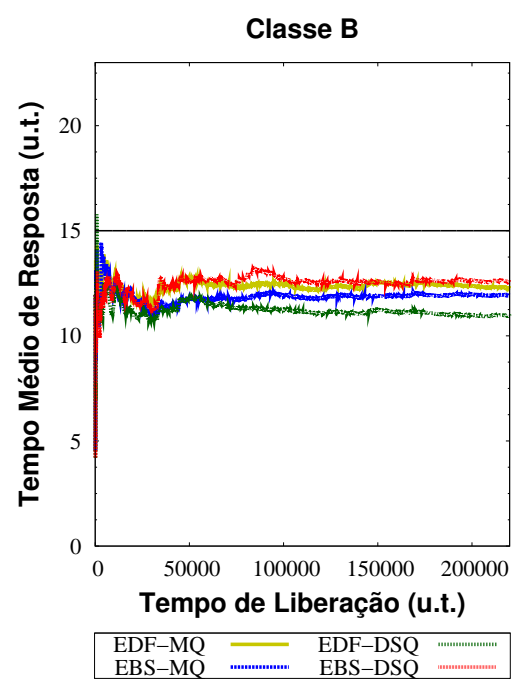

(b) CONTRATO B

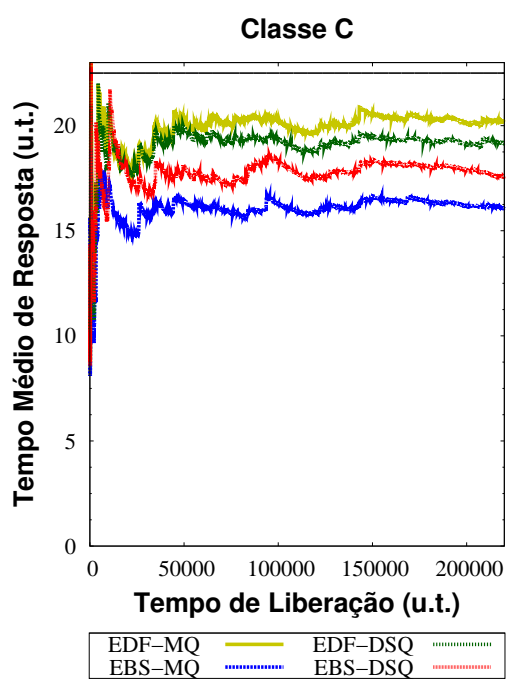

(c) CONTRATO C

Figura 5.6: Comparativo do Cenário 1 (MQ-(EDF,EBS) X DSQ-(EDF,EBS)) com Variação Contratual de $50 \%$

Apesar da abordagem $S Q$ possuir tempos médios de resposta menores, segundo os gráficos da Figura 5.7 não foi capaz de cumprir os contratos da classe A. Isso mostra que apesar do desempenho empregado por essa abordagem ser eficiente, isso não é suficiente para que todas as classes recebam um tratamento de forma diferenciada, criando assim a diferenciação de serviço.

Contudo, é a política $D S Q$, principalmente a combinação $E B S-D S Q$, que apresenta o fenômeno singular (entre os casos estudados, Figuras 5.5, 5.6 e 5.7) de inverter-se nessa relação de desempenho, passando a ser a que oferece menores tempos médios de resposta 


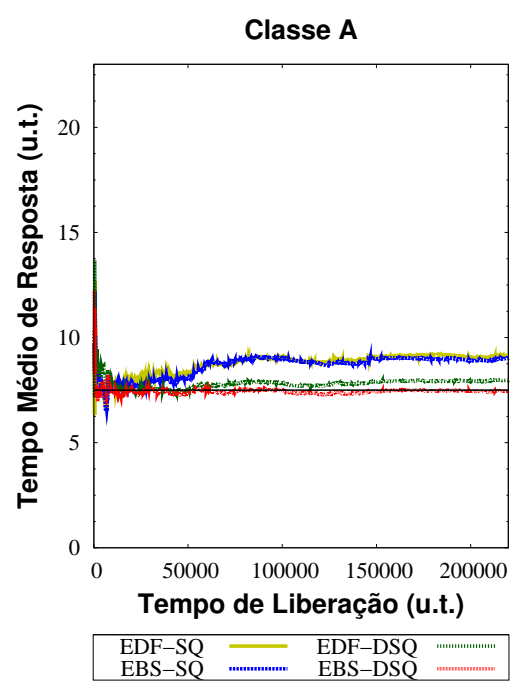

(a) CONTRATO A

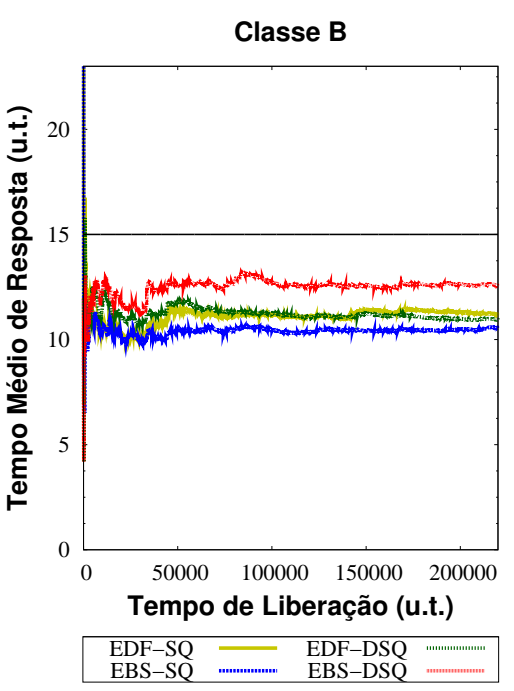

(b) CONTRATO B

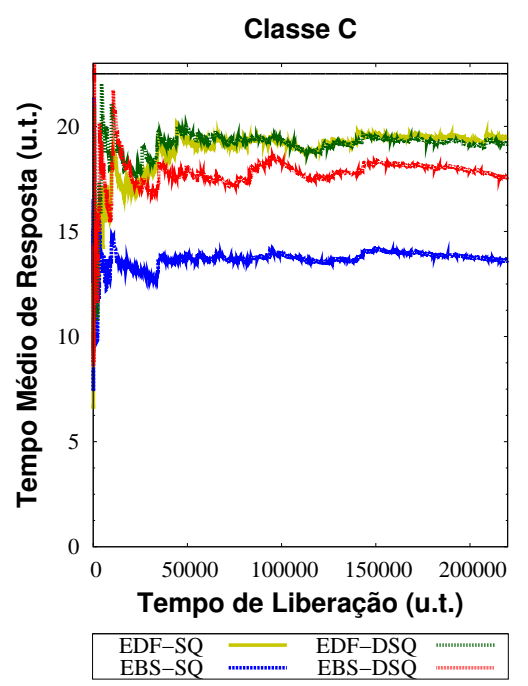

(c) CONTRATO C

Figura 5.7: Comparativo do Cenário 1 (SQ-(EDF,EBS) X DSQ-(EDF,EBS)) com Variação Contratual de $50 \%$

para a classe $A$ mais exigente, à custa de uma ligeira diminuição de desempenho para a classe $B$, embora ainda plenamente cumprindo o contrato daquela classe. Essa propriedade de buscar a garantia de contratos diferenciadamente, balanceando a exigência imposta ao escalonador no atendimento de cada classe, demonstra que a $D S Q$, dentre os três algoritmos ensaiados, é a que opera de modo mais coerente com as características da política $E B S$, sendo a única que realiza o cumprimento dos contratos da classe A.

A validação estatística confirma que os menores intervalos para o tempo médio de resposta do Cenário 1 é realmente da abordagem EBS-DSQ, segundo uma estipulação de variação contratual de 50\%. O gráfico da Figura 5.8 mostra o intervalo de confiança dos dados da classe A que foram traçados para as principais abordagens desenvolvidas.

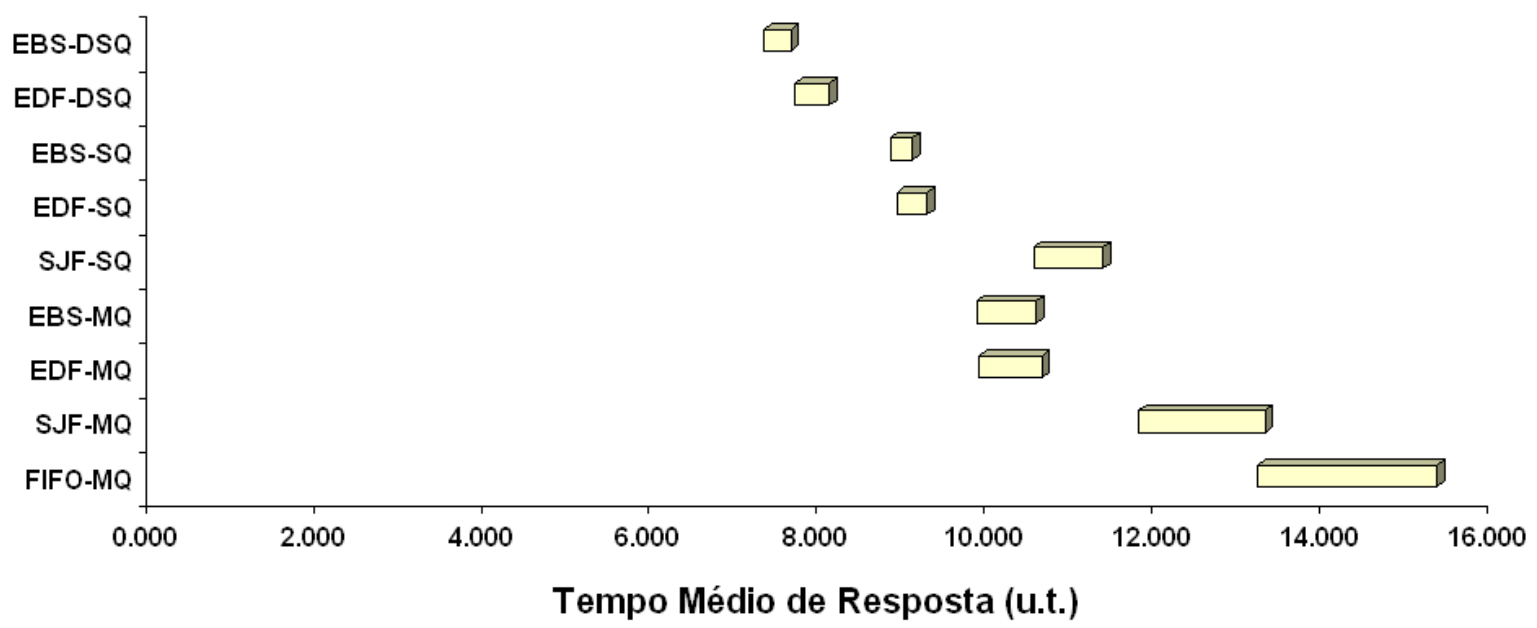

Figura 5.8: Intervalo de Confiança do Cenário 1 com Variação Contratual de 50\% 
O cenário 2 é caracterizado por um nível igual de proporção de requisição de todas as classes. Portanto, em relação ao cenário 1 a quantidade de requisição para a classe A é acrescida, tornando-a mais exigente ainda. Foi realizada a comparação com as diversas abordagens fixadas com uma variação contratual de $40 \%$.

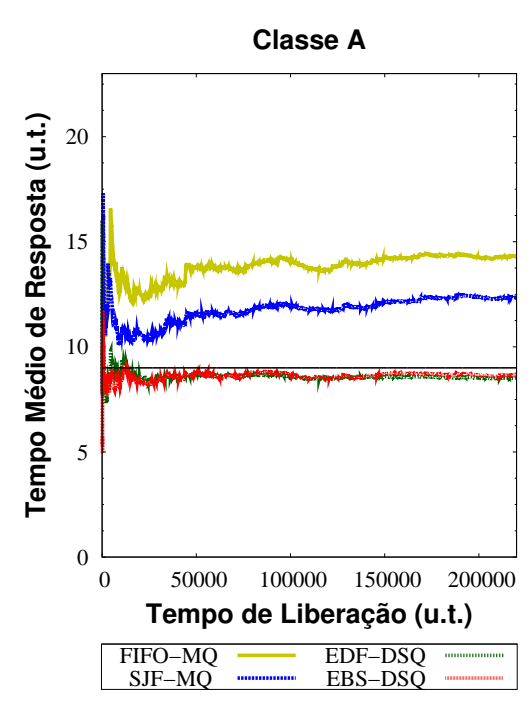

(a) CONTRATO A

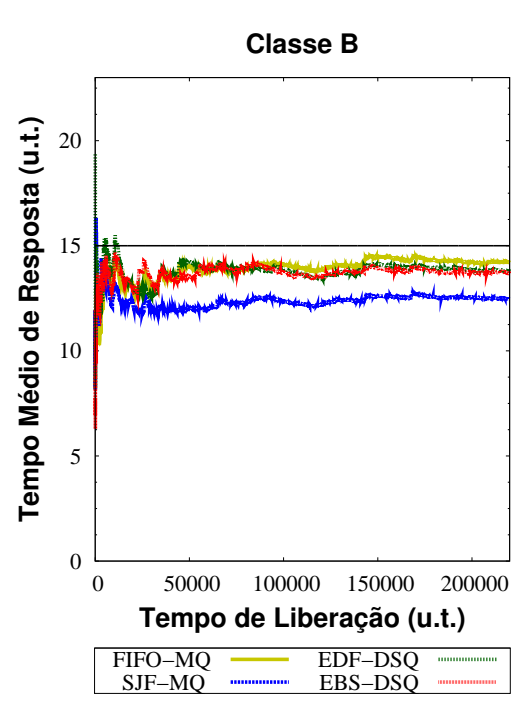

(b) CONTRATO B

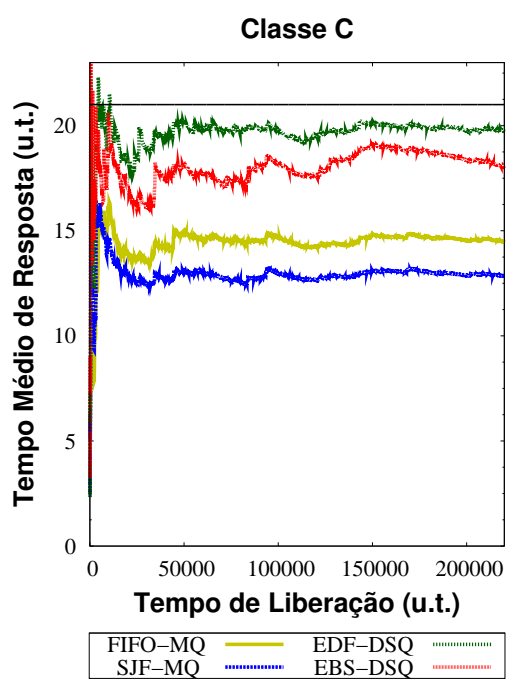

(c) CONTRATO C

Figura 5.9: Comparativo do Cenário 2 (MQ-(FIFO,SJF) X DSQ-(EDF,EBS)) com Variação Contratual de 40\%

Como se pode observar na ilustração dos gráficos da Figura 5.9, a qualidade das médias oferecidas a uma classe mais exigente pelas EBS-DSQ e EDF-DSQ são melhores se comparada com as oferecidas pelas outras duas disciplinas. Os ganhos de desempenho e a qualidade de serviço oferecida em relação ao FIFO-MQ são bem consideráveis. Comparadas com a $S J F-M Q$, a média oferecida a um usuário menos exigente (Classes B e C) foram registradas médias maiores pela EBS-DSQ e EDF-DSQ, enquanto que a oferecida a um usuário mais exigente teve uma considerável diminuição dos valores dos tempos de respostas de sistema.

Apesar da abordagem $M Q$ adotar políticas como EDF e EBS para realizar a priorização das requisições afim de cumprir os contratos, as médias dos tempos de resposta oferecidas para a Classe A foram superiores ao contrato estipulado, como mostrado nos gráficos da Figura 5.10.

A política $E B S-D S Q$, ao ponderar a urgência das requisições e o peso imposto ao sistema como um todo e a política $E D F-D S Q$ ponderando apenas a urgência das requisições foram capazes de lidar melhor com a situação de sobrecarga, oferecendo médias de tempo de resposta melhores para a Classe A e abaixo das especificadas para todas as classes. 


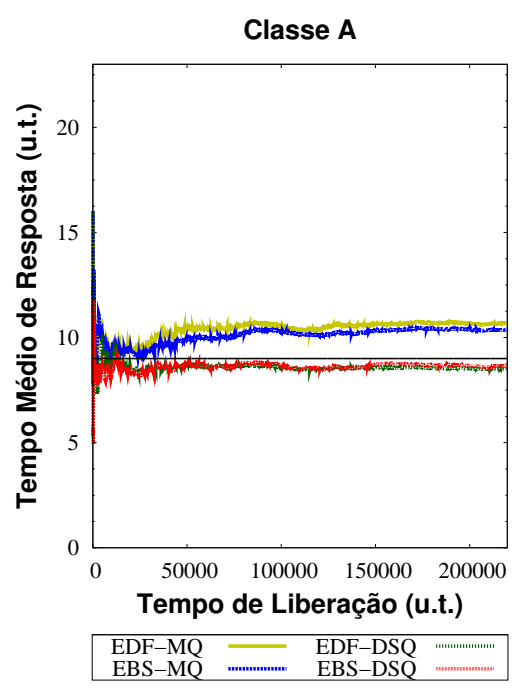

(a) CONTRATO A

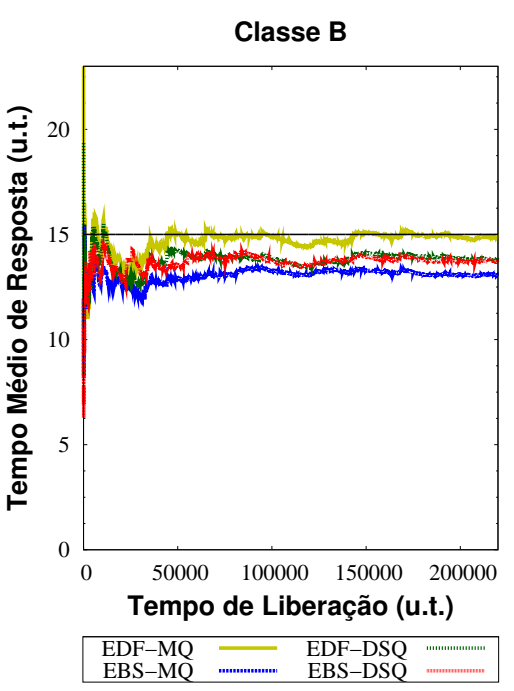

(b) CONTRATO B

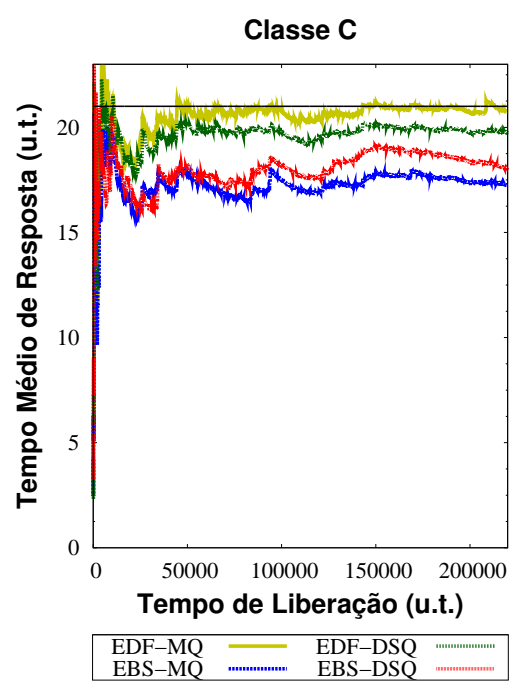

(c) CONTRATO C

Figura 5.10: Comparativo do Cenário 2 (MQ-(EDF,EBS) X DSQ-(EDF,EBS)) com Variação Contratual de $40 \%$

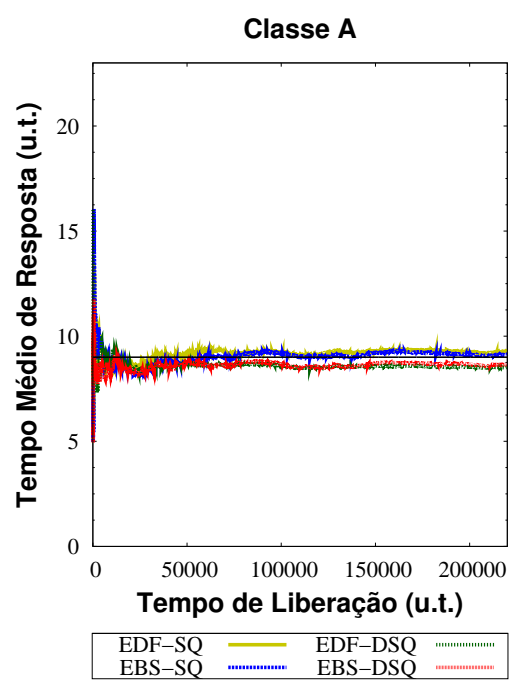

(a) CONTRATO A

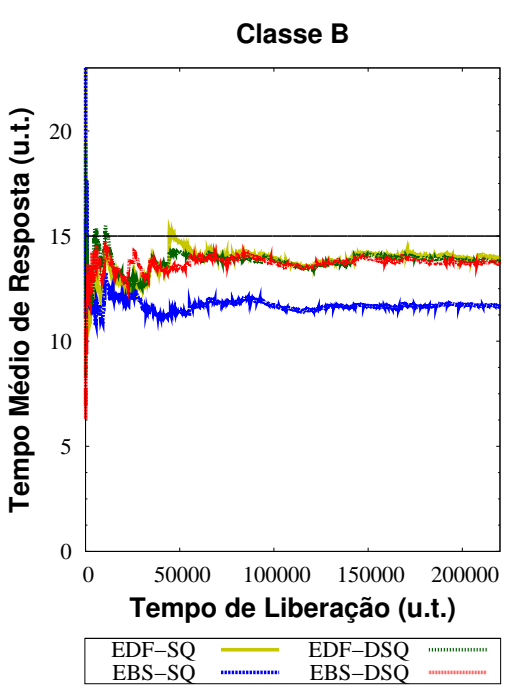

(b) CONTRATO B

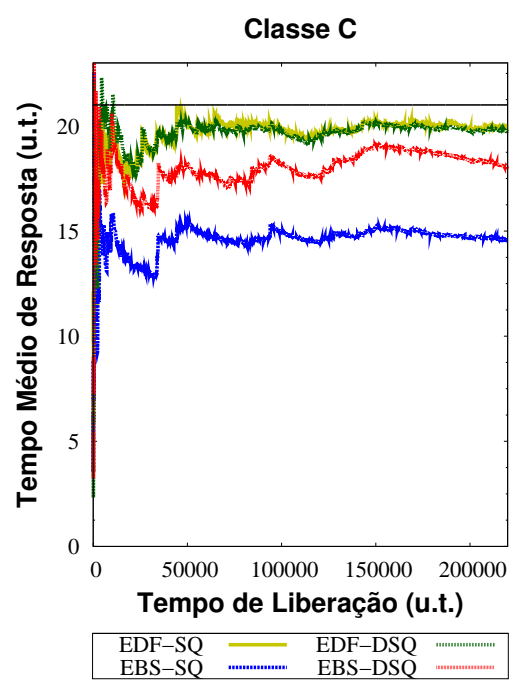

(c) CONTRATO C

Figura 5.11: Comparativo do Cenário 2 (SQ-(EDF,EBS) X DSQ-(EDF,EBS)) com Variação Contratual de $40 \%$

A validação estatística confirma que os menores intervalos para o tempo médio de resposta do Cenário 1 é realmente da abordagem $D S Q$ combinada a política de fila EDF e EBS, segundo uma estipulação de variação contratual de 40\%. O gráfico da Figura 5.12 mostra o intervalo de confiança dos dados da classe A que foram traçados para as principais abordagens desenvolvidas.

O Cenário 3 é caracterizado por baixa proporção de requisição na Classe A, mais exigente, e para a menos exigente, a Classe C. Configura-se assim, um Cenário de requisições 


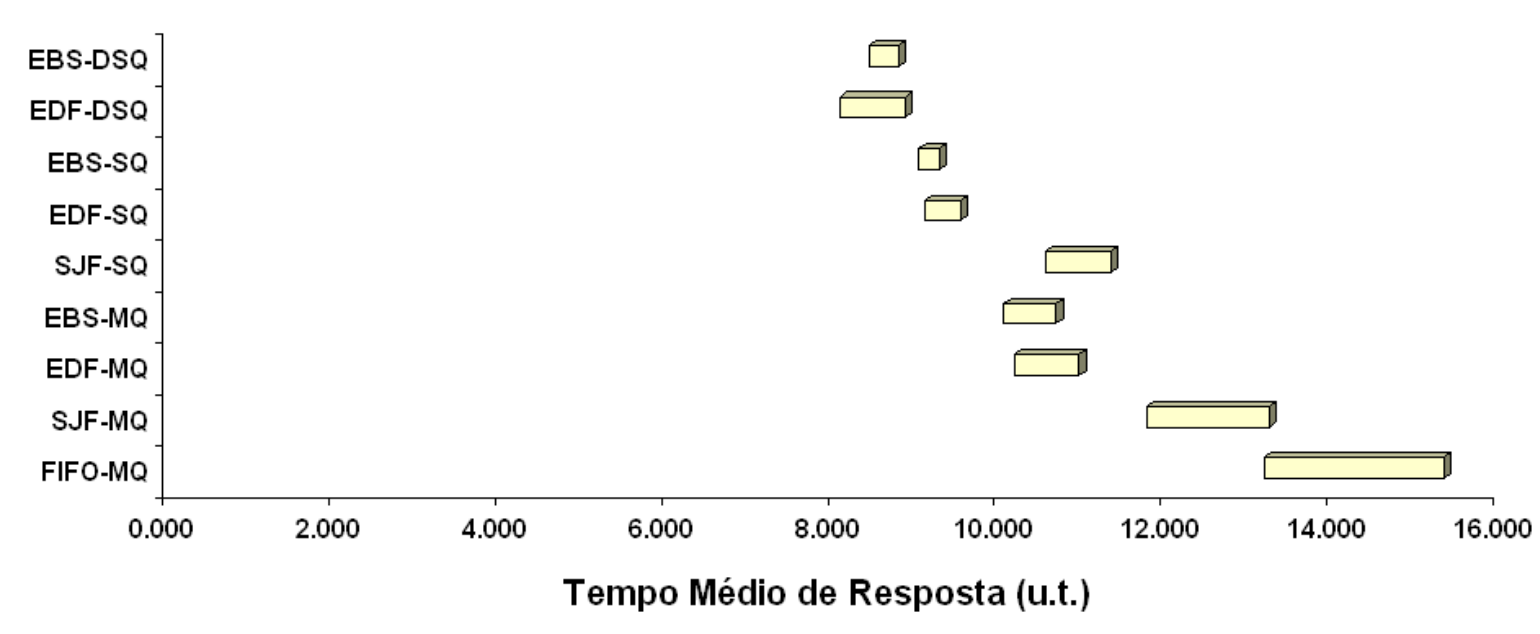

Figura 5.12: Intervalo de Confiança do Cenário 2 com Variação Contratual de $40 \%$

com exigências medianas, ou seja, a tendência é cumprir os requisitos da Classe B, com valor de referência $P$.

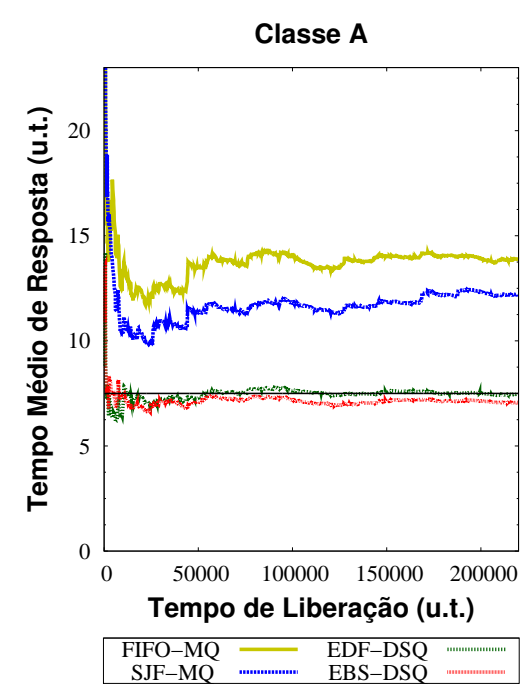

(a) CONTRATO A

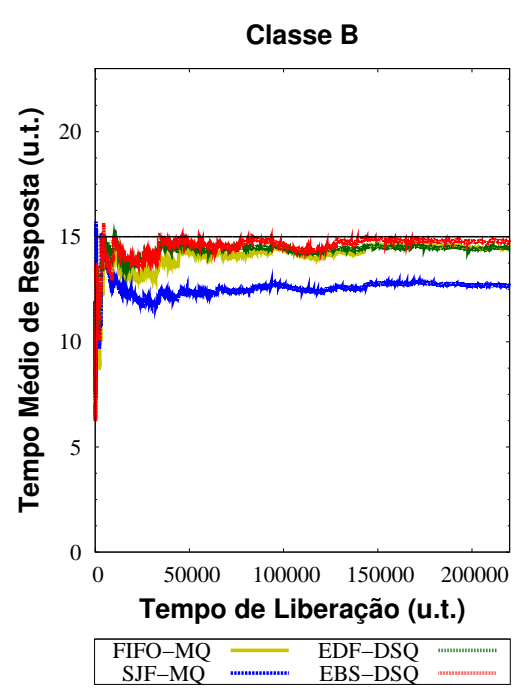

(b) CONTRATO B

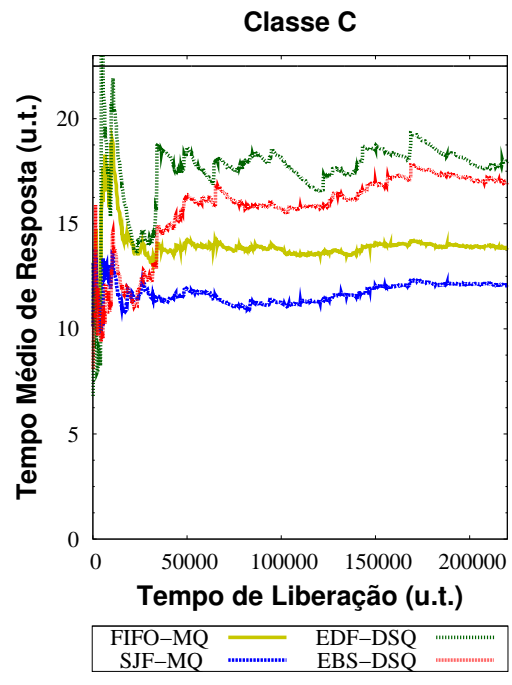

(c) CONTRATO C

Figura 5.13: Comparativo do Cenário 3 (MQ-(FIFO,SJF) X DSQ-(EDF,EBS)) com Variação Contratual de 50\%

É válido ressaltar que a $S J F-M Q$ possui melhor desempenho quando tem a disposição todo o conjunto de requisições a priori. No entanto, mesmo no escalonamento dinâmico o SJF-MQ consegue baixas médias de tempo de resposta no sistema, como verificado para as Classes B e C. Entretanto, tanto o SJF-MQ quanto o FIFO-MQ não são úteis para fornecer QoS diferenciada entre as classes, fornecendo valores similares para todas as classes. Dessa forma, a Classe A, a mais exigente do sistema, torna-se negligenciada por tais políticas e apresenta altas médias de tempo de reposta. Por outro lado, mesmo 
que um número alto de proporção de requisições para a Classe $\mathrm{B}$, as políticas EBS-DSQ e EDF-DSQ cumprem todos os contratos nesse sistema com altas exigências impostas.

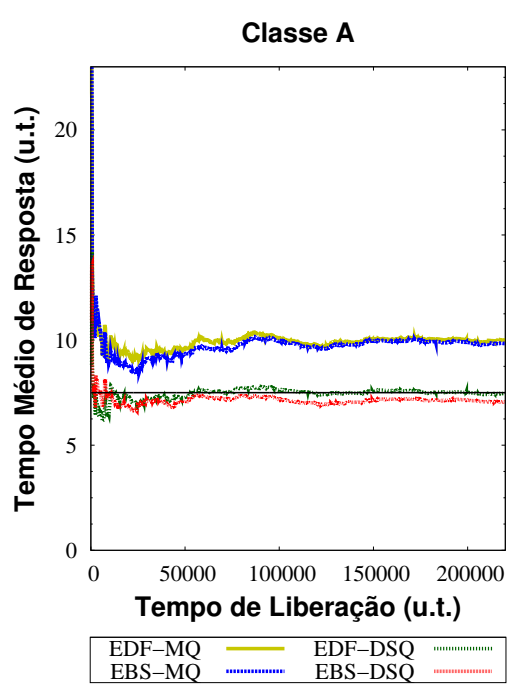

(a) CONTRATO A

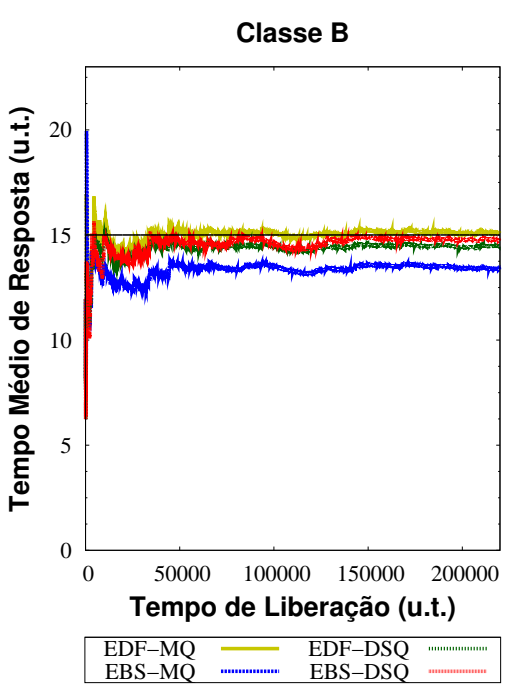

(b) CONTRATO B

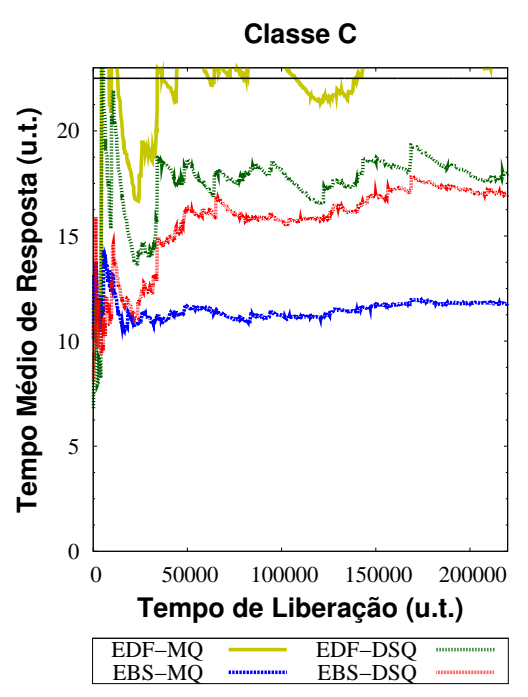

(c) CONTRATO C

Figura 5.14: Comparativo do Cenário 3 (MQ-(EDF,EBS) X DSQ-(EDF,EBS)) com Variação Contratual de 50\%

A Figura 5.14 apresenta um comparativo interessante para esse mesmo cenário 3. Pode-se perceber que a grande proporção de requisições de termos médios tolerantes (classe B) diminuiu a dificuldade de gerenciamento de deadlines imposta a ambas as políticas. Por meio desta configuração, são as políticas EBS-DSQ e EDF-DSQ que apresentam a melhor capacidade de gerenciamento da qualidade de serviço, sendo as únicas que cumprem todos os contratos estipulados das classes A, B e C.

Como foi mostrado nas Figuras 5.13, 5.14 e 5.15, nota-se também a capacidade de garantia dos contratos de serviço por parte das abordagens EDF-DSQ e EBS-DSQ, pois as médias oferecidas para todas as classes ficaram em níveis significativamente melhores do que os contratados. Os baixos tempos de residência de sistema, devido ao menor impacto da exigência das classes sobre as médias de tempo de resposta, proporcionam menores tempos de resposta percebidos pelos clientes.

A validação estatística confirma os menores intervalos para o tempo médio de resposta do Cenário 3 é realmente da abordagem $D S Q$ combinada a política de fila $E B S$, segundo uma estipulação de variação contratual de 50\%. O gráfico da Figura 5.16 mostra o intervalo de confiança dos dados da classe A que foram traçados para as principais abordagens desenvolvidas.

Estabelecer uma variação contratual de 30\%, para o Cenário 4, em relação ao tempo de residência oferecido por um sistema de melhor esforço (FIFO) significa que os escalonado- 


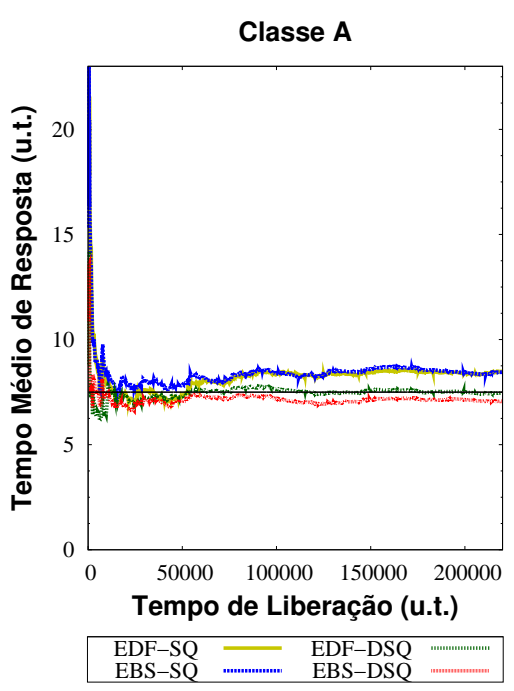

(a) CONTRATO A

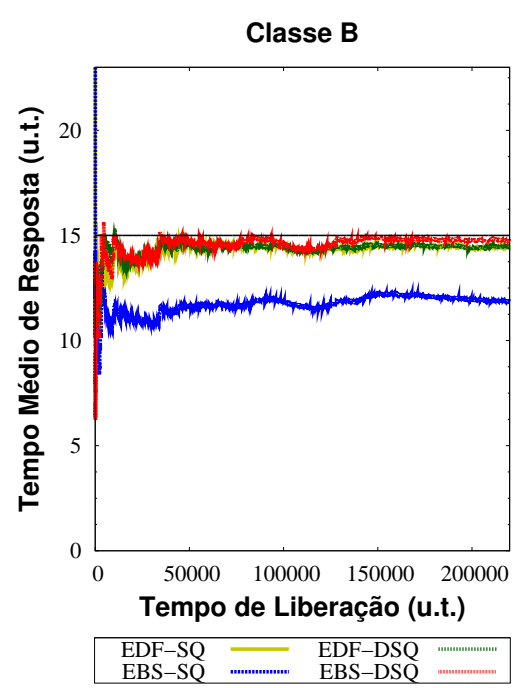

(b) CONTRATO B

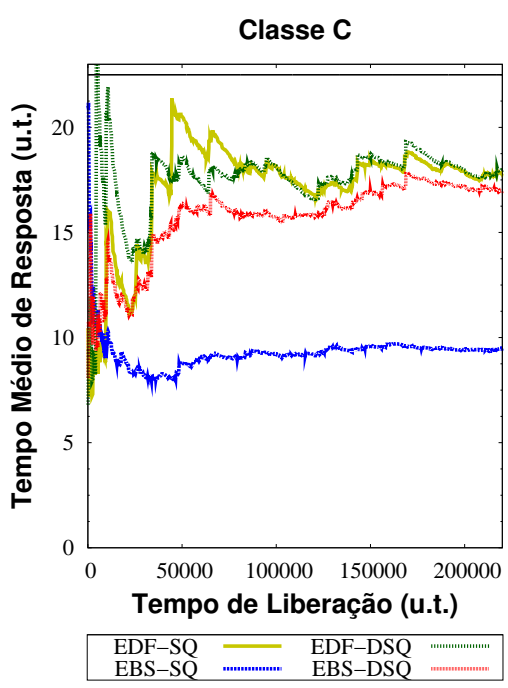

(c) CONTRATO C

Figura 5.15: Comparativo do Cenário 3 (SQ-(EDF,EBS) X DSQ-(EDF,EBS)) com Variação Contratual de $50 \%$

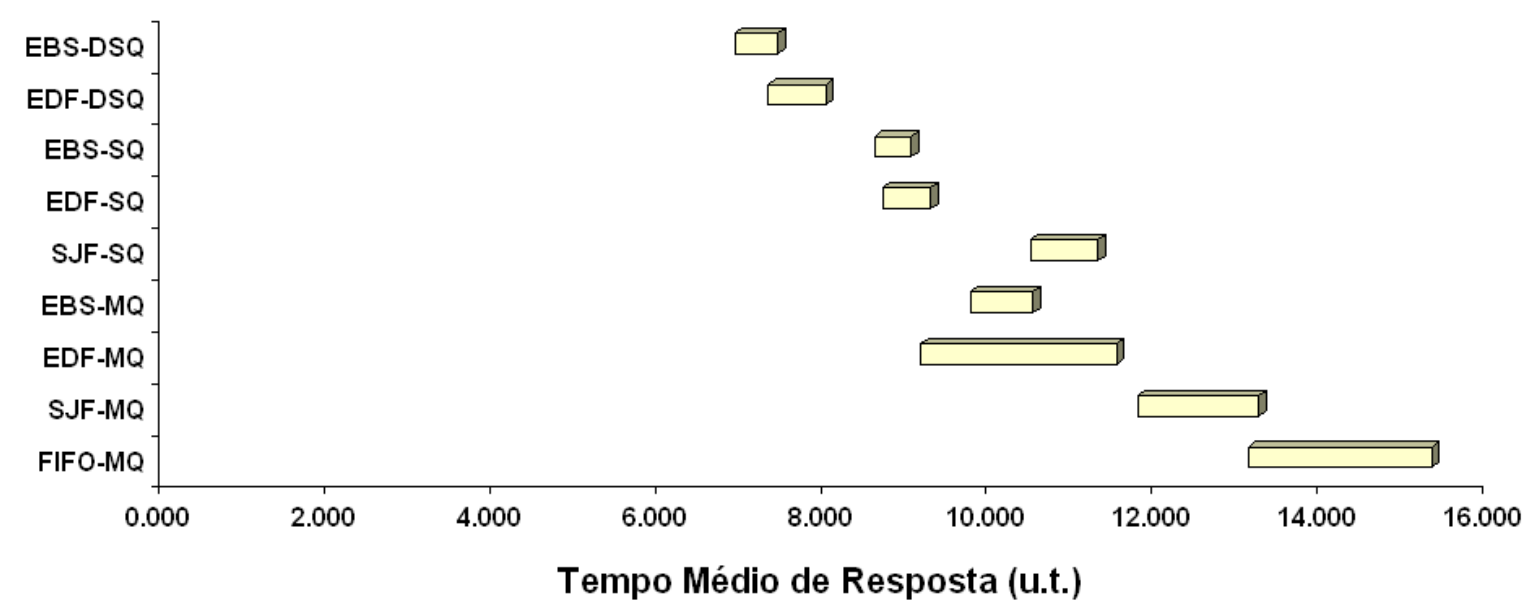

Figura 5.16: Intervalo de Confiança do Cenário 3 com Variação Contratual de 50\%

res EBS-DSQ e EDF-DSQ podem trabalhar com a meta de garantir uma média de tempo de resposta do sistema, 30\% melhor para requisições mais exigentes (classe A). Para que isto ocorra, os contratos das classes B e C precisam oferecer uma tolerância maior em seus valores de residência média no sistema, de forma a contrabalancear a demanda de desempenho.

A fim de verificar como este aumento de tolerância é percebido pelos usuários das classes B e C, ou seja, quanto que suas médias de tempo de resposta pioram para que usuários da classe A recebam melhor atendimento, simularam-se outros cenários propriamente ajustados, caracterizados na Seção 5.2.1, que podem ser visualizados a seguir. Os gráficos das Figuras 5.17, 5.18 e 5.19 mostram a capacidade do escalonador em garantir 


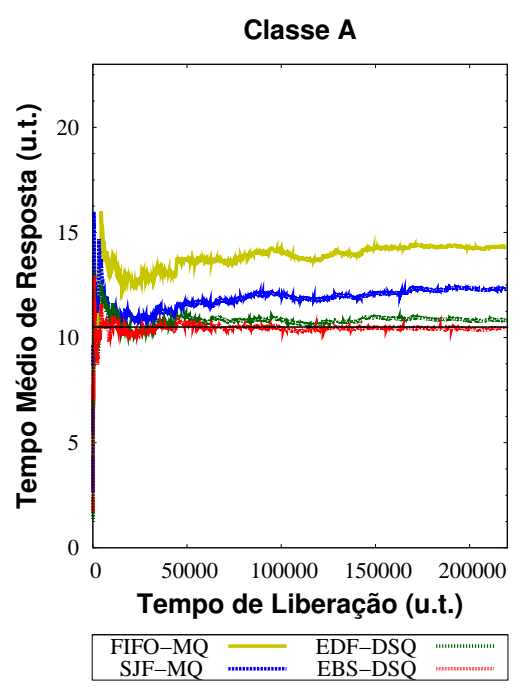

(a) CONTRATO A

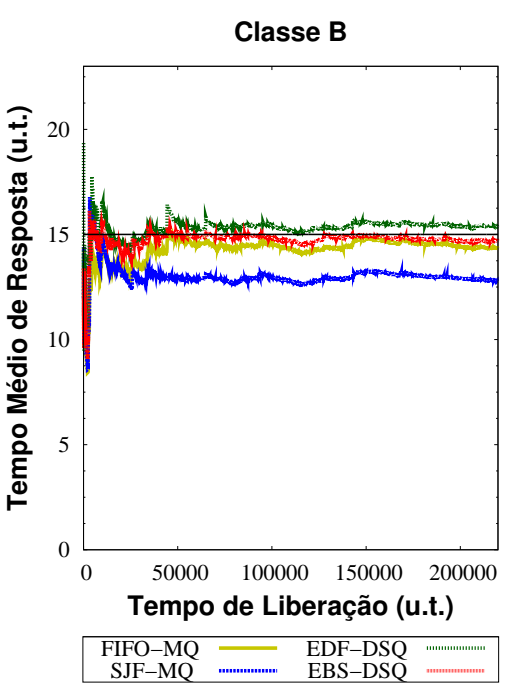

(b) CONTRATO B

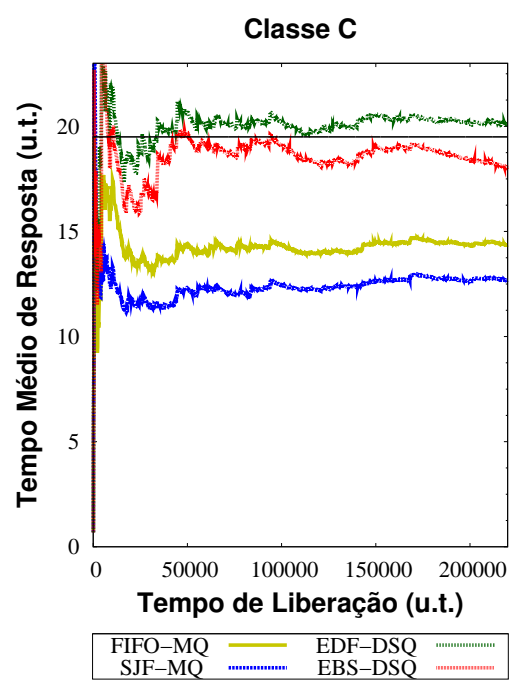

(c) CONTRATO C

Figura 5.17: Comparativo do Cenário 4 (MQ-(FIFO,SJF) X DSQ-(EDF,EBS)) com Variação Contratual de $30 \%$

aumento da exigência e também a variação da qualidade do atendimento sob diferentes proporções entre classes.

Um fato interessante de se notar é que pela análise da Figura 5.17 as médias oferecidas tanto pela disciplina FIFO-MQ quanto pela SJF-MQ não apresentam significativa diferença de qualidade entre as classes, pois o parâmetro de QoS não está relacionado ao mecanismo de priorização implementado por elas.

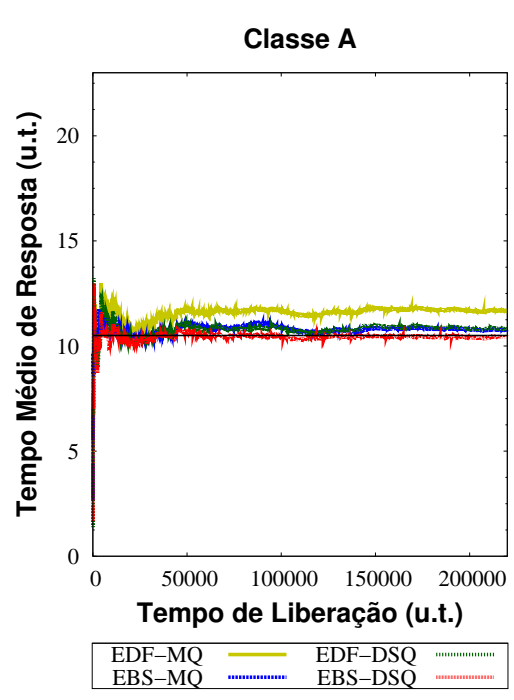

(a) CONTRATO A

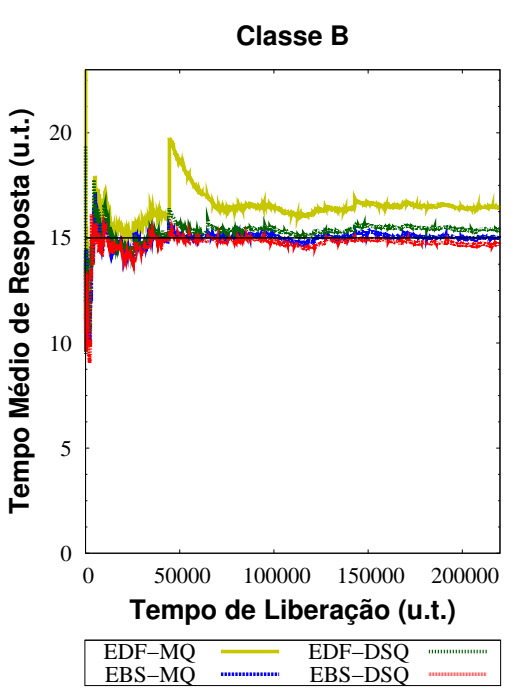

(b) CONTRATO B

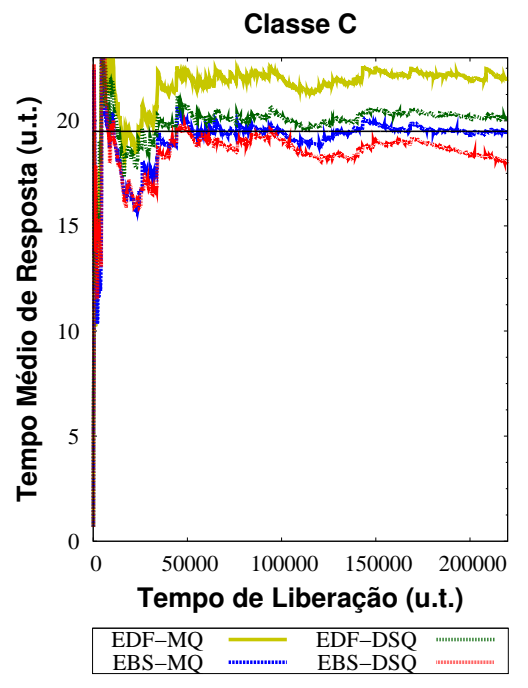

(c) CONTRATO C

Figura 5.18: Comparativo do Cenário 4 (MQ-(EDF,EBS) X DSQ-(EDF,EBS)) com Variação Contratual de $30 \%$ 
A preocupação estrita com o deadline da política de fila EDF mesmo que combinada com a política de recurso $D S Q$ impõe maior dificuldade de escalonamento quando a fila de entrada do sistema está cheia de requisições urgentes, mesmo com baixa variação contratual dos contratos de serviço. Em função disso, apesar de próximos dos contratos, os tempos médios de resposta não são cumpridos para nenhuma classe do Cenário 4 com variação contratual de $30 \%$.

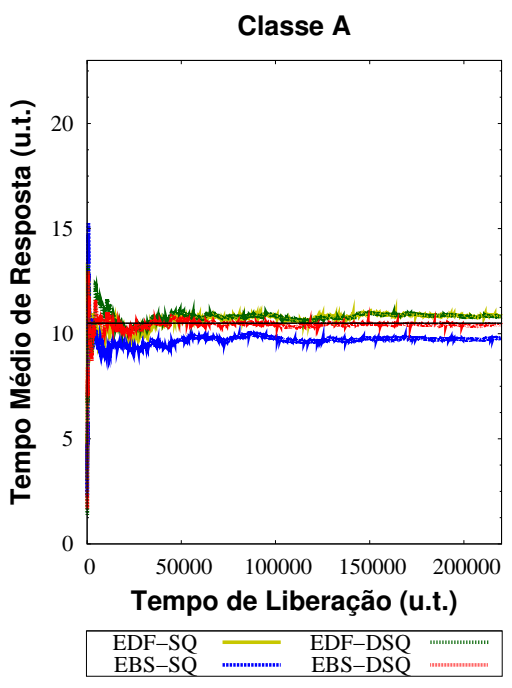

(a) CONTRATO A

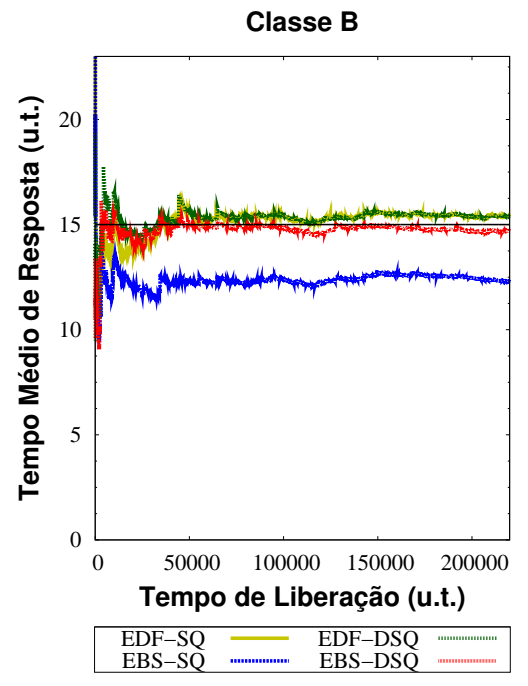

(b) CONTRATO B

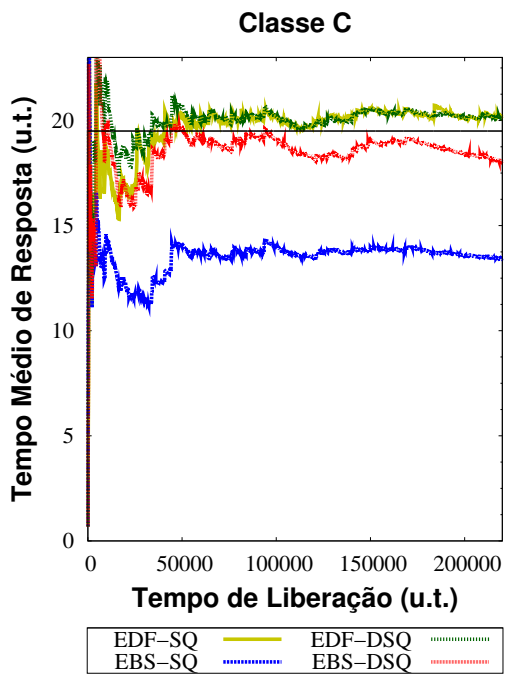

(c) CONTRATO C

Figura 5.19: Comparativo do Cenário 4 (SQ-(EDF,EBS) X DSQ-(EDF,EBS)) com Variação Contratual de 30\%

O aumento da tolerância do contrato B e C, com referência a variação contratual de $30 \%$, e a grande proporção de requisições desse tipo no sistema, facilitam o gerenciamento dos deadlines por parte da política EBS-DSQ e a EBS-SQ, como ilustram os gráficos das Figura 5.19. A maior flexibilidade contratual impõe menor peso ao sistema, facilitando o gerenciamento dos deadlines. Aproveitando indiretamente esse menor peso do sistema, a disciplina EBS-SQ apresenta um bom comportamento com relação aos tempos médios de repostas $(\Omega)$, evidenciando assim a importância de se considerar a exigência do sistema como um todo para se obter melhores níveis de qualidade de serviço. Portanto, confere-se a abordagem EBS-SQ ao que se refere-se aos menores tempos médios de reposta quando o Cenário experimentado não possui alta variação contratual.

Para esse cenário 4, o qual possui um alto nível de proporção para a classe mais exigente, a validação estatística confirma que os menores intervalos para o tempo médio de resposta do Cenário 4 é da abordagem $E B S-S Q$, segundo uma estipulação de variação contratual de 30\%. O gráfico da Figura 5.20 mostra o intervalo de confiança dos dados da classe A que foram traçados para as principais abordagens desenvolvidas. 


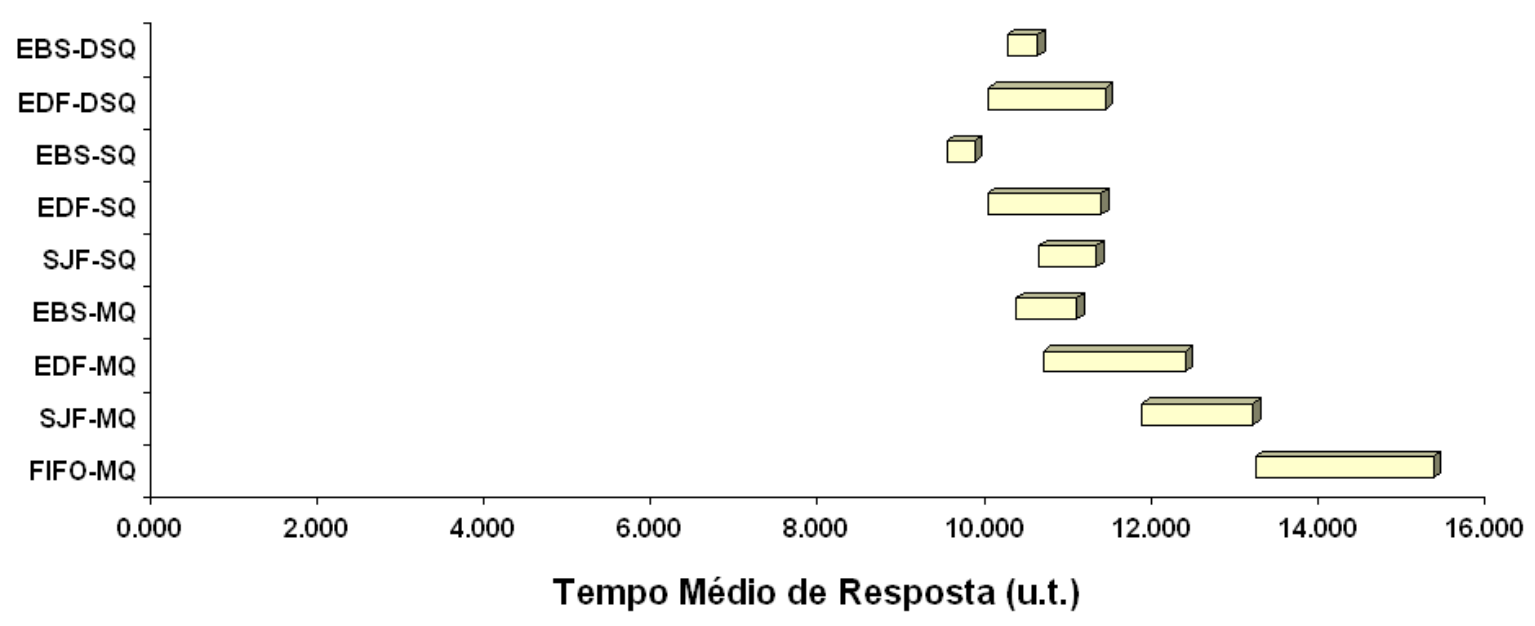

Figura 5.20: Intervalo de Confiança do Cenário 4 com Variação Contratual de $30 \%$

Quando a proporção de requisições mais exigentes aumenta para 50\% no Cenário 5 , como ilustram as Figura 5.21, 5.22 e 5.23, percebe-se um aumento das médias dos tempos de respostas oferecidos se comparado ao cenário anterior, em razão da maior exigência imposta ao escalonador.

Valores de exigência maiores, quando potencializadas pelo aumento da proporção de requisições do tipo A, resultam em maiores cargas impostas ao sistema, tornando difícil a função do escalonador em manter os níveis de tempos médios de reposta abaixo do contratado.

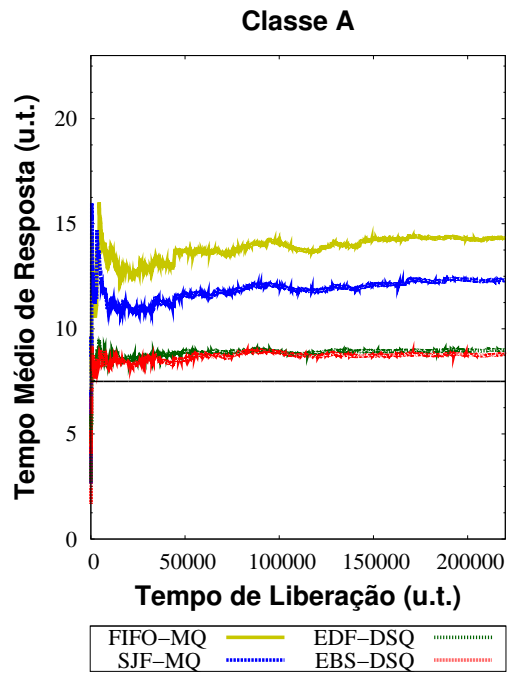

(a) CONTRATO A

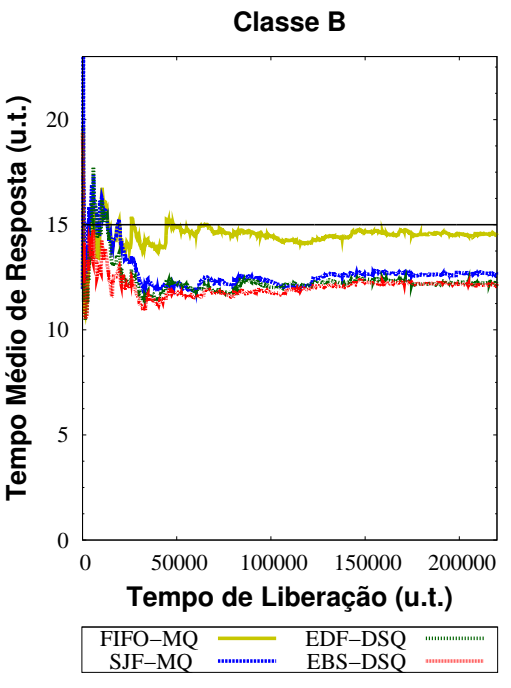

(b) CONTRATO B

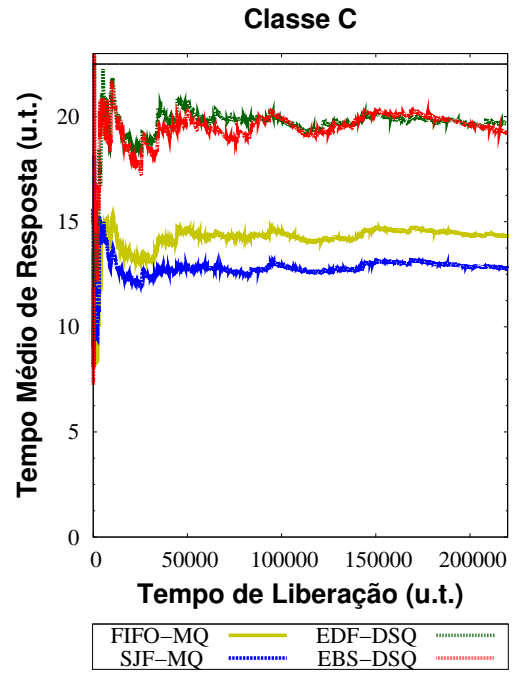

(c) CONTRATO C

Figura 5.21: Comparativo do Cenário 5 (MQ-(FIFO,SJF) X DSQ-(EDF,EBS)) com Variação Contratual de 50\%

Quando comparado com a política SJF-DSQ, Figura 5.21, o serviço prioritário oferecido pelo escalonamento $E B S-D S Q$ continua sendo superior em termos de qualidade e 
garantia de diferenciação, com valores de médias bem menores dos que observados no outro escalonador. No entanto, para garantir tal grau de diferenciação, e qualidade, observase também um aumento das médias reais da classe C, devido ao aumento da tolerância contratual.

O nível da média do tempo de resposta oferecida para as requisições da classe de alta exigência aumenta um pouco se comparadas às proporcionadas pelo algoritmo SJFDSQ. Entretanto, mesmo um pouco mais elevados, seus valores ainda ficam abaixo do especificado a sua classe de serviço e próximo do especificado à classe de alta prioridade, garantindo bom nível de desempenho.

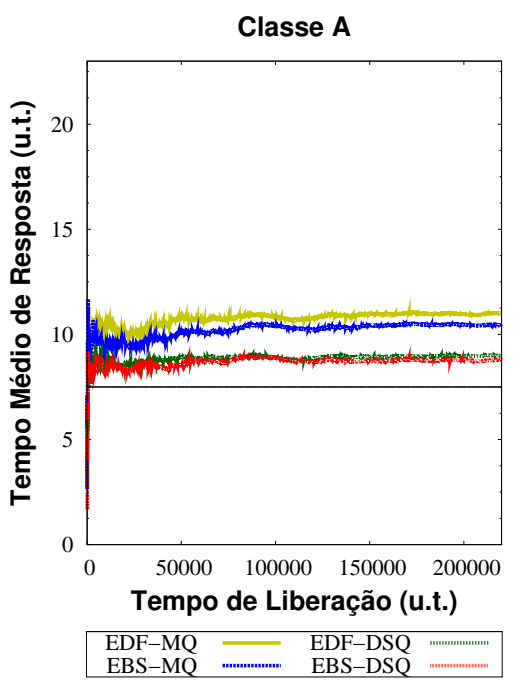

(a) CONTRATO A

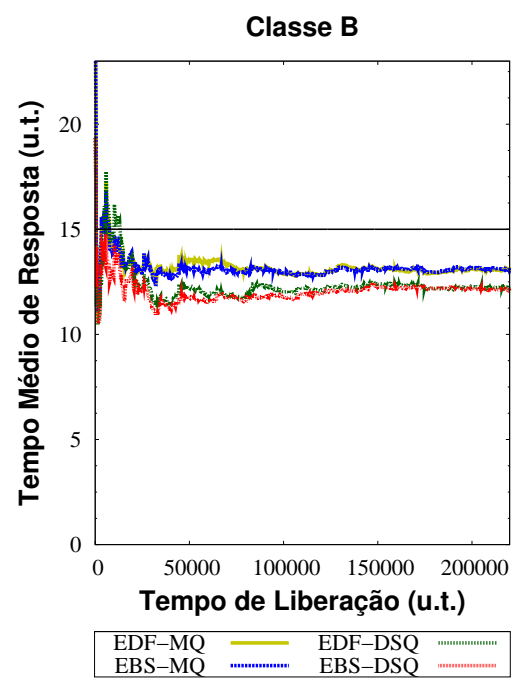

(b) CONTRATO B

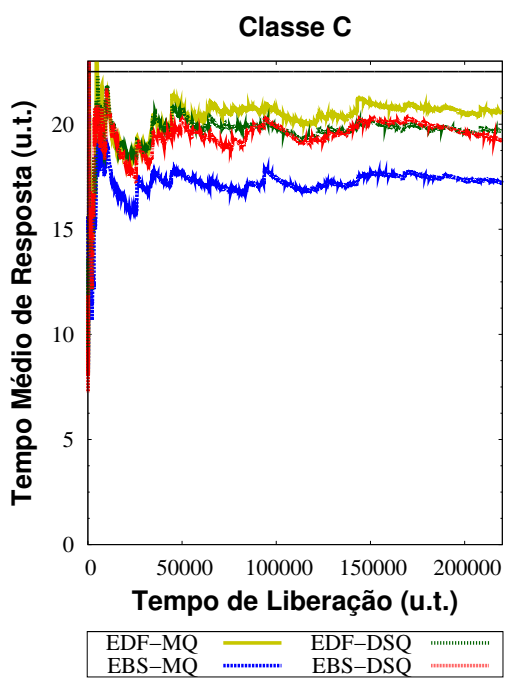

(c) CONTRATO C

Figura 5.22: Comparativo do Cenário 5 (MQ-(EDF,EBS) X DSQ-(EDF,EBS)) com Variação Contratual de 50\%

O Cenário 5 possui alta proporção de requisição para a classe A e uma alta variação contratual de 50\%. Essa configuração desse ambiente foi responsável por nenhuma abordagem conseguir alcançar os contratos estipulados para a Classe A. Porém, a abordagem que mais próxima ficou do cumprimento do contrato da Classe A foi a abordagem EBS-DSQ, como pode ser visto nos gráficos das Figuras 5.22 e 5.23.

Observa-se claramente que a abordagem EBS-SQ possui bons tempos médios de resposta para as classes B e C, porém é a abordagem que menor realiza a diferenciação de serviço entre as classes, como dito anteriormente, é uma abordagem que dá um peso maior para o desempenho do sistema como um todo.

Apesar de não cumprir o contrato da classe A, a validação estatística confirma os menores intervalos $\Omega$ para o Cenário 5 sendo da abordagem $D S Q$ combinada a política de fila $E B S$, segundo uma estipulação de variação contratual de 50\%. O gráfico da Figura 5.24 


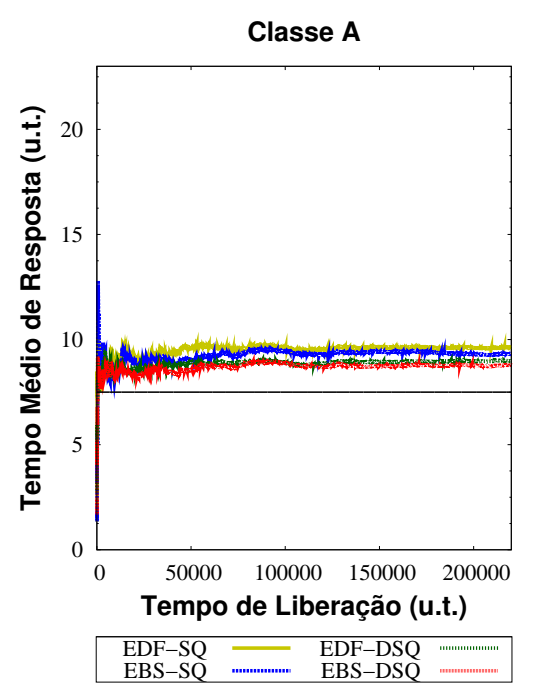

(a) CONTRATO A

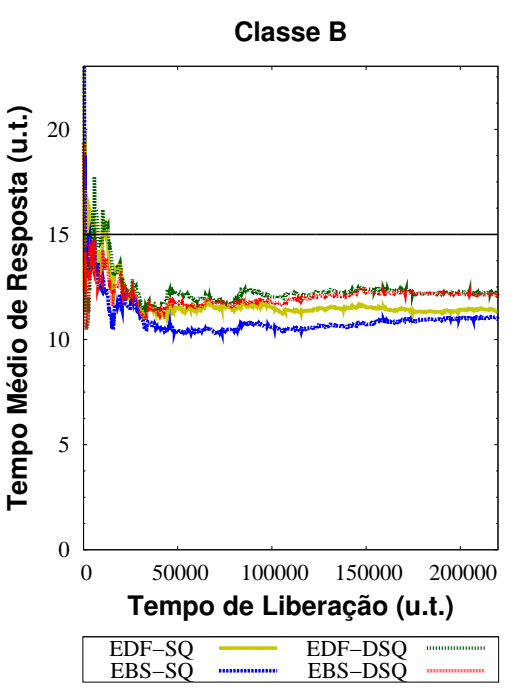

(b) CONTRATO B

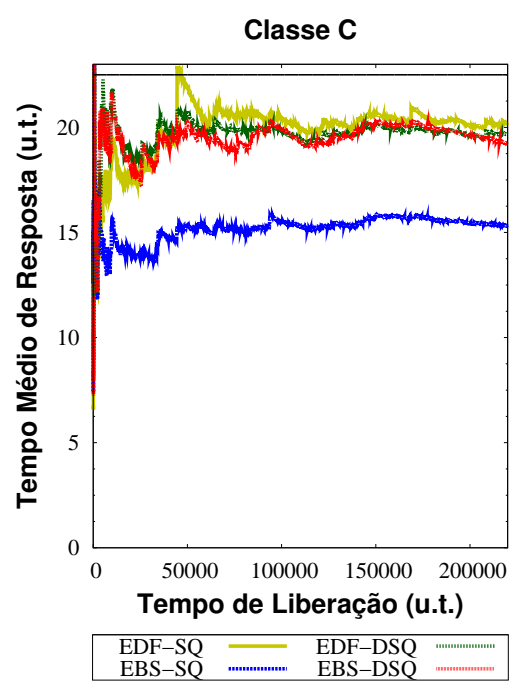

(c) CONTRATO C

Figura 5.23: Comparativo do Cenário 5 (SQ-(EDF,EBS) X DSQ-(EDF,EBS)) com Variação Contratual de 50\%

mostra o intervalo de confiança dos dados da classe A que foram traçados para as principais abordagens desenvolvidas.

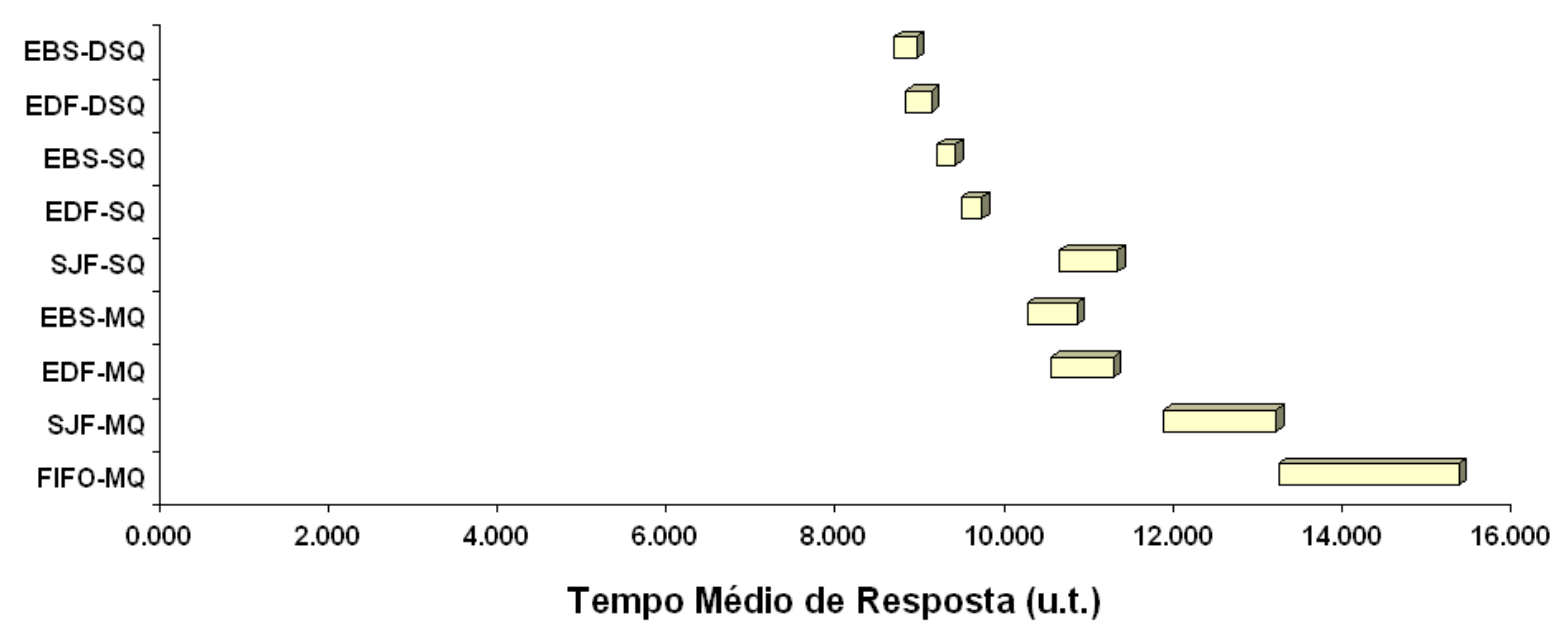

Figura 5.24: Intervalo de Confiança do Cenário 5 com Variação Contratual de $50 \%$

\subsection{Overhead do Escalonador}

Durante as simulações foram medidas para cada abordagem o overhead gerado pela tomada de decisão do escalonador implementado. Adotou-se nulo os tempos de overhead para os cálculos do escalonador, uma vez que, esses tempos não são significantes com respeito aos outros tempos que caracterizam o processo dinâmico da Web, já que o trabalho 
do escalonador é dado em termos temporais de milisegundos (ms), enquanto o tempo médio de serviço é dado em segundos (s).

O valor médio do overhead para um cenário geral mostrado na Tabela 5.2 ratifica que não foi necessário incluir o valor do overhead, pois esse valor não afeta o desempenho do sistema. Evidencia-se que a média dos Ticks de relógio por segundo ${ }^{2}$ é baixa para todas as abordagens. Nota-se que a abordagem EBS-DSQ possui o índice um pouco maior em relação as demais, deve-se ao fato de se realizar mais cálculos na composição das prioridades da fila de requisições.

Tabela 5.2: Estatísticas do Overhead do Escalonador

\begin{tabular}{|r|r|r|r|r|}
\hline & TCS & DP & IC-Menor & IC-Maior \\
\hline FIFO-MQ & 0,045 & 0,027 & 0 & 0,103 \\
\hline SJF-MQ & 0,022 & 0,019 & 0 & 0,062 \\
\hline EDF-MQ & 0,031 & 0,019 & 0 & 0,073 \\
\hline EBS-MQ & 0,060 & 0,020 & 0,017 & 0,103 \\
\hline SJF-SQ & 0,039 & 0,024 & 0 & 0,091 \\
\hline EDF-SQ & 0,086 & 0,025 & 0,032 & 0,141 \\
\hline EBS-SQ & 0,081 & 0,022 & 0,033 & 0,129 \\
\hline EDF-DSQ & 0,270 & 0,049 & 0,166 & 0,375 \\
\hline EBS-DSQ & 0,545 & 0,067 & 0,401 & 0,689 \\
\hline \multicolumn{5}{|l|}{} \\
\hline TCS: Ticks de relógio por segundo \\
\hline DP: Desvio Padrão \\
\hline IC: Intervalo de Confiança \\
\hline
\end{tabular}

Adotou-se também nulo o overhead referente a sinalização da ocorrência de servidores livres em função de uma mínima influência no comportamento do escalonador.

\subsection{Controle de Admissão}

Como mencionado na Seção 4.4, o Controle de Admissão influência de maneira significativa na satisfação do Cliente, uma vez que, a cada descarte de uma requisição é decrementado o número de vezes em que a média do tempo de resposta de sistema dessas requisições ficou abaixo do limiar contratado $\left(N_{i}\right)$.

\footnotetext{
${ }^{2}$ Ticks de clock é o mesmo que um ciclo, uma unidade pequena de tempo reconhecida por um dispositivo.
} 
Através da Tabela 5.3, média de todos os cenários, nota-se que a abordagem $S Q$ possui um índice alto de descartes, devido a forma que essa abordagem manipula as requisições na fila, ou seja, servidores de baixa potência de processamento são lidados por essa abordagem de forma igual a um servidor com alta potência de processamento. Por isso, essa abordagem é penalizada significativamente através das regras de contrato previamente estipuladas na Seção 4.4.

Tabela 5.3: Valor Médio de Descartes do Controle de Admissão

\begin{tabular}{|r|r|r|r|r|r|}
\hline & \multicolumn{5}{|c|}{ Variação Contratual de 30\% } \\
\hline & Cenário 1 & Cenário 2 & Cenário 3 & Cenário 4 & Cenário 5 \\
\hline FIFO-MQ & 35 & 35 & 35 & 35 & 35 \\
\hline SJF-MQ & 35 & 35 & 35 & 35 & 35 \\
\hline EDF-MQ & 36 & 35 & 36 & 37 & 35 \\
\hline EBS-MQ & 37 & 35 & 36 & 36 & 35 \\
\hline SJF-SQ & 5759 & 5759 & 5759 & 5759 & 5759 \\
\hline EDF-SQ & 5596 & 5572 & 5570 & 5580 & 5560 \\
\hline EBS-SQ & 5733 & 5735 & 5760 & 5703 & 5702 \\
\hline EDF-DSQ & 30 & 33 & 27 & 32 & 27 \\
\hline EBS-DSQ & 20 & 23 & 33 & 28 & 24 \\
\hline
\end{tabular}

O controle de admissão, portanto, evita aceitar no sistema um número excessivo de requisições, as quais apenas contribuiriam para o aumento de sua sobrecarga. Assim, tem-se uma melhora superficial no tempo médio de resposta $(\Omega)$ das requisições que são admitidas para processamento. A diminuição do tempo médio de resposta é mínima (Tabela 5.4) pois mediante as cargas impostas ao sistema $(\lambda$ e $\mu$ ) resulta-se a uma taxa de utilização próximas do limiar pré-estabelecido de $77 \%$.

O algoritmo de controle de admissão implementado não realiza acepção entre as classes de serviço ao lidar com as decisões de descarte, recusando as requisições indistintamente assim que o servidor atinge o limiar de utilização estipulado.

Conclui-se que o mecanismo de controle de admissão proposto consegue efetivamente controlar a sobrecarga do servidor para todas as abordagens propostas, mantendo a utilização sempre abaixo do limiar desejado e propiciando um atendimento aceitável para todas as classes de serviço. A escolha da utilização sob o array de servidores do sistema como referência para o controle de admissão tem conseqüências imediatas sobre o tamanho das filas, portanto sobre o tempo de resposta médio das requisições, o que contribui para a melhoria de desempenho do sistema como um todo. 
Tabela 5.4: Valor Médio de $\Omega$ e Satisfação dos Clientes

\begin{tabular}{|c|c|c|c|c|}
\hline & \multicolumn{2}{|c|}{ S/ Controle de Admissão } & \multicolumn{2}{|c|}{ C/ Controle de Admissão } \\
\hline & $\Omega$ da Classe $A$ & Satisfação Total & $\Omega$ da Classe $A$ & Satisfação Total \\
\hline & \multicolumn{4}{|c|}{ Cenário 1 com variação contratual de $30 \%$} \\
\hline EBS-SQ & 9,10 & 99,69 & 8,90 & 93,59 \\
\hline EBS-DSQ & 8,90 & 99,73 & 8,90 & 99,71 \\
\hline \multirow[t]{2}{*}{ EBS-MQ } & 10,28 & 98,05 & 10,27 & 98,16 \\
\hline & \multicolumn{4}{|c|}{ Cenário 2 com variação contratual de 30\% } \\
\hline EBS-SQ & 9,31 & 99,65 & 9,29 & 93,59 \\
\hline EBS-DSQ & 9,86 & 99,46 & 9,86 & 99,45 \\
\hline \multirow[t]{2}{*}{ EBS-MQ } & 10,46 & 96,83 & 10,46 & 96,93 \\
\hline & \multicolumn{4}{|c|}{ Cenário 3 com variação contratual de $30 \%$} \\
\hline EBS-SQ & 8,82 & 99,56 & 8,80 & 93,43 \\
\hline EBS-DSQ & 9,48 & 99,20 & 9,47 & 99,18 \\
\hline \multirow[t]{2}{*}{ EBS-MQ } & 10,16 & 96,76 & 10,15 & 96,97 \\
\hline & \multicolumn{4}{|c|}{ Cenário 4 com variação contratual de $30 \%$} \\
\hline EBS-SQ & 9,67 & 99,41 & 9,64 & 93,35 \\
\hline EBS-DSQ & 10,39 & 98,16 & 10,39 & 98,23 \\
\hline \multirow[t]{2}{*}{ EBS-MQ } & 10,68 & 85,34 & 10,68 & 85,66 \\
\hline & \multicolumn{4}{|c|}{ Cenário 5 com variação contratual de $30 \%$} \\
\hline EBS-SQ & 9,51 & 99,63 & 9,45 & 93,56 \\
\hline EBS-DSQ & 9,99 & 99,35 & 9,99 & 99,37 \\
\hline EBS-MQ & 10,61 & 93,20 & 10,61 & 93,74 \\
\hline
\end{tabular}

\subsection{Avaliação da Satisfação do Cliente}

A análise dos resultados por meio do tempo médio de resposta, como realizada na Seção 5.3, é importante pois fornece detalhes do comportamento do escalonador. No entanto, uma visão mais abrangente, com maior validade estatística também se faz necessária. Por ela pode-se constatar se a eficiência e desempenho vistos nos gráficos anteriores são ou não casos isolados.

Dados de satisfação dos usuários e da variação dos tempos de repostas individuais em relação às médias contratadas foram coletados para todas as classes, de acordo com o planejamento especificado na seção 5.2.1. Apresentados em termos percentuais médios das três classes, esses valores foram calculados a partir de uma faixa de tolerância de $3 \%$ em relação aos parâmetros contratuais. 
A satisfação de um dado usuário mostra o percentual de vezes que a média real oferecida ficou dentro da faixa de tolerância especificada por cada contrato de serviço. O número dos tempos de respostas oferecidos abaixo da média contratada quantifica a variação da qualidade de um dado atendimento, pois, em média, a satisfação pode se manter alta, mas os valores individuais dos tempos de respostas oferecidos podem variar muito. Esse percentual reflete a estabilidade da qualidade do escalonamento oferecido.

Os gráficos da Figura 5.25 apresentam um comparativo estatístico da satisfação contratual, obtidos através da média de todas as classes e pelas diferentes disciplinas de escalonamento do cenário 1. A parte mais escura da barra dos gráficos representa o intervalo de confiança da Satisfação dos Usuários no sistema.

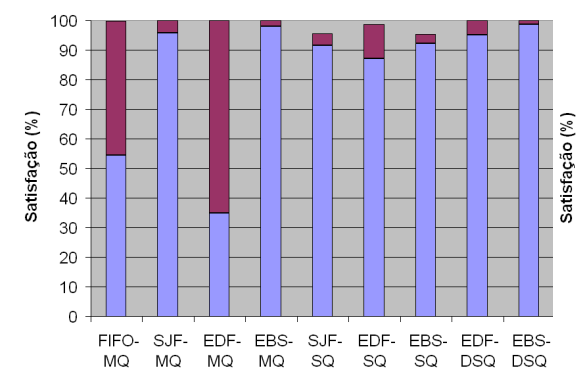

(a) Variação Contratual $10 \%$

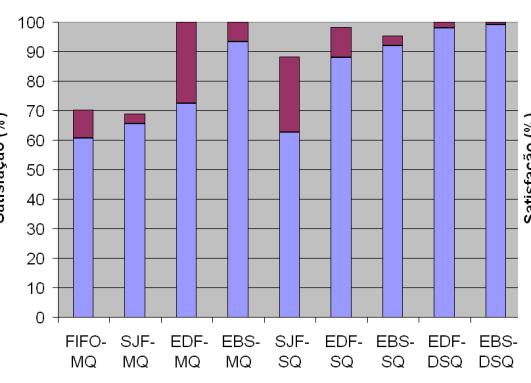

(b) Variação Contratual $30 \%$

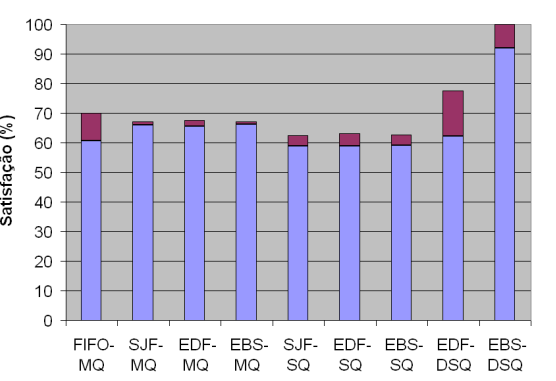

(c) Variação Contratual $50 \%$

Figura 5.25: Intervalo de Confiança para a Satisfação dos Usuários do Cenário 1

Pela Figura 5.25 pode-se verificar como varia a qualidade individual de atendimento das requisições para o Cenário 1. No escalonamento EBS-DSQ, mesmo sob grandes variações contratuais das exigências, a qualidade do escalonamento se mantém em nível bom para os três gráficos de variações contratuais. Para variações contratuais de até $50 \%$ a qualidade individual dos tempos de reposta reais é melhor que a contratada em mais de 90\% dos casos, o que mostra que, mesmo sob graus mais altos de diferenciação, o algoritmo EBS-DSQ consegue manter ótima qualidade de serviço, quando o sistema não está saturado por requisições prioritárias. Comparadas às demais políticas, a SJF-MQ consegue oferecer pouca oscilação de qualidade para classes prioritárias, mas com pouca diferenciação de serviço, apenas para contratos até $10 \%$ mais exigentes. A política EDF$D S Q$, para o Cenário 1 com alta variação contratual, apresentou qualidade de tempo de reposta inferior à $E B S-D S Q$ e alta oscilação no intervalo de confiança.

Observa-se nos gráficos da Figura 5.26 um fenômeno interessante da disciplina EDF$M Q$. Essa abordagem apresenta um intervalo de confiança que inicia de $0 \%$ até $100 \%$ para as variações contratuais de $10 \%$ e 30\%. Essa alta oscilação da métrica de Satisfação dos Clientes deve-se ao fato do alto valor encontrado para o desvio padrão registrado durante 


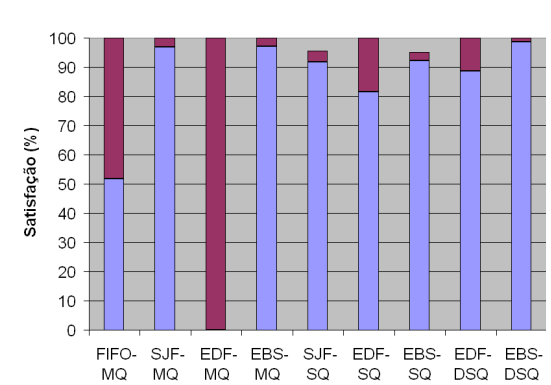

(a) Variação Contratual $10 \%$

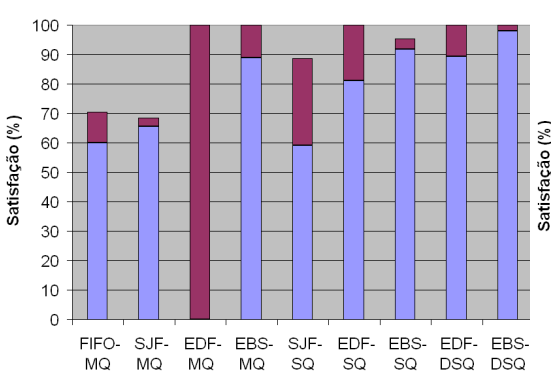

(b) Variação Contratual $30 \%$

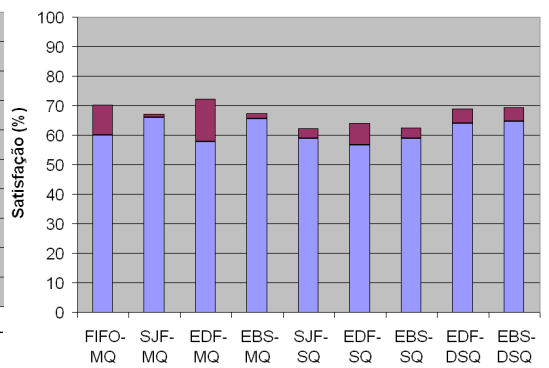

(c) Variação Contratual $50 \%$

Figura 5.26: Intervalo de Confiança para a Satisfação dos Usuários do Cenário 2

as simulações, deste modo mostrando-se inconstante. Nota-se também que as melhores satisfações dos clientes continua a ser provenientes da abordagem EBS-DSQ.

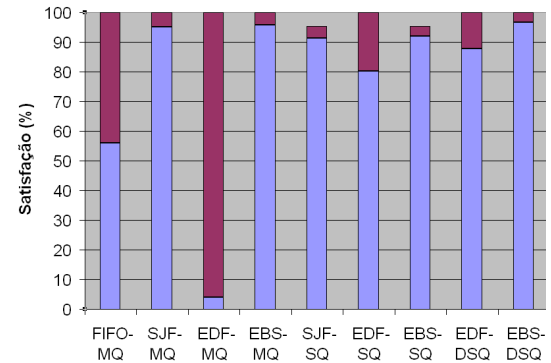

(a) Variação Contratual $10 \%$

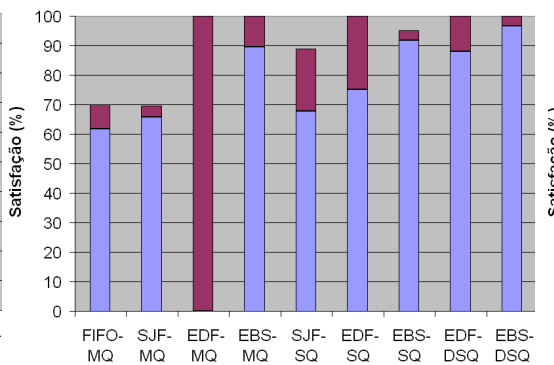

(b) Variação Contratual $30 \%$

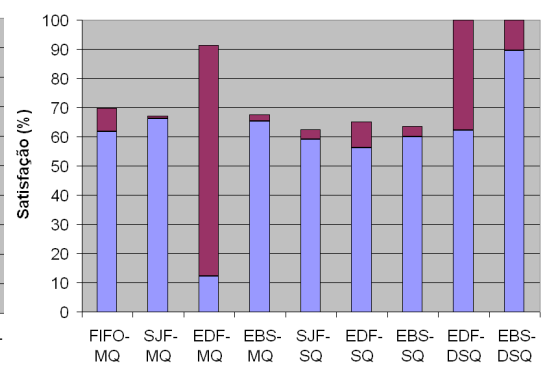

(c) Variação Contratual $50 \%$

Figura 5.27: Intervalo de Confiança para a Satisfação dos Usuários do Cenário 3

Ratifica-se mais uma vez no Cenário 3, Figura 5.27, que a abordagem EBS-DSQ retém os melhores resultados, para todas as variações contratuais ensaiadas. Essa maior estabilidade se deve ao fato da EBS-DSQ se preocupar com o impacto da exigência de cada requisição a ser atendida sobre o sistema como um todo, influenciando assim na satisfação das demais requisições.

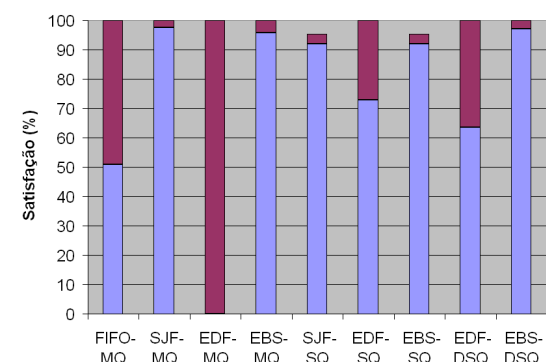

(a) Variação Contratual 10\%

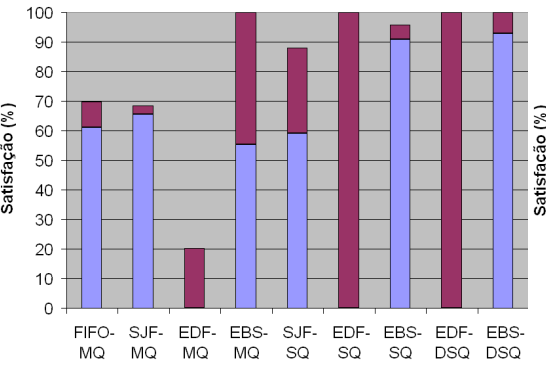

(b) Variação Contratual $30 \%$

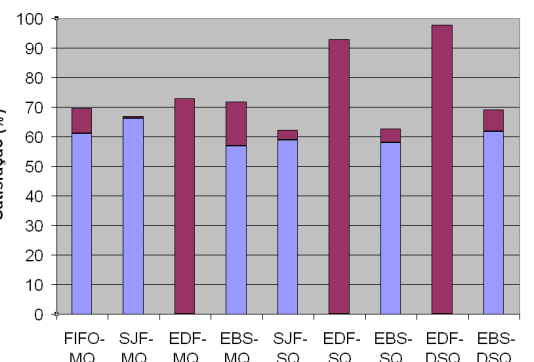

(c) Variação Contratual 50\%

Figura 5.28: Intervalo de Confiança para a Satisfação dos Usuários do Cenário 4

À medida que o sistema fica sobrecarregado por requisições prioritárias, Figura 5.28, a exigência imposta ao escalonador para garantir as requisições de QoS aumenta excessivamente. Para taxas muito altas dessa variação contratual observa-se que o peso imposto ao 
sistema inviabiliza um bom escalonamento, oferecendo baixa satisfação contratual para usuários mais exigentes. Variações de até $30 \%$ oferecem uma satisfação aos usuários prioritários superior a $90 \%$ por meio da abordagem $E B S-D S Q$, além de uma sólida diferenciação de serviço. Por outro lado, quando a variação contratual atinge o limite de $50 \%$ todas as abordagens apresentam resultados ruins, em média com garantias de 50\% da satisfação média para todas as classes.

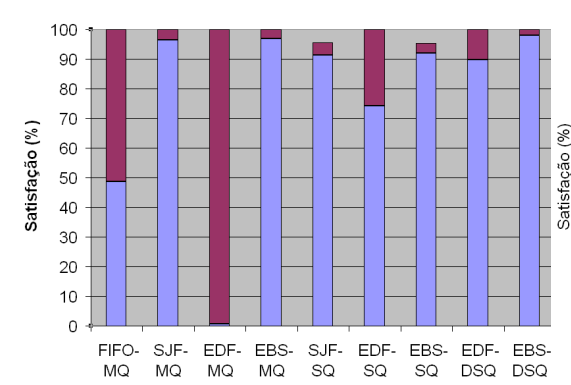

(a) Variação Contratual $10 \%$

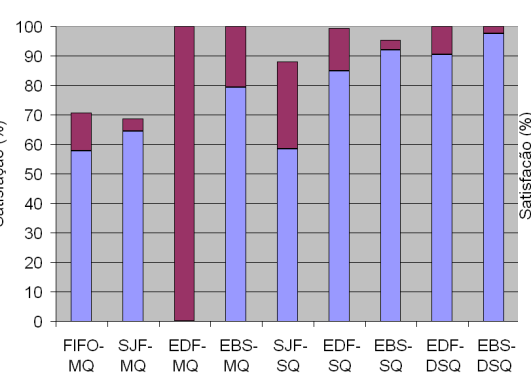

(b) Variação Contratual $30 \%$

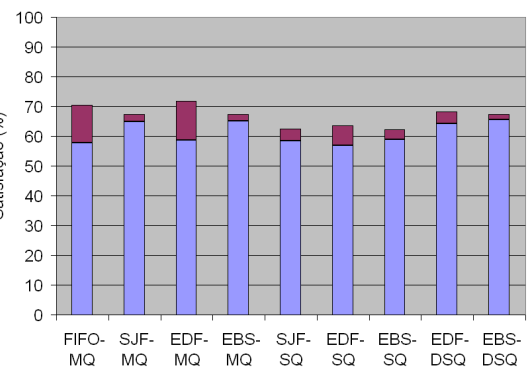

(c) Variação Contratual $50 \%$

Figura 5.29: Intervalo de Confiança para a Satisfação dos Usuários do Cenário 5

É possível notar através dos gráficos da Figura 5.29 que apesar das proporção de requisições da classe mais exigente ser alta com uma variação de até 30\%, as abordagens EBS-DSQ, EDF-DSQ e EBS-SQ apresentaram resultados bons, dada uma satisfação superior a 90\%, porém esse mesmo valor não reflete para altas variações contratuais devido a alta carga imposta aos escalonadores em manter abaixo do contratado os tempos médios de resposta da classe A.

\subsection{Política Adaptativa}

É possível utilizar as vantagens de cada abordagem em relação às características corrente do ambiente. A especificação da arquitetura adaptativa motiva o uso de todas as abordagens em conjunto, realizando a troca entre elas no momento em que uma se mostra superior. Essa troca é dada de acordo com as características das variações contratuais conhecidas a priori. O gráfico da Figura 5.30 representa os melhores estados de cada modelo já apresentado para cada Cenário em um dado instante da variação contratual. Essa análise é realizada exclusivamente através da métrica de tempo médio de resposta da Classe A, que determina a maior exigência do sistema.

Observa-se que em Cenários com baixa variação contratual a abordagem EBS-SQ é indicada; quando a variação é intermediária o uso da abordagem EDF-DSQ apresenta melhores resultados. Por outro lado, é melhor usar a abordagem EBS-DSQ para variações 


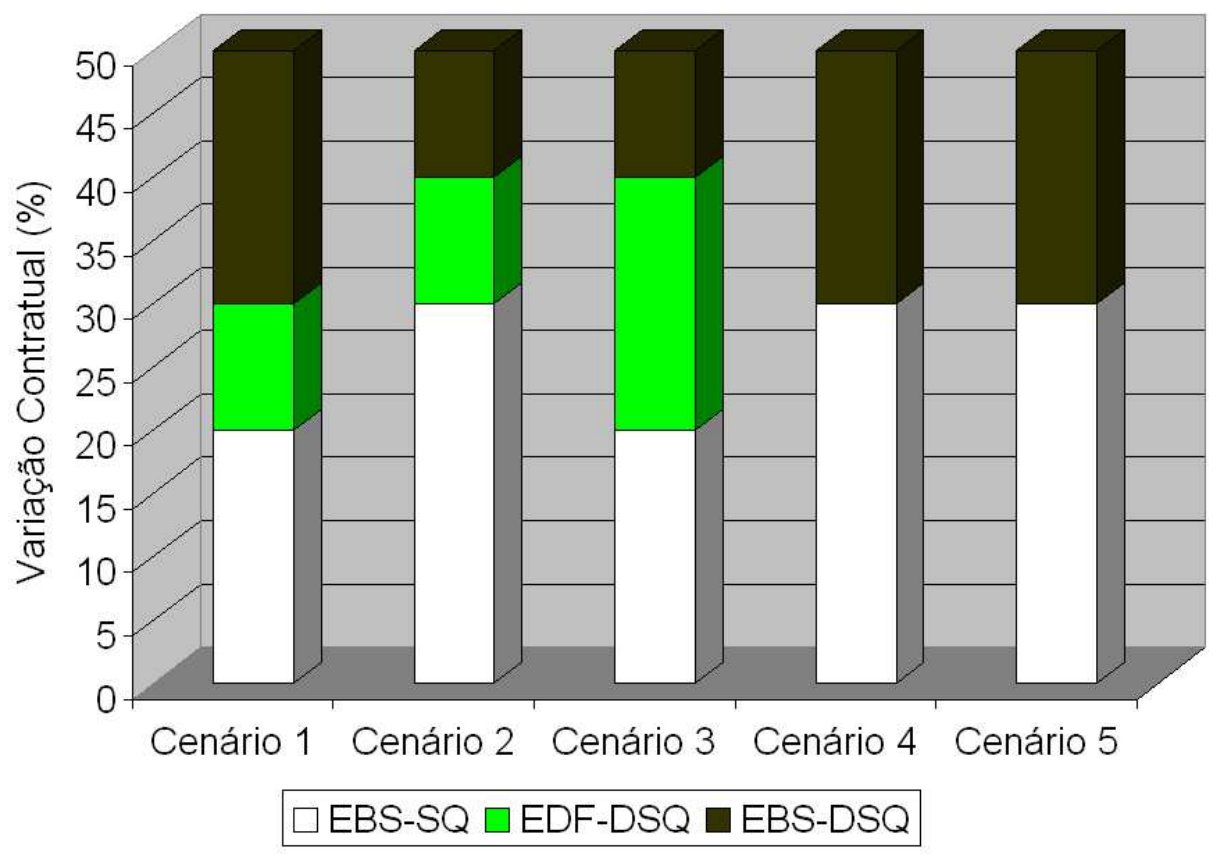

Figura 5.30: Abordagem Adaptativa com Referência o Tempo Médio de Resposta

contratuais altas. Por outro lado, quando a métrica envolvida é a Satisfação do Cliente, determinada por meio da média das três classes, Figura 5.31, observa-se que a métrica preponderante é a EBS-DSQ.

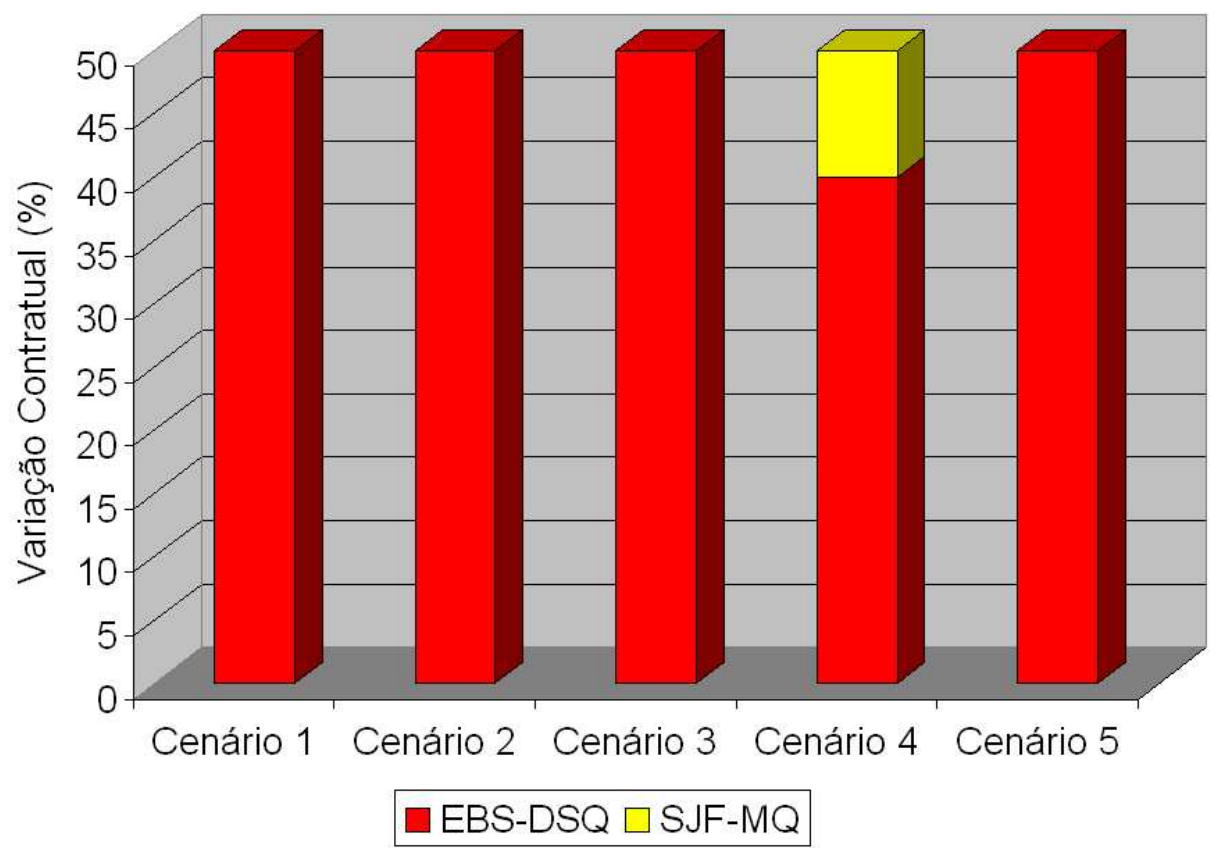

Figura 5.31: Abordagem Adaptativa com Referência a Satisfação do Cliente

O custo envolvido entre as trocas das abordagens é baixo. Mudar EBS-SQ para EDF$D S Q$ significa apenas ativar o calculo do $(\tau)$ utilizando assim a fila virtual na politica 
de recurso e desativar o uso da informação de carga de trabalho $\left(T_{p_{j}}\right)$ no cálculo das prioridades da política de fila. A mudança do modelo EDF-DSQ para EBS-DSQ é feita por meio da inclusão da informação de carga das requisições na política de fila.

Essas trocas realizadas na política adaptativa podem ocorrer em alguns momentos do ambiente, com o objetivo de melhorar os tempos médios de resposta e possivelmente a Satisfação dos Clientes.

\subsection{Considerações Finais}

Este capítulo apresentou resultados obtidos com a implementação dos diversos algoritmos pertencentes a arquitetura ortogonal, propostos neste trabalho. Foi avaliado o comportamento do Controle de Admissão e tempo de médio de fila para as classes de serviços, principalmente quando há diversos parâmetros envolvidos. Dentre estes, destacam-se a variação da taxa de chegada das requisições e também o uso de diferentes limiares da utilização do array de servidores Web.

As validações estatísticas foram importantes para avaliar o comportamento dos servidores Web com qualidade de serviço, quando estes apresentam uma carga de trabalho excessiva e precisam tomar decisões quanto ao atendimento das classes de serviços das requisições.

Foi discutido o emprego das diversas abordagens em diferentes cenários de uso. Foi realizada uma minuciosa análise dos dados obtidos por meio das validações estatísticas de todas as etapas dos experimentos, com as necessidades observadas e as melhorias realizadas para alcançar melhores níveis de qualidade de serviço.

Apresentou-se o planejamento feito para a realização dos experimentos de avaliação da arquitetura proposta, bem como os resultados obtidos e a análise realizada. Na discussão dos gráficos apresentados, ficou evidenciado que segundo a satisfação do cliente a abordagem EBS-DSQ obteve os melhores resultados.

O próximo capítulo tem como objetivo apresentar as conclusões obtidas com o desenvolvimento deste trabalho e suas contribuições, além de abordar propostas para trabalhos futuros relacionados à análise de desempenho em aplicações Web. 



\section{Capítulo \\ 6}

\section{Conclusão}

\subsection{Conclusões Gerais}

Nesse projeto foi introduzida uma nova técnica que utiliza uma arquitetura ortogonal para dinamicamente escalonar requisições aos servidores compostos no array. A abordagem proposta controla automaticamente o tempo de escalonamento para garantir que o serviço seja entregue segundo o contrato estipulado. Os algoritmos e modelos foram simulados considerando diferentes parâmetros e configurações do ambiente.

O objetivo deste projeto foi investigar um modelo conjugado de escalonamento uma política de fila e uma política de recurso - adequada às características dos sistemas interativos on-line, com foco em uma solução otimizada para array de servidores Web heterogêneos, proporcionando assim a gerência dos tempos de respostas contratados e, ao mesmo tempo, maximizando a utilização de recursos.

O modelo clássico Web Switch, $M Q$, com balanceamento de carga foi utilizado como referência: nessa arquitetura, as requisições são direcionadas para diferentes processadores, cada qual com sua fila individual. Nestas, foi a disciplina de fila EBS que obteve melhores resultados, já demonstrada superior às alternativas clássicas para o caso de restrições de tempo-real estocásticas.

Um primeiro modelo alternativo baseado em uma fila única foi inicialmente comparado com a Web Switch clássica. Nesse esquema, denominado $S Q$, os melhores resultados para esse modelo é aquele conjugado a disciplina de fila única EBS. A requisição mais à frente 
da lista (prioritária segundo o critério $E B S$ ) é atribuída ao mais rápido dos servidores livres a qualquer momento.

Em uma segunda alternativa, a política $D S Q$ implementa um híbrido entre o $S Q$ com fila única, e o Web Switch com balanceamento. Esta terceira modalidade possui também a visão global da fila de requisições pendentes, mas em lugar de atribuir a requisição mais prioritária ao primeiro servidor livre, a $D S Q$ faz, segundo o mesmo princípio da EBS, uma previsão do impacto causado ao sistema, buscando atribuir ao processador livre um job prioritário (não necessariamente o primeiro), que tenha chance de ser completado mais rapidamente naquele recurso.

Sintetizando essa discussão, pode-se assim resumir a comparação entre as três políticas:

- Web Switch é uma política clássica para balanceamento de carga em clusters heterogêneos. Funciona analisando cada requisição que chega ao sistema e encaminhando-a para o servidor que terminaria de executá-la mais cedo. Não mantém fila única, então políticas para provisão de QoS teriam que ser implementadas em cada nó do cluster. Esse fato implica em uma menor eficiência da política para provisão de QoS, visto que a percepção de relação de exigência entre as requisições é limitada às requisições presentes localmente em cada nó do cluster.

- $S Q$ é uma política que retém as requisições Web no balanceador e as libera para serem atendidas apenas quando algum nó do cluster se encontra livre. Caso mais de um nó do cluster esteja livre, o nó com maior desempenho é o escolhido. Este tipo de política de balanceamento não é tão eficiente quanto a clássica Web Switch, mas políticas para provisão de QoS que sejam implementadas nesse sistema contariam com a vantagem de ter uma visão global de relação de exigência entre as requisições, devido ao fato da política $S Q$ reter as requisições Web no balanceador.

- A política DSQ funciona de forma parecida com o Web Switch, com a diferença que a requisição escalonada é mantida no balanceador, caso o servidor escolhido para atender aquela requisição esteja ocupado. A conseqüência principal dessa abordagem se dá pelo fato de existir uma única fila, o que resulta numa visão global de relação de exigência entre requisições caso seja implementada alguma política para provisão de $Q o S$. Em outras palavras, pode-se dizer que a política $D S Q$ incorpora as boas características de balanceamento de carga da política Web Switch com a visão global do sistema da política $S Q$. 
Os resultados experimentais mostraram que as melhores combinações foram: $S Q-E B S$, $D S Q-E D F$ e DSQ-EBS. As avaliações de desempenho destes modelos demonstraram que eles provêem uma taxa de atendimento robusta e garantias de serviços com relação às instantâneas mudanças nas cargas de trabalho da Web.

Apesar dos tempos médios de resposta serem significativamente maiores para a abordagem $M Q$, é importante ressaltar que a $M Q$ possui a vantagem da tolerância a faltas, pois ela distribui a carga entre os servidores presentes no sistema, não necessitando de um centralizador para gerenciamento do sistema, como também o overhead nulo para identificação de um servidor livre, o qual é necessário para as abordagens $S Q$ e $D S Q$.

No momento em que o cenário corrente apresenta uma alta variação contratual, é utilizado DSQ-EBS, devido à propriedade de balanceamento inerente ao escalonador. A $D S Q$ é o algoritmo que melhor adaptou-se às características da política de fila EBS.

Finalmente, foi implementado um mecanismo de controle de admissão para todas as abordagens, que emprega uma média exponencialmente ponderada da utilização do array de servidores para orientar as decisões de descarte. Esse mecanismo consegue manter a carga de trabalho sempre abaixo do limiar especificado, evitando aceitar no sistema requisições que não poderão ser atendidas. A variação do peso da média ponderada permite, ainda, ajustar a sensibilidade do sistema a mudanças no perfil da carga de trabalho.

Os experimentos realizados permitem concluir que a utilização de um Controle de Admissão é fundamental para o fornecimento de serviços diferenciados na Web com uma melhor qualidade, pois, torna a diferenciação de serviços ainda mais eficiente, sendo possível fornecer um serviço com uma característica mais estável e, principalmente, mais justa. Assim, evita-se penalizar ou favorecer demasiadamente uma das classes de clientes.

Devido aos muitos parâmetros que são envolvidos e, certamente não foram abordados todos eles neste trabalho, mas tentou-se relacionar os mais importantes e que refletissem alguma medida de desempenho, indicando o quão bom ou ruim seria o atendimento para uma dada classe de serviço. Aliás, a grande quantidade de variáveis envolvidas quando se trabalha especificamente com servidores Web é uma dificuldade que surgiu ao longo do desenvolvimento deste estudo e que continua sendo muito explorada em trabalhos da área de análise de desempenho em servidores Web ao longo dos anos.

\subsection{Contribuições}

Os principais resultados deste trabalho são relacionados a seguir, destacando-se as contribuições relevantes para a área. 
1. Revisão Bibliográfica: Foi feita uma revisão crítica da bibliografia existente, a fim de contextualizar o presente trabalho e relatar os mais recentes avanços obtidos na área. Destaca-se especialmente o levantamento feito sobre o fornecimento de QoS, em nível de aplicação nos servidores Web.

2. A demanda pelos diversos serviços da $W e b$, incluindo os que buscam QoS absoluta, tornou essencial fornecer diferenciação de serviços com diferentes níveis de qualidade para diferentes tipos de requisições, o qual foi realizado neste trabalho. Para atingir tal objetivo houve a colaboração de todos os componentes envolvidos no processo.

3. Através da arquitetura ortogonal, uma inovadora forma de se realizar garantias de QoS, unidos aos outros diversos componentes, tais como: Controle de Admissão baseado na taxa de utilização média e técnicas de Tempo-Real para caracterizar o atendimento do serviço, alcançando assim, uma contribuição na área de $Q o S$ absoluta para sistema não-determinísticos.

4. A abordagem $D S Q$, que proporciona aos clientes de um sistema interativo Web tempo médios de resposta garantidos previamente por meio de um contrato e maximizando a utilização dos recursos do sistema.

Estas contribuições foram tema de um artigo publicado em um evento científico qualificado (Qualis A - Nacional), o qual sintetiza o resultado e conclusões aqui relacionados ${ }^{1}$.

- Peixoto, M. L. M. ; TOTT, R. F. ; MOnACO, F. J. . (Full Paper) - Política de Escalonamento de Tempo-Real para Garantia de QoS Absoluta em Cluster de Servidores Web Heterogêneos. Brazilian Symposium on Multimedia and the Web (WebMedia), 2007.

\subsection{Trabalhos Futuros}

A proposta de uma arquitetura ortogonal consiste em uma definição inicial, a qual pode ser ampliada de diversas formas, tanto no que se refere ao modelo quanto aos mecanismos de controle de admissão e critérios de QoS absoluta. A seguir, são comentadas algumas

\footnotetext{
${ }^{1}$ Como trabalho adicional durante o período do mestrado, também foi publicado:
}

- MOnACO, F. J. ; Cheng, X. S. ; PEIXOTO, M. L. M. . A Tool for Statistical Analysis of Navigational Modelling for Web Site Personalization and Reengineering. Lecture Notes in Computer Science, v. 4832, p. 386/978-3-540-7-394, 2007. 
sugestões para trabalhos futuros, organizadas por assunto, as quais servem também para demonstrar que o desenvolvimento desta dissertação abre uma linha de pesquisa ampla, permitindo seu prosseguimento através de trabalhos de iniciação científica e dissertações de mestrado.

\subsubsection{Métrica Satisfação do Cliente}

- Melhorias na métrica de Satisfação do Cliente: pode ser conveniente transformar a variável $S_{i}$ de hard para soft, ou seja, ao passo que uma requisição não é atendida dentro do contrato estipulado ela é julgada segundo o critério de tempo de extrapolamento $\left(\right.$ Tex $\left._{i}\right)$, (Equação 6.1) faixa que varia de 0 a 1 , que representa a porcentagem do tempo ultrapassado com referência o contrato, isso torna eficiente o emprego de políticas com menores tempos médios de resposta, ainda que esses tempos tenham sido ultrapassados.

$$
S_{i}=\frac{N_{i}+\left(1-T e x_{i}\right)}{R_{i}}
$$

Essa métrica também proporciona um sistema de promoção para as requisições atendidas abaixo do contrato estipulado. ( Tant $_{i}$ ) representa a porcentagem do tempo médio de resposta atendido abaixo da referência do limite contratado, dado pela equação 6.2 .

$$
S_{i}=\frac{N_{i}+\text { Tant }_{i}}{R_{i}}
$$

\subsubsection{Controle de Admissão}

- O mecanismo de controle de admissão pode ser utilizado como um importante meio de controle da qualidade serviço. A redução de requisições aceitas no sistema proporciona melhores tempos médios de resposta. Entretanto, aumentaria o número de descartes que prejudicaria a satisfação do cliente. Devem ser mensuradas essas duas variáveis ( $\Omega$ e descartes) e então analisar qual a melhor configuração apresente melhores resultados tanto para o provedor quanto para o cliente.

- Explorar também a diferenciação de serviços no controle de admissão.

- Caracterizar melhor a penalização pelo descarte do Controle de Admissão: tornar o sistema de controle de admissão de Hard para Soft. Pode ser conveniente incluir uma 
taxa de descarte de requisições. Esta taxa $\left(d_{i}\right)$ representa o peso que uma requisição descartada pelo controle de admissão influência o $i$-ésimo usuário, tendo seu valor variando entre 0 e 1 . Isso significa que pode ser instituido por meio de um contrato qual o peso que um usuário dá para uma requisição descartada, coloborando com o mecanismo de negociação. Enquanto fixar $d_{i}=0$ significa ausência desse tipo de controle, fixar $d_{i}=1$ significa que nenhuma requisição do usuário $i$ pode ser descartada. Conforme a taxa de descarte aumenta, a satisfação do cliente diminui, como é o esperado.

$$
S_{i}=\frac{N_{i} \cdot\left(1-d_{i}\right)}{R_{i}}
$$

- Um mecanismo de negociação de serviço no módulo de controle de admissão, proporcionando com isso melhores médias de tempo de resposta e menores taxas de descarte de requisições, melhorando a qualidade de serviço oferecida.

\subsubsection{Interface e Protótipo da Arquitetura Ortogonal}

- Implementar um protótipo para o Servidor Apache.

- Especificar a política adaptativa segundo a união das métricas de Satisfação do Cliente e Tempo Médio de Resposta, tornando-a multiobjetiva.

- Implementar a nova política adaptativa apresentada e especificada na Seção 5.7.

- Inclusão de um mecanismo para controle da variância das médias dos tempos de respostas oferecidos, objetivando garantias um pouco mais rígidas de qualidade de serviço.

- Estudar alternativas para a geração de carga de trabalho, possivelmente por meio de traces, a fim que se possa produzir diferentes perfis de carga para a verificação do modelo, o que nem sempre é possível com o uso de cargas sintéticas para servidores Web;

- Melhor caracterização das cargas de trabalho segundo o ambiente da Web. 


\section{APÊNDICE}

A

\section{Demais Gráficos}
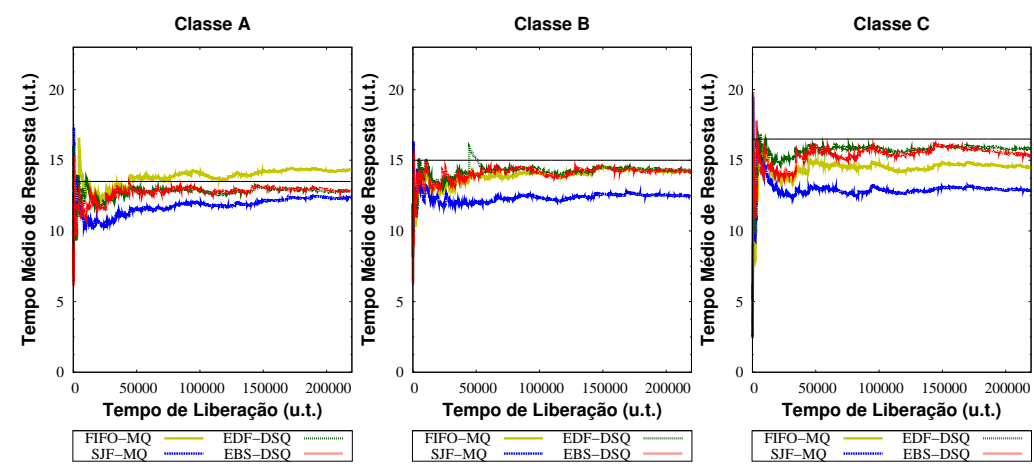

$\begin{array}{lll}\text { (a) CONTRATO A } & \text { (b) CONTRATO B } & \text { (c) CONTRATO C }\end{array}$

Figura A.1: Comparativo do Cenário 2 (MQ-(FIFO,SJF) X DSQ-(EDF,EBS)) com Variação Contratual de $10 \%$
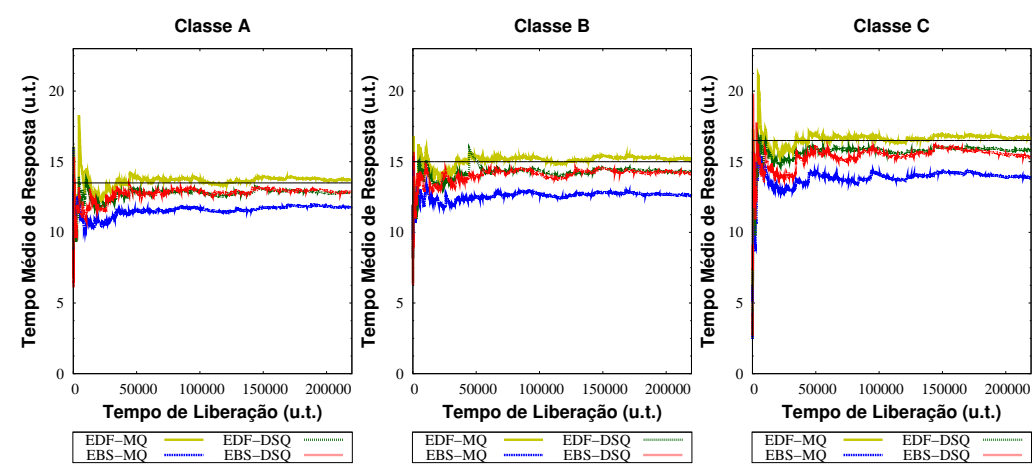
(a) CONTRATO A
(b) CONTRATO B
(c) CONTRATO C

Figura A.2: Comparativo do Cenário 2 (MQ-(EDF,EBS) X DSQ-(EDF,EBS)) com Variação Contratual de $10 \%$ 

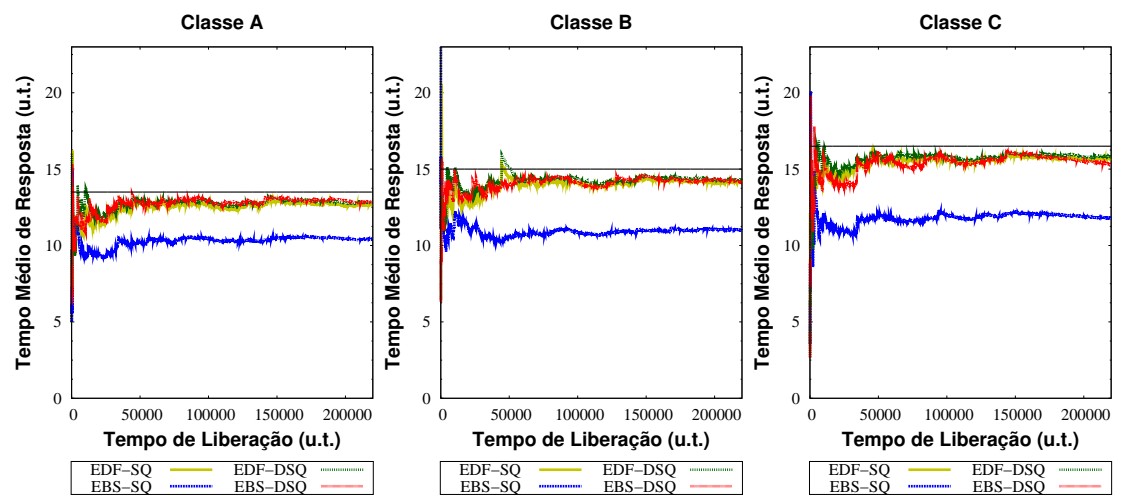

(a) CONTRATO A

(b) CONTRATO B

(c) CONTRATO C

Figura A.3: Comparativo do Cenário 2 (SQ-(EDF,EBS) X DSQ-(EDF,EBS)) com Variação Contratual de $10 \%$

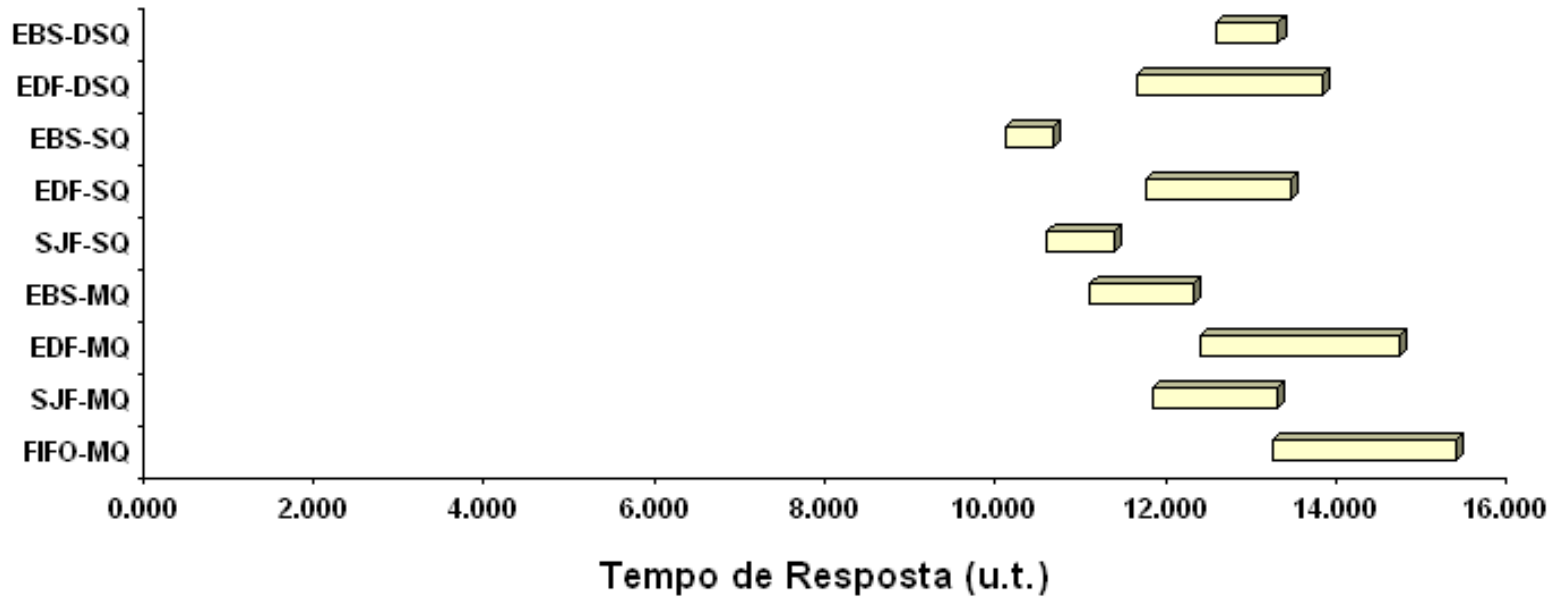

Figura A.4: Intervalo de Confiança do Cenário 2 com Variação Contratual de 10\%
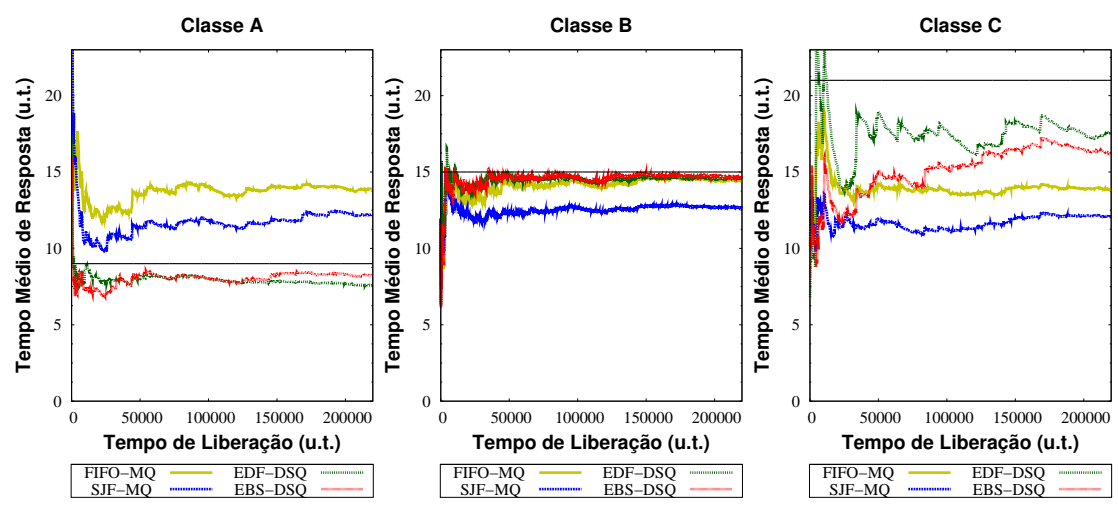

(a) CONTRATO A

(b) CONTRATO B

(c) CONTRATO C

Figura A.5: Comparativo do Cenário 3 (MQ-(FIFO,SJF) X DSQ-(EDF,EBS)) com Variação Contratual de $40 \%$ 

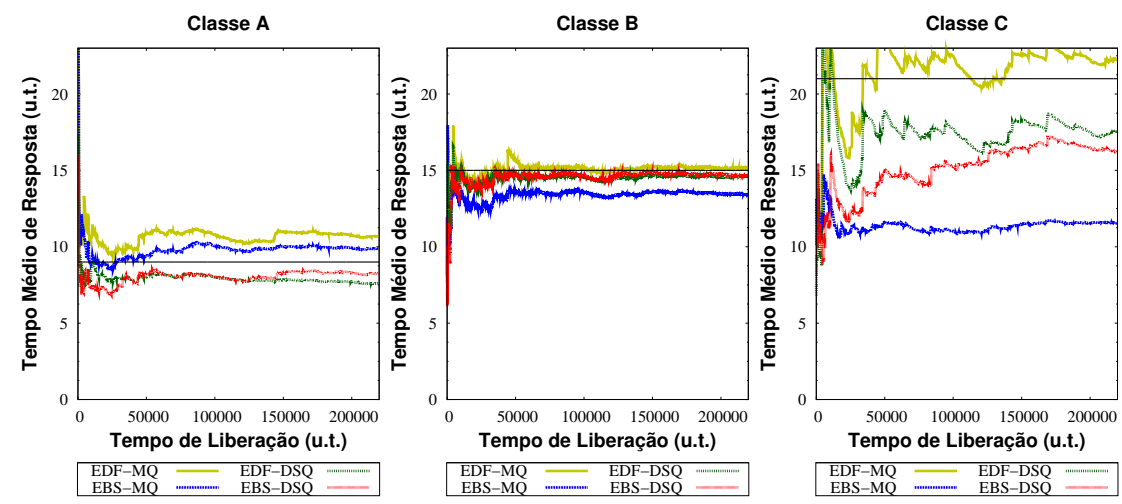

(a) CONTRATO A

(b) CONTRATO B

(c) CONTRATO C

Figura A.6: Comparativo do Cenário 3 (MQ-(EDF,EBS) X DSQ-(EDF,EBS)) com Variação Contratual de $40 \%$

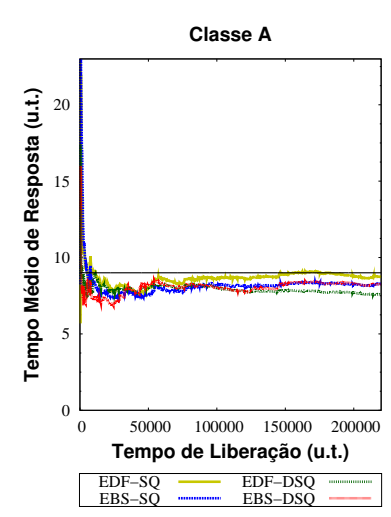

(a) CONTRATO A

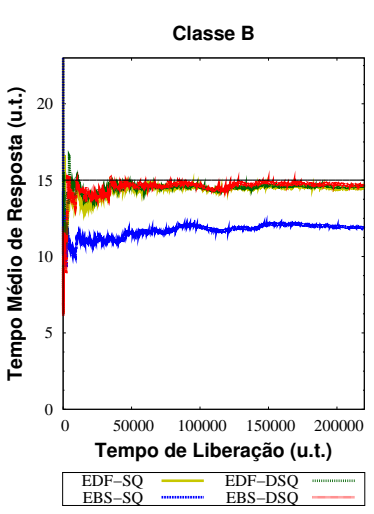

(b) CONTRATO B

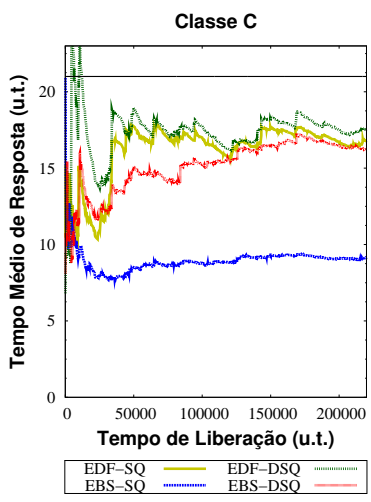

(c) CONTRATO C

Figura A.7: Comparativo do Cenário 3 (SQ-(EDF,EBS) X DSQ-(EDF,EBS)) com Variação Contratual de $40 \%$

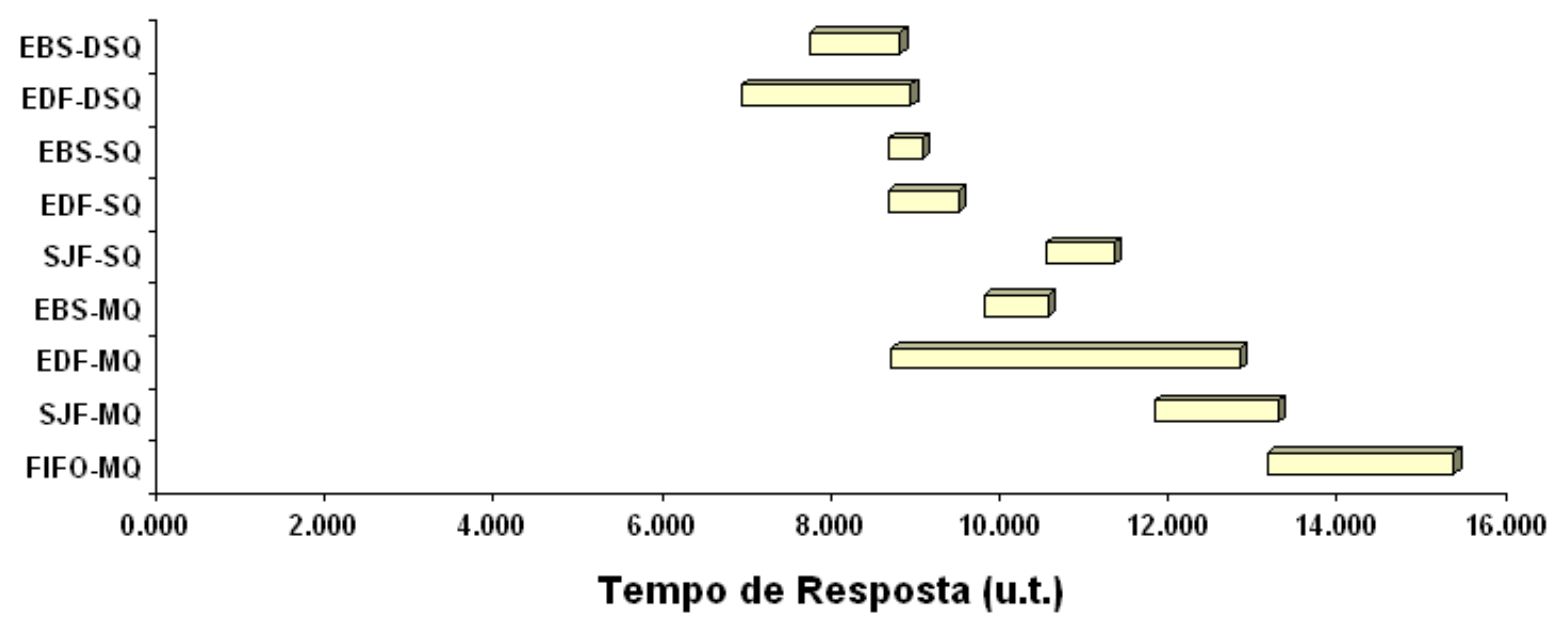

Figura A.8: Intervalo de Confiança do Cenário 3 com Variação Contratual de 40\% 


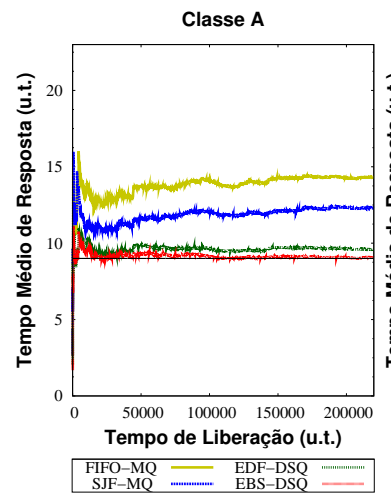

(a) CONTRATO A

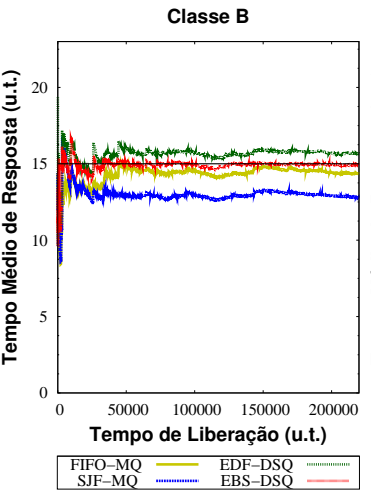

(b) CONTRATO B

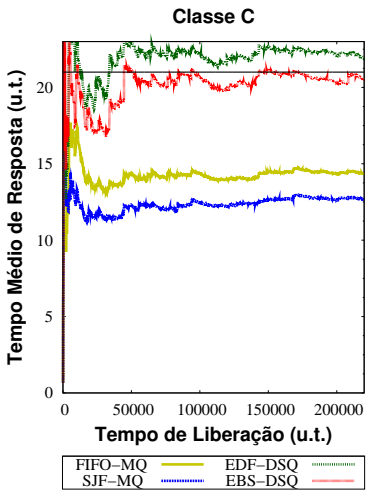

(c) CONTRATO C

Figura A.9: Comparativo do Cenário 4 (MQ-(FIFO,SJF) X DSQ-(EDF,EBS)) com Variação Contratual de $40 \%$

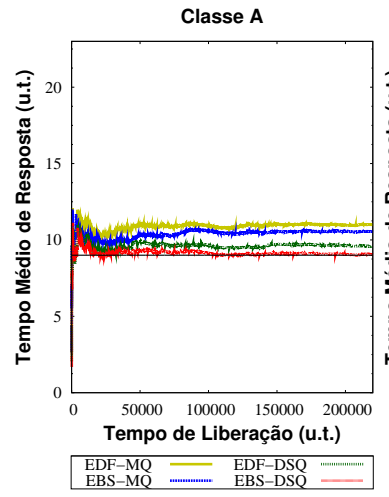

(a) CONTRATO A

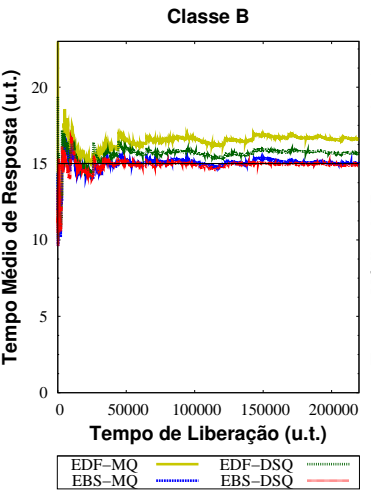

(b) CONTRATO B

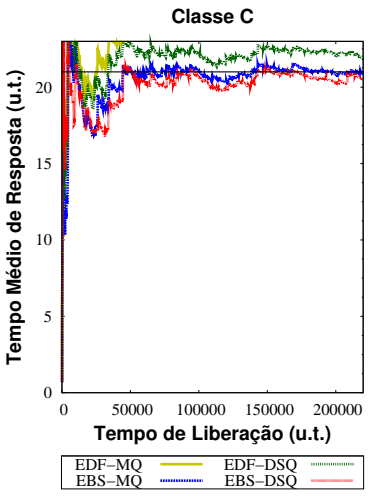

(c) CONTRATO C

Figura A.10: Comparativo do Cenário 4 (MQ-(EDF,EBS) X DSQ-(EDF,EBS)) com Variação Contratual de 40\%

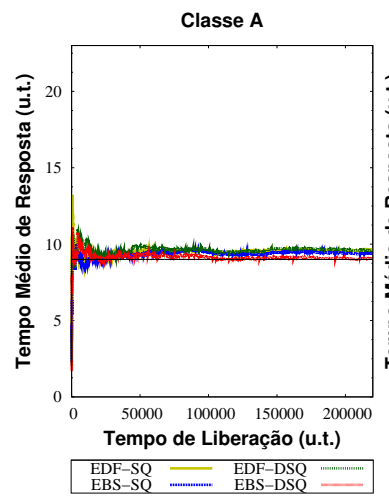

(a) CONTRATO A

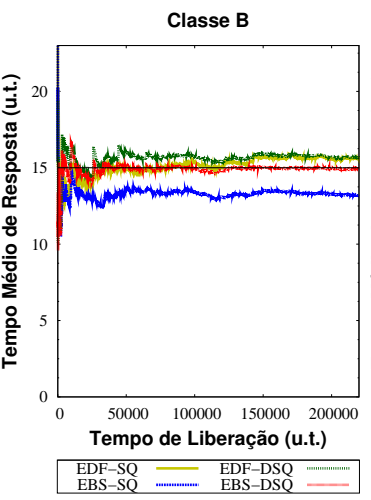

(b) CONTRATO B

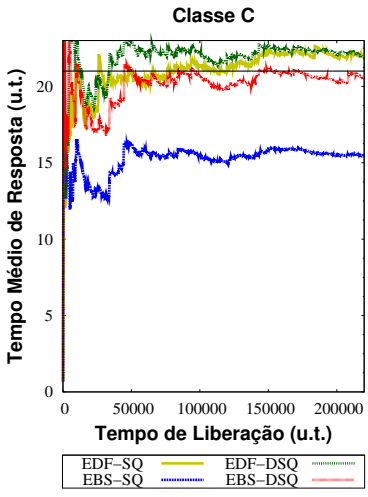

(c) CONTRATO C

Figura A.11: Comparativo do Cenário 4 (SQ-(EDF,EBS) X DSQ-(EDF,EBS)) com Variação Contratual de $40 \%$ 


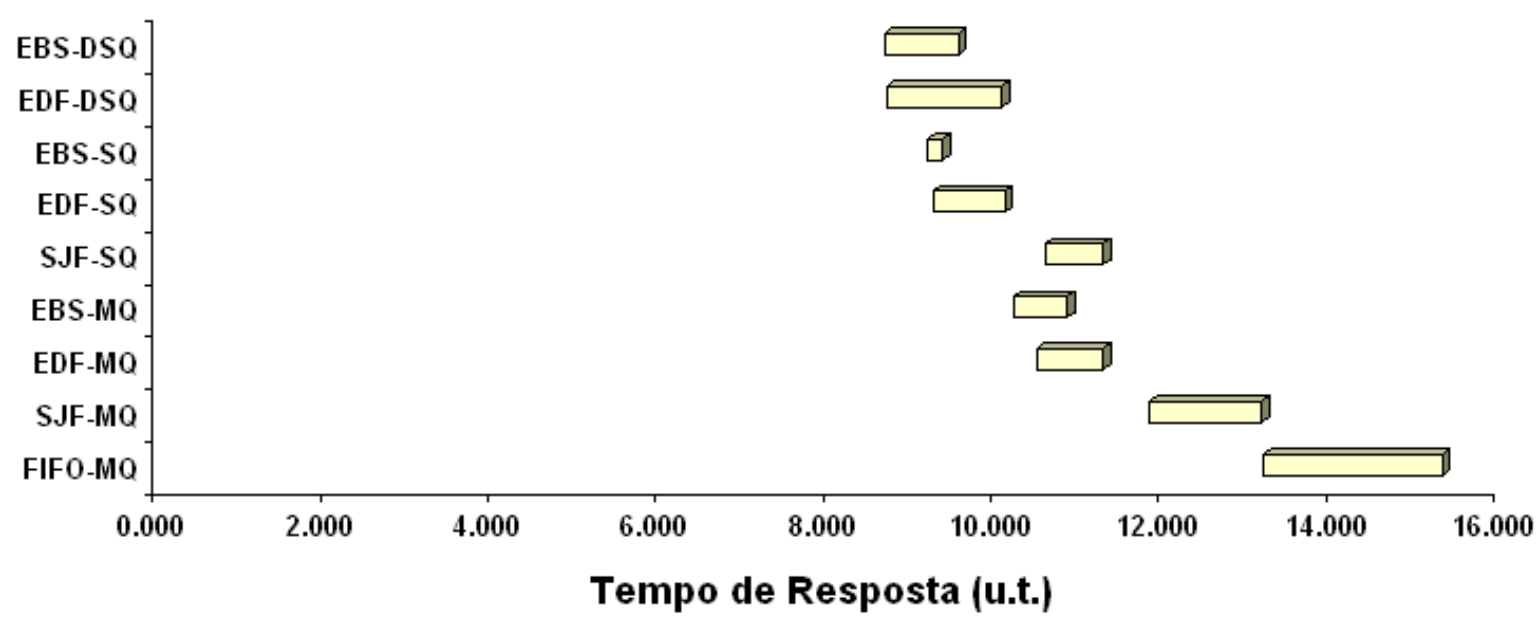

Figura A.12: Intervalo de Confiança do Cenário 4 com Variação Contratual de $40 \%$

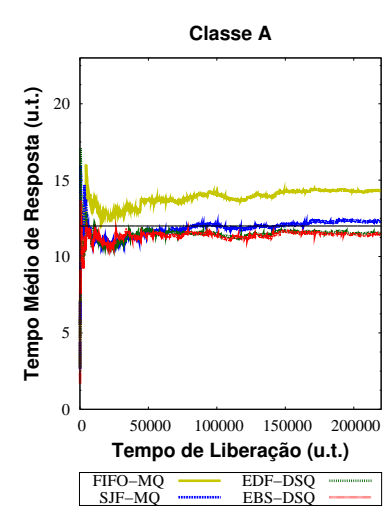

(a) CONTRATO A

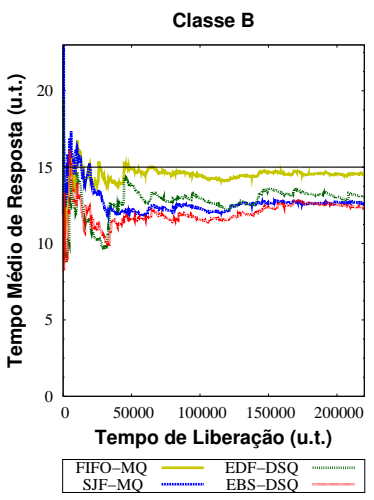

(b) CONTRATO B

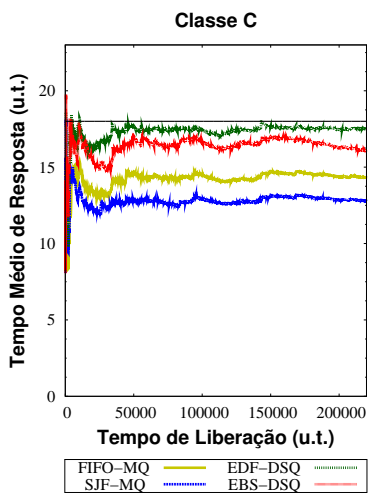

(c) CONTRATO C

Figura A.13: Comparativo do Cenário 5 (MQ-(FIFO,SJF) X DSQ-(EDF,EBS)) com Variação Contratual de $20 \%$

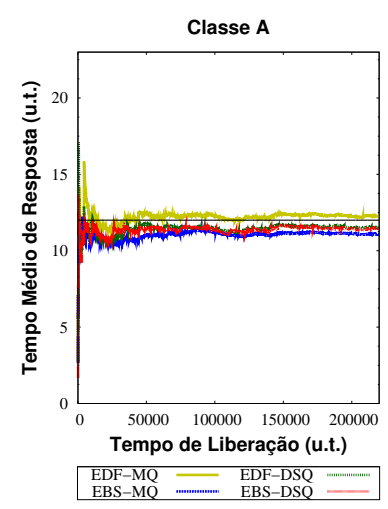

(a) CONTRATO A

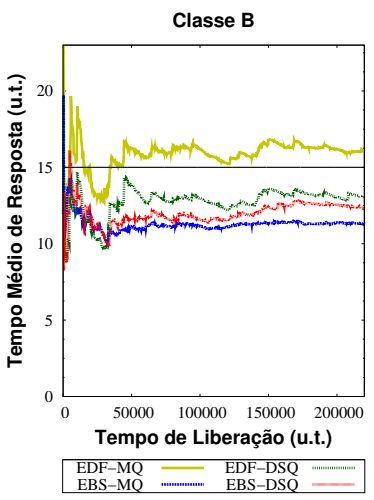

(b) CONTRATO B

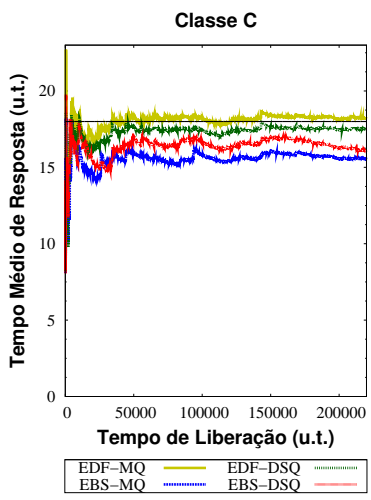

(c) CONTRATO C

Figura A.14: Comparativo do Cenário 5 (MQ-(EDF,EBS) X DSQ-(EDF,EBS)) com Variação Contratual de $20 \%$ 


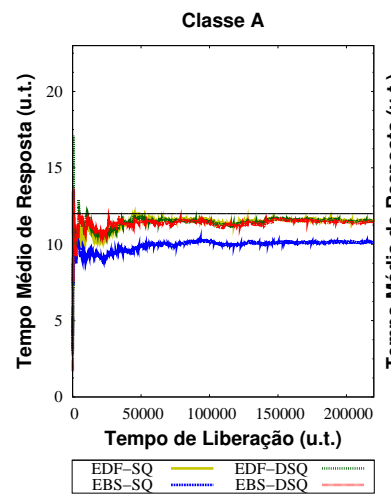

(a) CONTRATO A

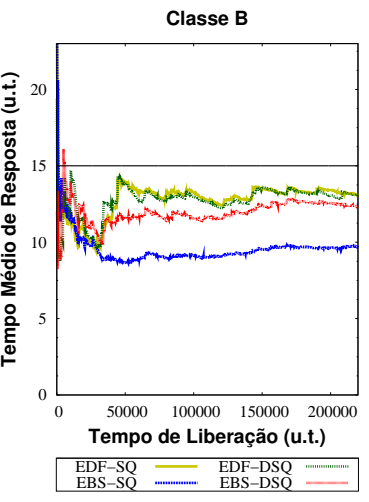

(b) CONTRATO B

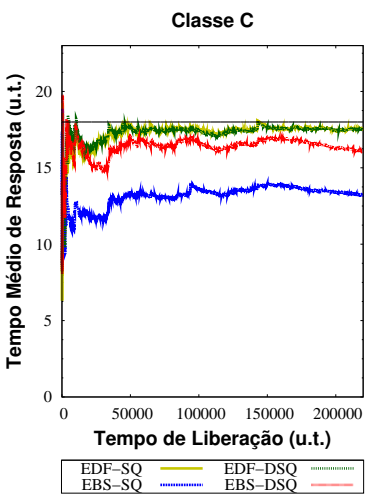

(c) CONTRATO C

Figura A.15: Comparativo do Cenário 5 (SQ-(EDF,EBS) X DSQ-(EDF,EBS)) com Variação Contratual de $20 \%$

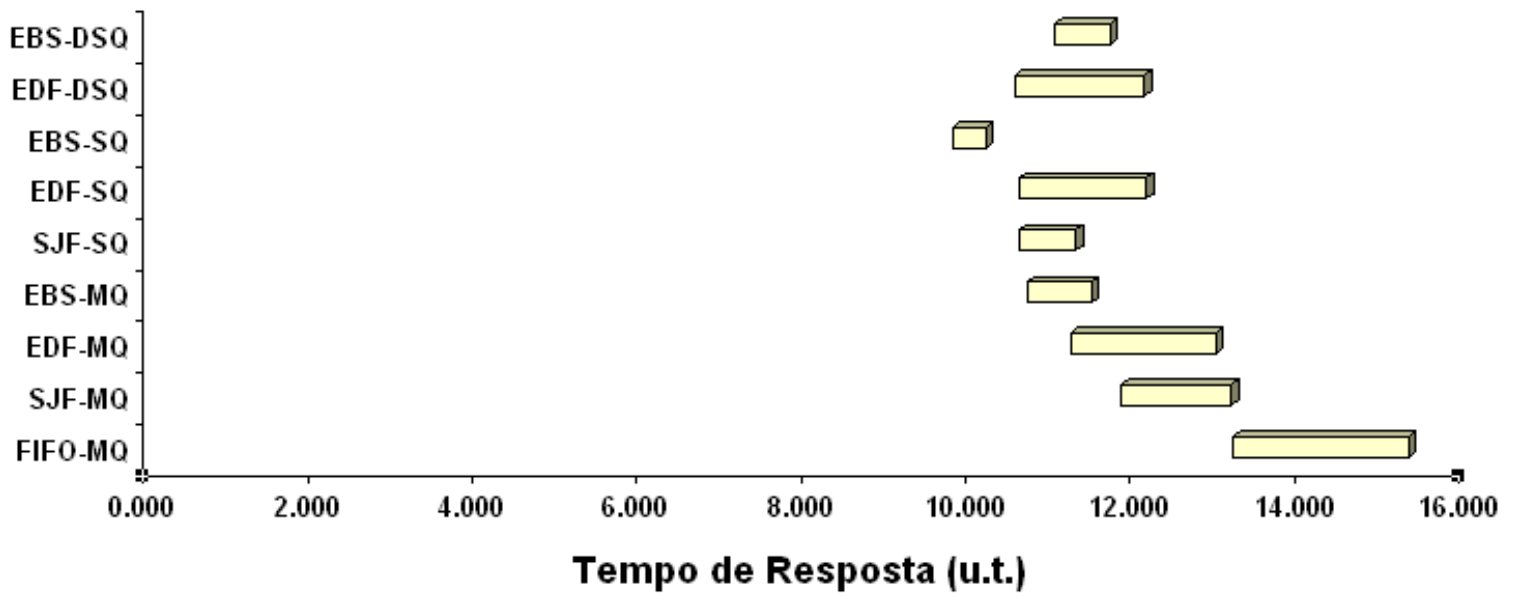

Figura A.16: Intervalo de Confiança do Cenário 5 com Variação Contratual de 20\% 


\section{Referências Bibliográficas}

Abdelzaher, T.; Stankovic, J.; Lu, C.; Zhang, R.; Lu, Y. (2003). Feedback performance control in software services.

Abdelzaher, T. F.; Bhatti, N. (1999). Web server qos management by adaptive content delivery. IEEE - Seventh International Workshop on Quality of Service (London, UK: 1999), v.31, n.11-16, p.216-225.

Almeida, J.; Dabu, M.; Manikutty, A.; Cao, P. (1998). Providing differentiated levels of service in web content hosting. Relatório Técnico CS-TR-1998-1364.

Babbar, D.; Krueger, P. (1994). On-line hard real-time scheduling of parallel tasks on partitionable multiprocessors. ICPP '94: Proceedings of the 1994 International Conference on Parallel Processing, p. 29-38. IEEE Computer Society.

Bampis, E.; Kononov, A. (2001). On the approximability of scheduling multiprocessor tasks with time-dependent processor and time requirements. IPDPS '01: Proceedings of the 15th International Parallel \& Distributed Processing Symposium, p. 200. IEEE Computer Society.

Banks, J.; Carson, J. S.; Nelson, B. L. (2000). Discrete-Event System Simulation. PrenticeHall, Upper Saddle River, New Jersey 07458, 3 edição.

Barbato, A. K.; Traldi, O.; Santana, R. H. C.; Santana, M. J.; Teixeira, M. M. (2006). Algoritmo de escalonamento para servidores web baseado em sessão. XII Simpósio Brasileiro de Sistemas Multimídia e Web (WebMedia). Natal, RN.

Birtwhistle, G. M.; Dahl, O.-J.; Myhrhaug, B.; Nygaard, K. (1973). Simula begin. Academic Press. 
Brun, A.; Vogt, E. M. G.; da Silveira Mendes, A. (2002). Qos - Qualidade de Serviço em $T C P / I P$.

Burns, A.; Wellings, A. J. (2001). Real-time systems and programming languages:ada 95, real-time java, and real-time posix. Addison-Wesley, Reading, MA, USA, third edition.

Buttazo, G. C. (1997). Hard real-time computing systems: Predictable scheduling algorithms and applications. Kluwer Academic Publishers.

Buttazo, G. C.; Lipari, G.; Abeni, L. (1998). Elastic task model for adaptive rate control. Proceedings of the IEEE Real-Time Systems Symposium, Madrid, Spain. IEEE RealTime.

Casagrande, L. S. (2007). Política de escalonamento de tempo real baseada em exigência para provisão de QoS absoluto em serviços Web. Dissertação de Mestrado - ICMC/USP, São Carlos, SP, Brasil.

Casagrande, L. S.; Monaco, F. J.; de Mello, R. F.; Bertagna, R.; Filho, J. A. A. (2007). Exigency-based real-time scheduling policy to provide absolute qos for web services. SBAC-PAD '0\%: Proceedings of the 19th International Symposium on Computer Architecture and High Performance Computing. IEEE Computer Society.

Chen, X.; Heidemann, J. (2003). Preferential treatment for short flows to reduce web latency. Computer Networks, v.41, n.6, p.779-794.

Cheng, A. M. K. (2002). Real-Time Systems. Wiley - Interscience, Hoboken, New Jersey.

Cruz, G. M.; Lima, G. (2005). Simulador de escalonamento para sistemas de tempo real.

Dovrolis, C.; Ramanathan, P. (1999). A case for relative differentiated services and the proportional differentiation model.

Eggert, L.; Heidemann, J. (1999). Application-level differentiated services for web servers. World Wide Web, v.2, n.3, p.133-142.

Estrella, J.; Teixeira, M.; Santana, M.; Santana, R. H. C.; Bruschi, S. M. (2006). Negotiation mechanisms on application level: a new approach to improve quality of service in web servers. Software Technologies for Future Embedded and Ubiquitous Systems, 2006 and the 2006 Second International Workshop on Collaborative Computing, Integration, and Assurance. SEUS 2006/WCCIA 2006., p. 5pp. 
Farines, J.-M.; da Silva Fraga, J.; de Oliveira, R. S. (2000). Sistemas de Tempo Real. Departamento de Automação e Sistemas, Universidade Federal de Santa Catarina, Florianópolis, Brasil.

Fishwick, P. A. (1992). Simpack: Getting started with simulation programming in c and c++. Winter Simulation Conference, p. 154-162.

Franklin, G. F. (1993). Feedback Control of Dynamic Systems. Addison-Wesley Longman Publishing Co., Inc., Boston, MA, USA.

Freitas, P. J. F. (2001). Introdução a modelagem e simulação de sistemas. Ed. VisualBooks, Florianópolis.

Ghosal, D.; Serazzi, G.; Tripathi, S. K. (1991). The processor working set and its use in scheduling multiprocessor systems. IEEE Trans. Softw. Eng., v.17, n.5, p.443-453.

Heidemann, J.; Shenker, S.; Dupuy, A.; Helmy, A.; Kumar, S. (2007). The network simulator - ns-2. http://www.isi.edu/nsnam/ns/. Acessado em Maio de 2007.

Henriksson, D.; Lu, Y.; Abdelzaher, T. (2004). Improved prediction for web server delay control. ECRTS '04: Proceedings of the 16th Euromicro Conference on Real-Time Systems (ECRTS'04), p. 61-68. IEEE Computer Society.

Jain, R. (1991). The art of computer systems performance analysis : techniques for experimental design, measurement, simulation, and modeling. New York, NY, USA : Wiley.

Kang, K.-D.; Son, S. H.; Stankovic, J. A. (2003). Differentiated real-time data services for e-commerce applications. Electronic Commerce Research, v.3, n.1-2, p.113-142.

Kanodia, V.; Knightly, E. (2003). Ensuring latency targets in multiclass web servers. Parallel and Distributed Systems, IEEE Transactions on, v.14, n.1, p.84-93.

Kopetz, H. (1997). Real-Time Systems: Design Principles for Distributed Embedded Applications. Kluwer Academic Publishers, Norwell, MA, USA.

Lazowska, E. D.; Zahorjan, J.; Graham, G. S.; Sevcik, K. C. (1984). Quantitative System Performance: Computer System Analysis Using Queueing Network Models. PrenticeHall, Upper Saddle River, NJ, USA. 
Lee, W. Y.; Hong, S. J.; Kim, J. (2003). On-line scheduling of scalable real-time tasks on multiprocessor systems. J. Parallel Distrib. Comput., v.63, n.12, p.1315-1324.

Leiner, B. M.; Cerf, V. G.; Clark, D. D.; Kahn, R. E.; Kleinrock, L.; Lynch, D. C.; Postel, J.; Roberts, L. G.; Wolff, S. S. (1997). The past and future history of the internet. Commun. ACM, v.40, n.2, p.102-108.

Liebeherr, J.; Burchard, A.; Oh, Y.; Son, S. H. (1995). New strategies for assigning realtime tasks to multiprocessor systems. IEEE Trans. Comput., v.44, n.12, p.1429-1442.

Lin, T.-H.; Tarng, W. (1991). Scheduling periodic and aperiodic tasks in hard real-time computing systems. SIGMETRICS '91: Proceedings of the 1991 ACM SIGMETRICS conference on Measurement and modeling of computer systems, p. 31-38, New York, NY, USA. ACM Press.

Liu, C. L.; Layland, J. W. (1973). Scheduling algorithms for multiprogramming in a hard-real-time environment. Journal of ACM, v.20, n.1, p.46-61.

Liu, J. W.-S. (2000). Real-time Systems. Prentice-Hall, Upper Saddle River, New Jersey 07458, 1 edição.

Lu, C.; Abdelzaher, T. F.; Stankovic, J. A.; Son, S. H. (2001). A feedback control approach for guaranteeing relative delays in web servers. RTAS '01: Proceedings of the Seventh Real-Time Technology and Applications Symposium (RTAS '01), p. 51. IEEE Computer Society.

MacDougall, M. H. (1987). Simulating computer systems: techniques and tools. MIT Press, Cambridge, MA, USA.

MacDougall, M. H. (1989). Simulating Computer Systems. Computer Systems. MIT Press, Cambridge, Massachusetts London, England, 2 edição.

MacDougall, M. H.; McAlpine, J. S. (1973). Computer simulation with ASPOL. Symposium on the simulation of computer systems.

Manimaran, G.; Murthy, C. S. R.; Ramamritham, K. (1998). A new approach for scheduling of parallelizable tasks inreal-time multiprocessor systems. Real-Time Syst., v.15, n.1, p.39-60.

Mok, A. K. (1983). Fundamental design problems of distributed systems for the hard real-time environment. MIT, Cambridge, Mass. 
Nissanke, N. (1997). Realtime Systems. Prentice-Hall, Upper Saddle River, New Jersey 07458, 1 edição.

Peixoto, M. L. M.; Tott, R. F.; Monaco, F. J. (2007). Política de escalonamento de tempo-real para garantia de qos absoluta em cluster de servidores web heterogêneos. WebMedia '07: Proceedings of the XIII Brazilian Symposium on Multimedia and the Web, Gramado, RS, Brazil. ACM Digital Library.

R. Iyer, V. T.; Kant, K. (2000). Overload control mechanisms for web servers.

Ramamritham, K.; Stankovic, J. A.; Shiah, P. F. (1990). Efficient scheduling algorithms for real-time multiprocessor systems. IEEE Trans. Parallel Distrib. Syst., v.1, n.2, p.184-194.

Rashid, M. M.; Alfa, A. S.; Hossain, E.; Maheswaran, M. (2005). An analytical approach to providing controllable differentiated quality of service in web servers. IEEE Trans. Parallel Distrib. Syst., v.16, n.11, p.1022-1033.

Schwetman, H. (1986). Csim: A c-based, process-oriented simulation language. Winter Simulation Conference, p. 387 - 396.

Sha, L.; Abdelzaher, T.; Arzén, K.-E.; Cervin, A.; Baker, T.; Burns, A.; Buttazzo, G.; Caccamo, M.; Lehoczky, J.; Mok, A. K. (2004). Real time scheduling theory: A historical perspective. Real-Time Syst., v.28, n.2-3, p.101-155.

Sprunt, B.; Sha, L.; Lehoczky, L. (1989). Aperiodic task scheduling for hard real-time systems. p. 27-60. IEEE Real-Time Systems.

Stankovic, J. A.; Lu, C.; Son, S. H. (1998). The case for feedback control real-time scheduling. Relatório técnico, Charlottesville, VA, USA.

Stankovic, J. A.; Spuri, M.; Natale, M. D.; Buttazzo, G. C. (1995). Implications of classical scheduling results for real-time systems. Computer, v.28, n.6, p.16-25.

Strosnider, J.; Lehoczky, J. P.; Sha, L. (1989). The deferrable server algorithm for enhanced aperiodic responsiveness in real-time environmnents. p. 73-91. IEEE Trasactions on Computers.

Teixeira, M. A. M. (2004). Suporte a serviços diferenciados em servidores web: modelos e algoritmos. Tese de Doutorado - ICMC/USP, São Carlos, SP, Brasil. 
Teixeira, M. A. M.; Santana, M. J.; Santana, R. H. C. (2005). Servidor web com diferenciação de serviços: Fornecendo qos para os serviços da internet. In XXIII Simpósio Brasileiro de Redes de Computadores (SBRC), Fortaleza, CE.

Thesen, A.; Travis, L. (1988). Introduction to simulation. WSC '88: Proceedings of the 20th conference on Winter simulation, p. 7-14, New York, NY, USA. ACM.

Traldi, O. A.; Barbato, A. K.; Santana, R. H. C. (2006). Service differentiating algorithms for qos-enabled web servers. WebMedia '06: Proceedings of the 12th Brazilian symposium on Multimedia and the web, p. 263-272. ACM Press.

Vasiliou, N.; Lutfiyya, H. (2000). Providing a differentiated quality of service in a world wide web server. SIGMETRICS Perform. Eval. Rev., v.28, n.2, p.22-28.

Wang, F.; Ramamritham, K.; Stankovic, J. (1990). Bounds on the schedule length of some heuristic scheduling algorithms for hard real-time tasks. Relatório Técnico UMCS-1990-067.

Welsh, M.; Culler, D. (2003). Adaptive overload control for busy internet servers. USITS'03: Proceedings of the 4th conference on USENIX Symposium on Internet Technologies and Systems, p. 4-4, Berkeley, CA, USA. USENIX Association.

Ye, N.; Gel, E. S.; Li, X.; Farley, T.; Lai, Y.-C. (2005). Web server qos models: applying scheduling rules from production planning. Comput. Oper. Res., v.32, n.5, p.1147-1164.

Zhang, R.; Lu, C.; Abdelzaher, T. F.; Stankovic, J. A. (2002). Controlware: A middleware architecture for feedback control of software performance. ICDCS '02: Proceedings of the 22 nd International Conference on Distributed Computing Systems (ICDCS'02), p. 301. IEEE Computer Society.

Zhang, W.; Dechter, R.; Korf, E. R. (2001). Heuristic search in artificial intelligence. Special issue Artificial Intelligence, Vol. 129, nos. 1-2.

Zhao, W.; Olshefski, D.; Schulzrinne, H. (2000). Internet quality of service: an overview. Technical Report CUCS-003-00. http://www.cs.columbia.edu/techreports/cucs003-00.pdf. Acessado em Maio de 2007. 